\title{
Impaired activity-dependent neural circuit assembly and refinement in autism spectrum disorder genetic models
}

\author{
Caleb A. Doll' and Kendal Broadie ${ }^{1,2}$ * \\ ${ }^{1}$ Department of Biological Sciences, Vanderbilt University, Nashville, TN, USA \\ ${ }^{2}$ Kennedy Center for Research on Human Development, Vanderbilt University, Nashville, TN, USA
}

\section{Edited by:}

Hansen Wang, University of Toronto,

Canada

\section{Reviewed by:}

Randi Hagerman, University of California Davis Medical Center, USA Cara Jean Westmark, University of Wisconsin, USA

\section{*Correspondence:}

Kendal Broadie, Department of Biological Sciences, Vanderbilt University, 6270A MRBIII, Nashville, TN 37232-8548, USA

e-mail: kendal.broadie@vanderbilt.edu
Early-use activity during circuit-specific critical periods refines brain circuitry by the coupled processes of eliminating inappropriate synapses and strengthening maintained synapses. We theorize these activity-dependent (A-D) developmental processes are specifically impaired in autism spectrum disorders (ASDs). ASD genetic models in both mouse and Drosophila have pioneered our insights into normal A-D neural circuit assembly and consolidation, and how these developmental mechanisms go awry in specific genetic conditions. The monogenic fragile $X$ syndrome ( $F X S)$, a common cause of heritable ASD and intellectual disability, has been particularly well linked to defects in A-D critical period processes. The fragile $X$ mental retardation protein (FMRP) is positively activityregulated in expression and function, in turn regulates excitability and activity in a negative feedback loop, and appears to be required for the A-D remodeling of synaptic connectivity during early-use critical periods. The Drosophila FXS model has been shown to functionally conserve the roles of human FMRP in synaptogenesis, and has been centrally important in generating our current mechanistic understanding of the FXS disease state. Recent advances in Drosophila optogenetics, transgenic calcium reporters, highly-targeted transgenic drivers for individually-identified neurons, and a vastly improved connectome of the brain are now being combined to provide unparalleled opportunities to both manipulate and monitor A-D processes during critical period brain development in defined neural circuits. The field is now poised to exploit this new Drosophila transgenic toolbox for the systematic dissection of A-D mechanisms in normal versus ASD brain development, particularly utilizing the well-established Drosophila FXS disease model.

Keywords: fragile X syndrome, synaptogenesis, synapse elimination, E/I ratio, optogenetics, Drosophila

\section{INTRODUCTION}

The recent passing of David Hubel (September 22, 2013) occurs in the midst of a rich era of research into the activity-dependent (A-D) formation and refinement of neural circuitry during normal brain development and in neurodevelopmental disease states. Hubel and Wiesel's pioneering studies on monocular deprivation and activity manipulations in the cat visual system (Hubel and Wiesel, 1959, 1962, 1970; Wiesel and Hubel, 1963) laid the foundation for our understanding of the A-D assembly and pruning of synaptic connections. All synapses formed through the reciprocal, highly orchestrated crosstalk between axons and dendrites face the bottleneck decision of elimination versus long-term maintenance and strengthening to form a stable partnership (dendrite stabilization review, Koleske, 2013; intrinsic dendrite development, Puram and Bonni, 2013). Although early synaptogenesis proceeds via largely activity-independent mechanisms, the refinement of synapses is a progressive, A-D process most active during the early-use critical periods of postnatal development, when synaptic arrays are most amenable to pruning and de nova additions (Hensch, 2004). Following this refinement period, A-D modulation is greatly reduced in the mature brain, except for maintenance of the synaptic plasticity underlying behavioral adaptation (Rice and Barone, 2000; rodent visual cortex, Nataraj and Turrigiano,
2011). Recent advances in biotechnology provide high-fidelity readouts of neural activity, as well as precise, non-invasive methods for the bidirectional manipulation of neural activity (Chen etal., 2013; Lin etal., 2013b), generating the means to study A-D developmental processes at a previously inconceivable level.

Autism spectrum disorders (ASDs) are defined by social interaction impairments (Abrahams and Geschwind, 2008), frequently accompanied by sensory hypersensitivity, cognitive deficits, and A-D seizures (Kim and Lord, 2012; Kim et al., 2013b). The improper development of neural circuitry likely lies at the heart of ASDs, particularly the A-D processes of solidifying appropriate synaptic connections and concomitantly pruning superfluous or incorrect connections (Zoghbi and Bear, 2012). The apparently diverse genetic bases of the wide spectrum of autism-related disorders makes genetic modeling a challenge (Sanders et al., 2012), but recent hypotheses suggest that the variety of genetic variants associated with ASDs may converge on a more manageable set of core molecular pathways (Murdoch and State, 2013). With this in mind, targeted mouse and Drosophila animal model systems harboring deficiencies in ASD-linked human genes often show comparable phenotypic and behavioral defects to human patients (Hagerman et al., 2009; van Alphen et al., 2013). Among the strongest primary 
research contributions have come from models of fragile X syndrome (FXS), a monogenic disorder that is the leading heritable contributor to the autism spectrum (Harris et al., 2008; McBride et al., 2012). In both mouse and Drosophila FXS models, there is clear and consistent evidence that the causal fragile X mental retardation protein (FMRP) is directly activity-regulated and in turn regulates A-D processes of neural circuit assembly and refinement (Wang et al., 2010a,b; Wondolowski and Dickman, 2013). Preclinical studies with these animal models have already advanced to a number of human clinical trials [e.g., metabotropic glutamate receptor (mGluR) therapeutics], and groundbreaking tools to assess and manipulate A-D synapse and circuit development show great promise toward major breakthroughs in ASD therapeutic intervention strategies (Akerboom et al., 2013; Paz et al., 2013; Sukhotinsky et al., 2013).

In this review article, we seek to highlight recent advances in our understanding of A-D synaptic development in the normal and ASD brain, particularly focused on recent work from mouse and Drosophila genetic models. We will only mention is passing electrophysiological investigations of synaptic plasticity at maturity, which is the focus of many excellent reviews (Malenka and Bear, 2004; Nelson and Turrigiano, 2008; Castillo et al., 2011). Likewise, the broad genetic and molecular details of A-D neural circuit assembly have recently been presented elsewhere (Flavell and Greenberg, 2008; West and Greenberg, 2011; Ebert and Greenberg, 2013). Our main focus will be on the A-D basis of ASDs, and particularly on FXS, as the leading heritable contributor to this neurodevelopmental disease condition (Hagerman and Hagerman, 2002). Starting with a brief review of normal experience-dependent synaptic changes (Part 1), we will then focus on correlates between the ASD disease state and A-D circuit formation (Part 2), and finally finish with a detailed review of the recent technological advances for the manipulation and monitoring of A-D processes (Part 3) during neural circuit development.

\section{PART 1: NORMAL ACTIVITY-DEPENDENT NEURODEVELOPMENT}

Hebb (1949) theorized that neural activity would code neural circuit connectivity through a mechanism of coincident synapse elimination and consolidation. This theory was first tested in the cat visual cortex, with the first visual response recordings made in the 1950s (Bishop and Clare, 1951, 1952, 1955; Clare and Bishop, 1954; Jung, 1958), coincident with the pioneering work of Kuffler (1953) defining ganglion cell specificity/organization and producing some of the first primary evidence of higher order processing. Kuffler's students went on to establish the principles of A-D mechanisms (Figure 1A), including Horace Barlow's characterization of selectivity and lateral inhibition in the frog retina (Barlow, 1953a,b), and David Hubel and Torsten Wiesel's work on the basis of A-D (and later experience-dependent) synaptic development in the cat retinal system. Hubel and Wiesel first demonstrated that individual striatal cortical neurons (primary visual cortex) respond preferentially to slits of light (Hubel and Wiesel, 1959), providing a mechanism by which cortex organization enables higher order perception (Hubel and Wiesel, 1962). Their subsequent studies using monocular deprivation revealed profound changes in cortex development, with active-pathway axons from the lateral geniculate nucleus (LGN) dramatically out-competing inactive axons for cortex innervation of striatal cortical neurons (Wiesel and Hubel, 1963). The LGN innervated by the monocularly deprived retinal axons was also thinner, demonstrating a sensory experiencedependent restructuring of the developing neural circuit (Wiesel and Hubel, 1963).

Hubel and Wiesel went on to perform an extended series of A-D developmental studies, establishing a critical period for visual cortical development in kittens, and demonstrating that adult cats show no comparable experience-dependent morphological or electrophysiological changes (Wiesel and Hubel, 1963, 1965a,b; Hubel and Wiesel, 1970; Wiesel, 1982; Cohen and Greenberg, 2008). Following these pioneering studies, A-D morphological changes were similarly revealed in other areas of the sensory cortex. As one example, upon trimming whiskers in specific rows, axonal projections in the rat somatosensory cortex were reduced from non-deprived columns into deprived columns (axons from column A generally innervate column B; if the B column is deprived of input, the A axon receives no postsynaptic response and collapses), and increased horizontal axonal projections between non-deprived columns (Broser et al., 2008). Whisker trimming on the rat's snout from birth leads to a smaller contralateral motor area that evokes abnormal motor activity, a phenomenon not seen in adult rats (Huntley, 1997), again indicating a transient developmental window. Neuromuscular junction (NMJ) innervation is another classic system for studying A-D remodeling (Schuster, 2006). Motor axons compete to target individual muscle fibers during the early-use neonatal period (Sanes and Lichtman, 1999), and NMJ development in the first couple of neonatal weeks displays a progression of A-D synapse elimination, functional reinforcement, and eventual structural consolidation (Lichtman and Colman, 2000; Walsh and Lichtman, 2003). Consistently, impeding neural activity results in slowed synaptic refinement in the mouse neuromusculature, and enhancing activity increases the rate of development (Thompson, 1985).

Humans show similar mechanisms of A-D neural circuit development (Figure 1B). For example, the auditory cortex displays an early age critical window of experience-dependent maturation, with professional musicians developing asymmetric brain features when exposed to music before the age of 7. Specifically, development of absolute pitch correlates with a larger left planum temporale (Schlaug et al., 1995), and enlarged cortical representation of the left hand in dexterous string players (Elbert et al., 1995; Schlaug et al., 1995). Auditory cortical development may actually represent a more extensive (or indefinite) critical period, as compared to other sensory modalities (Kilgard and Merzenich, 1998; Chang and Merzenich, 2003). This relative extension may result from a late peak of parvalbumin-expressing $(\mathrm{PV}+)$ interneurons, as described in ferret brain development (Gao et al., 2000). The emergence of these inhibitory interneurons is progressive (Honig et al., 1996) and vital for the proper formation of cortical circuits (Figure 1C; Powell et al., 2012). The auditory critical period is not open ended, however, as childhood ear infections leading to long-term deficits in auditory perceptual acuity can occur if not treated before the age of 7 (Popescu and Polley, 2010). These select 


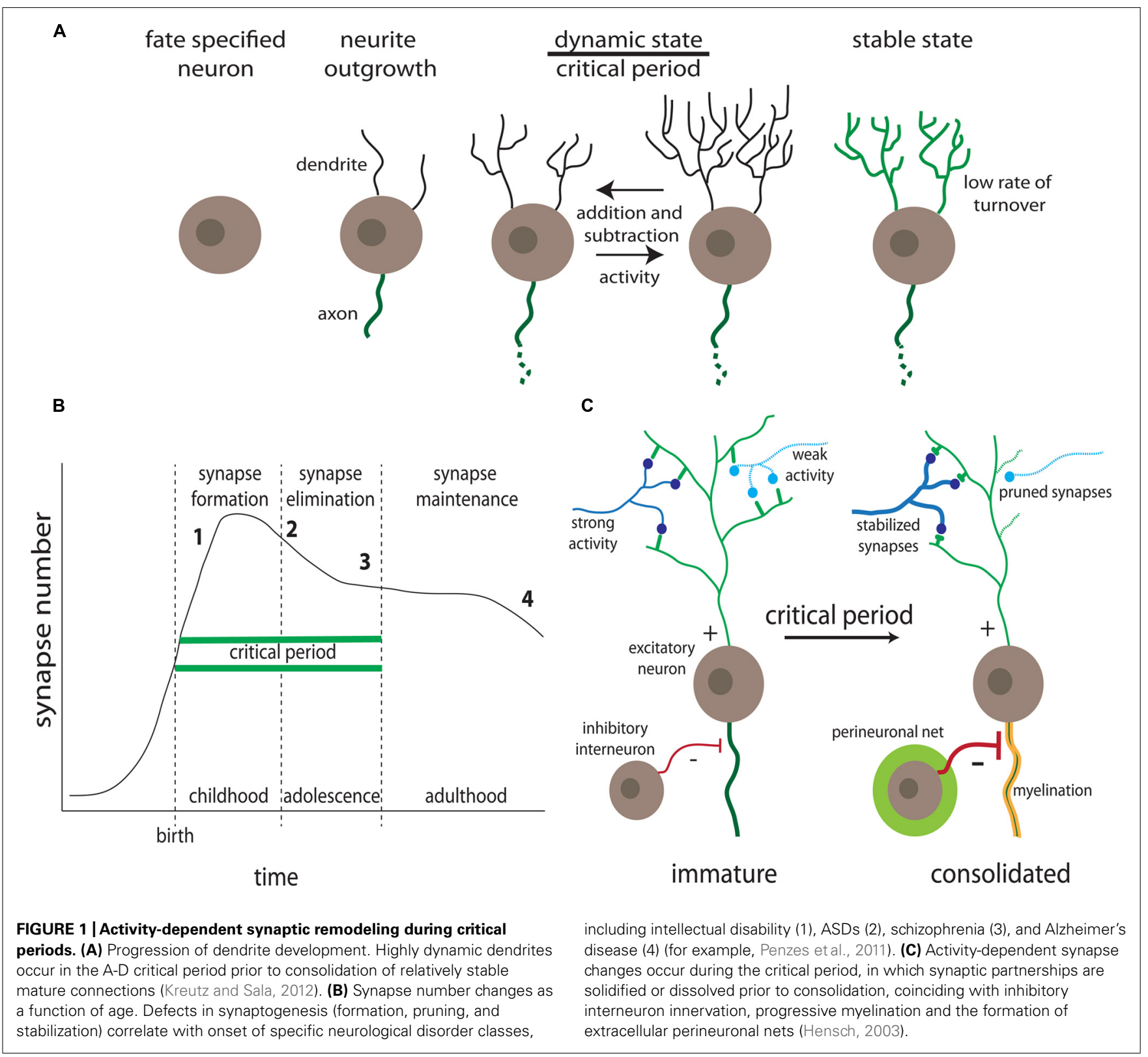

examples illustrate normal A-D development within single sensory modalities. ASD symptoms may manifest through faulty A-D development in a number of sensory systems, with impairments of higher-order cognition circuitry developing after formation of primary sensory circuitry (Belmonte et al., 2004; Geschwind and Levitt, 2007). Although ASD diagnoses focuses on higher order cognitive tasks such as social communication, language and cognitive development, and repetitive behaviors (Zwaigenbaum et al., 2013), precursor deficits in primary sensory processing are characteristic (Marco et al., 2011). A more detailed discussion of ASD phenotypes is presented in Part 2.

\section{CRITICAL PERIODS OF NEURAL CIRCUIT DEVELOPMENT}

The highly dynamic nature of synaptic connectivity is largely a transient feature of neurodevelopment: long-term imaging of dendritic spines in adult mice reveals that most mature synapses are relatively stable (Grutzendler et al., 2002). The critical window (or critical period) theory has emerged to explain the decline in synaptic dynamics as the brain develops, and as a mechanistic foundation toward understanding ASD disease states (Figure 1; Hensch, 2004). A critical period defines a temporary developmental window of heightened sensitivity to sensory stimuli, which drive connectivity changes (Holtmaat and Svoboda, 2009), with A-D modulation reduced after the window passes, as reflected by the decrease in spine turnover as the brain matures (Trachtenberg et al., 2002; Holtmaat et al., 2005; Zuo et al., 2005). The key critical period hallmarks include (1) competition between circuit elements, (2) neural activity regulation, (3) structural solidification of maintained connections, (4) sharply-defined experiencedependent window, (5) variable/hierarchical timing and duration 
of windows across systems, (6) a diversity of molecular mechanisms underlying A-D modulation, (7) emergence and connectivity of inhibitory neurons, (8) attention/motivation by aminergic and cholinergic modulation, and (9) the potential for reactivation in adulthood (Figure 1; Hensch, 2004). Synaptogenesis underlies these hallmarks in critical periods, and takes place sequentially through initial axonal/dendritic outgrowth, excess formation of synapses, and subsequent pruning through A-D maturation (Katz and Shatz, 1996; West and Greenberg, 2011). Although synapse regulation continues throughout life (Holtmaat et al., 2005; Grillo et al., 2013), peak synaptogenesis occurs during early postnatal life (Pan and Gan, 2008).

The terminal periods of critical windows coincide with other hallmarks of neurodevelopment (Figure 1C). These include the progressive myelination of nerve fibers, which is a process essential for cortical function; mice caged in isolation 2 weeks after weaning show reduced myelin and diminished cortical function (Makinodan et al., 2012). Importantly, myelination is also delayed in FXS (Pacey et al., 2013). Also relevant to ASD disease states is the emergence and maturation of local inhibitory (I) interneurons coincident with the end of critical periods, to provide balance to young excitatory (E) circuits (Figure 1C; Hensch, 2004, 2005). The correct development of E/I ratio is critical to neural circuit output, and defects in the E/I ratio balance is a leading candidate mechanism for explaining the emergence of ASD disease states (Gatto and Broadie, 2010). Both hyperexcitation and hypoinhibition are recurring themes in numerous ASD models (Casanova, 2006). More generally, genetic disruption of cortical interneuron development causes regional GABAergic deficits, epilepsy and ASD-like behavioral changes in mice (Powell et al., 2003). As one example, mice deficient for the axon guidance receptor neuropilin 2 display reduced cortical interneuron numbers and are more prone to seizure following neuronal excitation (Gant et al., 2009). Thus, the critical period theory must include the temporally phased regulation of first excitatory and then inhibitory synapses, such that A-D synapse selection generates the appropriate E/I synapse ratio balance. There are other hallmarks of critical period cessation, including the A-D establishment of the perineuronal network, a matrix of chondroitin sulfate proteoglycans (Figure 1C; Ye and Miao, 2013). Roles of glycan modifications in ASD models will be further discussed below in Part 2.

\section{ACTIVITY-DEPENDENT SYNAPSE MECHANISMS IN Drosophila}

Synaptic ultrastructure and function is remarkably conserved across species, for example, comparing mammalian brain glutamatergic synapses to Drosophila NMJ glutamatergic synapses (Schuster, 2006). Moreover, the underlying molecular elements of synapses are similarly extremely well conserved, allowing mutually complementary studies in animals ranging from rodents to flies (Featherstone and Broadie, 2000; Koles and Budnik, 2012). Most A-D work in Drosophila has focused on axonal (presynaptic) development (Rohrbough etal., 2003), whereas most comparable work in mouse has focused on dendritic (postsynaptic) spines. However, the Drosophila NMJ postsynaptic domain is well described and clearly subject to extensive A-D remodeling. It contains two functional classes of ionotropic glutamate receptors (iGluRs; Marrus et al., 2004) and a single metabotropic glutamate receptor (DmGluRA; Bogdanik et al., 2004). Postsynaptically, iGluRs are trafficked and stabilized downstream of A-D mechanisms (Thomas and Sigrist, 2012), and in vivo imaging has shown that presynaptic release of dense core vesicles is A-D, with potentiation of release dependent on $\mathrm{Ca}^{2+}$ influx and CaMKII $\left(\mathrm{Ca}^{2+} /\right.$ calmodulin-dependent protein kinase II) activation (Shakiryanova et al., 2007). DmGluRA nulls show increased A-D facilitation and decreased synaptic boutons of increased size, suggesting the receptor acts as an activity monitor controlling both synapse function and structure (Bogdanik et al., 2004). DmGluRA loss leads to increased expression of iGluRs, and DmGluRA over-expression leads to decreased iGluRs (Pan and Broadie, 2007), demonstrating a tight regulation of postsynaptic receptor composition as an activity response mechanism. These A-D processes in the postsynaptic domain are directly impacted in the Drosophila FXS disease model as discussed below in Part 2.

The Drosophila NMJ is a particularly dynamic synaptic structure during early development, with A-D growth modulated during larval crawling behavior and mediated via glutamatergic neurotransmission (Schuster, 2006). Live imaging shows NMJ growth proceeds by a variety of mechanisms: stretching of existing boutons and insertion of new boutons in between, adding new boutons to the end of an existing strand, de novo addition and branch formation from existing boutons (Zito et al., 1999). A crude method to increase NMJ transmission is through chronic rearing at $29-30^{\circ} \mathrm{C}$, which results in accelerated synapse growth (Sigrist et al., 2003; Zhong and Wu, 2004). Spaced depolarization via high $\mathrm{K}^{+}$saline application leads to the rapid extension and retraction of short filopodia, and the formation of synaptic boutons (Ataman et al., 2006). Reduced membrane excitability via inward current mutants (paralytic $\mathrm{Na}^{+}$channel) or other $\mathrm{Na}^{+}$channel loss-of-function ( $t i p E$ or $m l e^{n a p-t s 1}$ ) leads to improper synaptic refinement (Jarecki and Keshishian, 1995; White et al., 2001), with significantly smaller synaptic boutons (Lnenicka et al., 2003). Acute depolarization of the NMJ leads to the formation of "ghost boutons," that initially lack presynaptic active zones and postsynaptic iGluRs, which appear on a timescale of hours (Ataman et al., 2006, 2008). Generation of genetically targetable channels, such as the voltage-dependent UAS-EKO and UAS-Kir2.1 (Baines et al., 2001; Paradis et al., 2001), and the constitutively open UASdORK potassium channel shunt (White et al., 2001) allow a more precise dissection of the effects of activity regulating NMJ synaptic morphology. Recent advances in bioengineering have taken advantage of channel variants for genetically targeted hyperexcitation in Drosophila, including the transient receptor potential (TrpA1; Hamada etal., 2008) and TrpM8 thermogenic channels (Peabody etal., 2009), the constitutively active $\mathrm{NaChBac}$ channel (Nitabach etal., 2006), the expanding family of channelrhodopsin (ChR2) variants (Schroll et al., 2006; Ataman et al., 2008), and the hyperpolarizing eNpHR3.0 channel (Inada et al., 2011). These new methods will be more fully described below in Part 3.

Beyond neurotransmission per se, proper formation of the Drosophila NMJ entails other A-D trans-synaptic signaling mechanisms. Wnt signaling via wingless (Wg; Packard et al., 2002; 
Korkut and Budnik, 2009) functions downstream of activity (high $\mathrm{K}^{+}$depolarization, ChR stimulation) to regulate both structural and functional development (Ataman et al., 2008; Korkut et al., 2009). Similarly in mammals, activity regulates Wnt2 transcription, which stimulates dendritic arborization in hippocampal cultures (Wayman etal., 2006). Bone morphogenetic protein (BMP) signaling via glass bottom boat (Gbb; McCabe et al., 2003; Keshishian and Kim, 2004) leads to NMJ stabilization through LIM kinase 1 activity, preventing retraction and synapse loss (Eaton and Davis, 2005). Recent use of Shaker $\mathrm{K}^{+}$ channel mutants (or raising temperature to $30^{\circ} \mathrm{C}$ ) to increase excitability, shows that retrograde BMP signaling is required for A-D NMJ growth and maturation (Berke et al., 2013). Heparan sulfate proteoglycan (HSPG) co-receptors of such signaling ligands (Ren et al., 2009), including Dally-like protein (Dlp) and Syndecan (Sdc), play important roles in NMJ synaptogenesis (Johnson et al., 2006; Dani et al., 2012). Importantly, HSPGs interact closely with FMRP to modulate trans-synaptic signaling in the Drosophila FXS disease model (Friedman et al., 2013), suggesting a link to A-D processes. Laminin A (LanA) is another extracellular synaptic protein of interest that is downregulated in response to activity to regulate synaptic architecture: LanA expression is inversely correlated with NMJ size, and is regulated by larval crawling activity, synapse excitation, postsynaptic response, and Wnt signaling (Tsai et al., 2012). These A-D processes in the presynaptic domain are directly impacted in the Drosophila FXS disease model as discussed below in Part 2.

Although A-D development has been explored at length at the Drosophila NMJ, more limited studies have examined A-D mechanisms in the brain, mainly focusing on the mushroom body (MB) learning and memory center (Zars et al., 2000; Margulies et al., 2005). These studies have been enhanced by recent generation of more targeted Gal4 drivers and new optogenetic tools allowing cell-autonomous, single-cell resolution dissection of A-D mechanisms in normal and disease states (Chiang et al., 2011). Using the mosaic analysis with a repressible cell marker (MARCM) clonal technique (Lee and Luo, 2001), characterization of MB axons shows critical period development at the level of individual cells: synaptic branches display significant A-D pruning during the early-use period following eclosion, but become relatively static at maturity (Tessier and Broadie, 2008). Importantly, sensory deprivation (SD) elevated synaptic branch number during this critical period, whereas activity depolarization of single-cell MARCM clones by ChR2 optical stimulation significant decreased synaptic branching during this same critical period (Tessier and Broadie, 2008). Similarly, recent work silencing olfactory sensory neurons (via UAS-Kir2.1; Limb3b-Gal4 or UAS-DorK; Limb3b) lead to immature axonal morphology, including broad axon terminals and multiple filopodia (Prieto-Godino et al., 2012). Silencing of a limited subset of projection neurons innervating the MB (UASdORK1.deltaC; Mz19-Gal4) leads to increased size, number, and active zone density of axon terminals within the microglumeruli of the MB calyx (Kremer etal., 2010). These A-D processes in the brain MB learning/memory center are directly impacted in the Drosophila FXS disease model, as discussed below in Part 2.
Information on A-D mechanisms regulating dendrites in the Drosophila genetic model is more limited, but this research focus is rapidly expanding. For example, motor neuron dendrite structural development has been shown to be regulated downstream of high $\mathrm{K}^{+}$depolarization (Hartwig et al., 2008; Zwart et al., 2013). Moreover, a role for synaptic activity in dendritic remodeling has been shown via targeted transgenic tetanus toxin expression (UASTNT; Sweeney et al., 1995) blocking neurotransmitter release from cholinergic interneurons (Cha-Gal4; UAS-TNT) leads to increased dendritic structural complexity (Tripodi et al., 2008). Dendritic refinement in serotonergic neuron pupal development is also modulated by activity: hyperpolarization via UAS-Kir2.1 caused increased dendritic length, which was proposed to be due to A-D Wnt/Wg signaling with a pro-retraction role in sensory-input dendritic refinement (Singh et al., 2010). Similarly, the silencing of olfactory sensory neurons (via UAS-Kir2.1; Orco-Gal4) led to enhanced dendritic occupancy of the antennal lobe by projection neurons (Prieto-Godino et al., 2012). However, it is also clear that A-D differences may be found across different neuronal types or developmental stages. For example, increased firing of RP2 motor neurons caused by dominant negative Shaker and eag $\mathrm{K}^{+}$channel mutations resulted in increased dendritic complexity, whereas Kir2.1 silencing resulted in decreased dendritic structure (Timmermans et al., 2013). Moreover, constitutively active CaMKII also led to increased dendrite length and branching (Timmermans et al., 2013). Use of the temperaturegated TrpA1 channel to activate neuron firing demonstrated that MN5 flight motor neuron dendrites respond to activity differently over time: increased activity before pupal day 6 caused decreased dendritic branching (Vonhoff et al., 2013), whereas increased activity later in development caused increased branching (Duch et al., 2008), again suggesting differential A-D critical periods.

Mammalian models of dendritogenesis display similar A-D mechanisms to those characterized above in Drosophila. For example, increased neural activity and glutamatergic signaling led to dendritic spine outgrowth (Jontes and Smith, 2000; Antar et al., 2006), and spine turnover rates in young mice were shown to be sensory experience-dependent (Trachtenberg et al., 2002). Long-term SD through whisker trimming led to dendritic spine pruning that was more prominent in young mice (Zuo et al., 2005), and spine synapse densities changed upon rearing or training in enriched environments (Greenough et al., 1985; Beaulieu and Colonnier, 1987; Moser et al., 1995). Spaced depolarization of hippocampal neurons in culture led to extension of new spines, a process correlated with A-D MAPK activation (Wu et al., 2001). Recent advances in live imaging have elegantly provided in vivo evidence of A-D dendritic spine dynamics (Alvarez and Sabatini, 2007; Holtmaat and Svoboda, 2009). As one example, the immediate early gene Arc/Arg3.1 functions to eliminate surplus climbing fibers (CF) onto Purkinje cell synapses in the cerebellum, a process that is accelerated with ChR2 depolarizing stimulation for 2 days and suppressed by targeted CF knockdown of voltage-gated $\mathrm{Ca}^{2+}$ channels (Mikuni et al., 2013). Limited regions of the adult brain remain amenable to similar changes, for example, hippocampal spine density increased in adult rats following spatial learning (Moser et al., 1995), and multiphoton 
imaging of dendritic spines during mGluR-induced long-term depression (LTD) showed spine shrinkage and spine elimination that persisted for up to $24 \mathrm{~h}$ (Ramiro-Cortes and Israely, 2013), but in general these synaptic dynamics are confined to critical periods of synaptogenesis during defined developmental windows.

\section{ACTIVITY-DEPENDENT TRANSCRIPTIONAL AND TRANSLATIONAL REGULATION OF SYNAPTOGENESIS}

Activity-dependent gene transcription clearly leads to developmental changes in synaptic connectivity. Mouse studies of the transcriptional regulator methyl $\mathrm{CpG}$ binding protein 2 (MeCP2) are one elegant example, with knock-in mouse lacking the neuronal activity-induced phosphorylation (NAIP) sequence showing increased excitatory synaptogenesis (Li et al., 2011). MeCP2 is phosphorylated in response to activity and subsequent $\mathrm{Ca}^{2+}$ influx (CaMKII-dependent), leading to regulation of dendritic branching, spine morphogenesis, and A-D induction of brain-derived neurotrophic factor (BDNF) transcription (Zhou et al., 2006). Importantly, MeCP2-deficient mice exhibit delayed maturation of cortical synaptogenesis and neuronal architecture defects (Fukuda et al., 2005), and human MeCP2 mutations are causally associated with the ASD Rett syndrome (Amir et al., 1999). Indeed, many ASD candidate genes are expressed synaptically to modulate synapse function/morphology, and are directly regulated by synaptic activity (Zoghbi and Bear, 2012). Calcium influx has a profound impact on gene transcription (Greer and Greenberg, 2008). As one example, A-D Ca ${ }^{2+}$ influx leads to dephosphorylation of myocyte enhancing factor 2 (MEF2) by calcineurin, causing dissociation with histone deacetylases, CBP recruitment and ultimately, transcription-dependent synapse elimination (Flavell et al., 2006; Barbosa et al., 2008; Pulipparacharuvil et al., 2008). MEF2 activation also leads to suppression of excitatory synapse number via Arc (Flavell et al., 2006; Flavell and Greenberg, 2008), perhaps through Arc-mediated AMPA receptor internalization (Niere et al., 2012). This MEF2-regulated synapse elimination has been correlated with the acquisition of learning and memory abilities (Barbosa et al., 2008), such as those impacted in ASD disease states. Activity similarly regulates cAMP response element-binding protein (CREB), serum response factor (SRF), FBJ murine osteosarcoma viral oncogene (Fos; Greenberg et al., 1986), and neuronal PAS domain protein 4 (NPAS4; Lin et al., 2008), leading to the A-D transcriptional regulation of synaptic proteins, including ASD-associated BDNF, Arc, and ubiquitinprotein ligase E3A (Ube3A; Cohen and Greenberg, 2008; Greer and Greenberg, 2008). CREB and NPAS4 transcriptional activity, via BDNF A-D activation, also leads to a reduced number of inhibitory synapses on excitatory neurons (Hong et al., 2008; Lin et al., 2008), suggesting roles in the developmental regulation of E/I ratio.

Activity-dependent localized synaptic translation permits a rapid and synapse-specific response, which is particularly important in governing the multitude of differentially active synapses occurring at a distance from the cell body. RNA-binding proteins and translational regulation have been demonstrated in both axonal growth cones and mature axons (Hornberg and Holt, 2013), ostensibly permitting local protein production in presynaptic boutons. Highly motile RNA granules containing inactive ribosomes (Krichevsky and Kosik, 2001; Elvira et al., 2006), suggest neurons have evolved mechanisms to bypass translation initiation locally at the synapse (Costa-Mattioli et al., 2009; Batish et al., 2012). Assays of local translation using ribopuromycylation to visualize ribosomes associated with nascent peptide chains (David et al., 2012) demonstrate that mRNAs are transported alongside paused polyribosomes at hippocampal synapse, thereby bypassing the rate-limiting step of translation initiation (Graber et al., 2013). Importantly, these polyribosomes co-localize with RNA-binding FMRP and Staufen 2 (Antar et al., 2005; Elvira et al., 2006; Napoli et al., 2008; Darnell et al., 2011; Lebeau et al., 2011), and defects in A-D translational control can lead to ASD states, with unregulated translation causing synaptic impairment driving behavioral dysfunction (Santini et al., 2013). This topic will be explored at length in Part 2.

The strongest link between translation control and A-D synaptogenesis is the RNA-binding FMRP, which regulates translational initiation (Napoli etal., 2008), mRNA transport (Bassell and Warren, 2008), and translational elongation of mRNAs encoding synaptic proteins (Darnell et al., 2011). FMRP is strongly upregulated during critical periods of neural circuit refinement, where it associates with mobile RNA granules in dendrites, spines, filopodia, and growth cones that translocate in response to the level of neuronal activity (Antar et al., 2005; Cook et al., 2011). Importantly, FMRP is positivity upregulated by neuronal activity (Antar etal., 2004; Gabel et al., 2004; Tessier and Broadie, 2008; Wang et al., 2008b), and regulates multiple A-D processes including synapse elimination (Pfeiffer et al., 2010). Studies at the Drosophila NMJ first demonstrated that FMRP negatively regulates cytoskeletal targets, including the MAP1B/Futsch (Zhang et al., 2001) mediator of microtubule-associated synaptic growth (Roos et al., 2000). Interestingly, A-D transcriptional and translational control are linked through FMRP, as the activity of MEF2 in synapse elimination is wholly dependent on FMRP function, and occurs cell autonomously in the postsynaptic neuron (Pfeiffer et al., 2010). In Fmr1 knockout (KO) hippocampal culture, acute expression of FMRP (via timed transfection) at an early postnatal period leads to synapse growth, but FMRP during the second postnatal week led to suppression of synapse formation (Zang et al., 2013). Interestingly, MEF2 activity is progressively increased upon depolarization (via high $\mathrm{K}^{+}$treatment) over the same developmental period (Zang et al., 2013). These recent studies highlight both the impact of FMRP on synaptic growth and the importance of developmental timing within critical periods of development. In the following section (Part 2) we will elaborate the molecular details of FXS and other ASDs, highlighting A-D changes in the development of synaptic connectivity.

\section{PART 2: ACTIVITY-DEPENDENT MECHANISMS IN ASD DISEASE STATES}

For ASD diagnosis, children must display three core symptoms before 3 years of age: (1) atypical social behavior, (2) disrupted verbal/non-verbal communication, and (3) unusual patterns of restricted interests or repetitive behaviors (Geschwind and Levitt, 2007). It has been proposed that a "disconnect" between brain 
regions involved in higher-order associations lies at the root of these ASD behaviors (Frith, 2004; Courchesne and Pierce, 2005; for historical context, Geschwind, 1965a,b). For example, this disconnect may occur between a pair of higher-order association cortices (or several such centers), which represent input from multiple sensory modalities in cortical space (Geschwind and Levitt, 2007). More evidence for this disconnect theory comes from prefrontal cortex and anterior cingulate disconnection for joint attention (foundation of language and social behavior; Mundy, 2003), and demonstrated disconnect in functional magnetic resources imaging (fMRI) studies (Koshino et al., 2005). The root of this hypothesis is based on the hierarchical development of cortical circuitry (LeBlanc and Fagiolini, 2011; i.e., disrupted development of the initial architecture, e.g., via shifts in critical periods) results in faulty substrates for subsequent A-D mechanisms that are crucial for reorganization, pruning, and solidification of synapses within circuits. Primary sensory cortices develop progressively, with critical periods that are variable in time and often non-overlapping (Kroon et al., 2013). Furthermore, individual modalities develop progressively, as the critical periods of rodent somatosensory cortex begin at the subcortical level and then progress to cortical levels (Feldmeyer et al., 2013). The "missed window" theory of ASDs may help explain the root of auditory, visual, and somatosensory dysfunction in information processing, which drives the socialization and communication deficits defining ASDs (LeBlanc and Fagiolini, 2011). In terms of basic brain architecture, ASDs may emerge through faulty subcortical development, which precedes thalamic as well as subsequent cortical development (Kroon et al., 2013). Evidence for this theory includes early incidence of motor developmental delay, social impairment, and epileptic seizures (Zoghbi and Bear, 2012).

The hierarchical model of ASD brain development is built upon evidence that alterations in primary sensory modalities underlie higher order cognition defects. Broadly speaking, these primary sensory alterations appear to lessen in severity with age, although the severity of primary sensory impairments clearly correlates with the degree of social interaction impairment (Ben-Sasson et al., 2009; Simmons et al., 2009). Neuronal activity is essential for circuit development (Lendvai et al., 2000; Spitzer, 2006), and this activity is both intrinsically generated (Golshani et al., 2009; Rochefort et al., 2009) and sensory derived, as shown in primary visual cortex (Siegel et al., 2012). However, this A-D component of circuit development is obviously built upon genetic foundations, and several hundred genes are associated with ASDs (State and Sestan, 2012). Clinical characterizations of ASDs are highly suggestive of A-D synaptic defects (Toro et al., 2010; Ebert and Greenberg, 2013). For example, FXS patients display hypersensitivity to numerous sensory stimuli (Miller et al., 1999), as well as abnormal sensory gating in prepulse inhibition trials (Hessl et al., 2009). In addition, attention deficit/hyperactivity disorder (Murray, 2010) and developmentally transient epilepsy are also associated with FXS (Musumeci et al., 1999; Berry-Kravis, 2002) strongly indicating a core A-D impairment.

Although it is understandably difficult to model ASD behaviors in animals, several recent studies demonstrate inventive ways to address this essential issue. For example, Fmr1 KO mice display many behavioral disruptions similar to human FXS patients, including susceptibility to audiogenic seizure, hyperactivity, learning and memory deficits, and social interaction abnormalities (Kooy, 2003; Bear et al., 2004; Hagerman et al., 2009). Some studies report that Fmr1 KO mice show increased anxiety-related activity during social interaction (Mines et al., 2010), whereas other studies show decreased anxiety in open field studies (Michalon et al., 2014). It is quite clear that behavioral phenotypic effects are heavily dependent on genetic background (Spencer et al., 2011). However, Fmr1 KO mice in the C57 background show consistent impairments in social interaction behaviors (Baker et al., 2010). Research in mice has also focused on single sensory modalities, showing that Fmr1 KO mice display altered auditory processing (Rotschafer and Razak, 2013). Although higher cognition is difficult to test in mice, recent research using a touchscreen operant conditioning paradigm (which facilitates a conflict between sensory-driven and task-dependent signals, thereby increasing cognitive load) demonstrates that Fmr1 KO mice display defects in learning under heavy cognitive demand (Dickson et al., 2013). The Drosophila FXS model similarly shows disruptions closely resembling human FXS patients, including hyperactivity, learning/memory deficits, and social interaction abnormalities (Bolduc etal., 2008, 2010a,b; Coffee et al., 2010, 2012; Tessier and Broadie, 2012).

\section{CRITICAL PERIOD DEVELOPMENT OF E/I RATIOS IN ASDs}

Autism spectrum disorders have been ascribed to altered E/I synaptic balance, which likely reflects defects in A-D synapse elimination/addition specific to different classes of synapse (Rubenstein and Merzenich, 2003; Hensch, 2005; Ramocki and Zoghbi, 2008; Gatto and Broadie, 2010). Neural circuits must carefully balance excitatory and inhibitory connections during critical period development, and theories of synaptic homeostasis posit that compensatory alterations prevent runaway signaling (Turrigiano and Nelson, 2004; Maffei and Fontanini, 2009). The appearance of altered E/I ratio is linked with critical periods of brain development, as runaway hyperexcitable circuits fail to mature properly without inhibitory input (Rubenstein and Merzenich, 2003; Rippon et al., 2007). In support of this idea, postmortem neocortex tissue from ASD patients shows reduced vertical arrays of glutamatergic and GABAergic mini-columns and disordered peripheral neuropil space (Casanova, 2006). Moreover, ASD postmortem studies reveal a reduction in glutamic acid decarboxylase (GAD), the rate-limiting enzyme in GABA synthesis (Fatemi et al., 2002). On the postsynaptic membrane, samples from ASD patient brains also contain reduced GABA-A receptor expression (Fatemi et al., 2009a,b). Crucially, excitatory circuits must be balanced by GABAergic inhibitory interneurons that form connections progressively during late-stage critical period development (Bacci etal., 2005). Competing theories of both hypoinhibition (GABAergic deficits) and hyperexcitation (excitatory excess) underlying autistic disease states are well known (Gatto and Broadie, 2010). However, many results support hypoinhibition models that complement hyperexcitation models; these models are not necessarily mutually exclusive and may represent two counterbalancing underpinnings of ASD disease states.

Fragile X syndrome is among the best-characterized ASD disease states. FMRP is found at the synapse, positivity upregulated by 


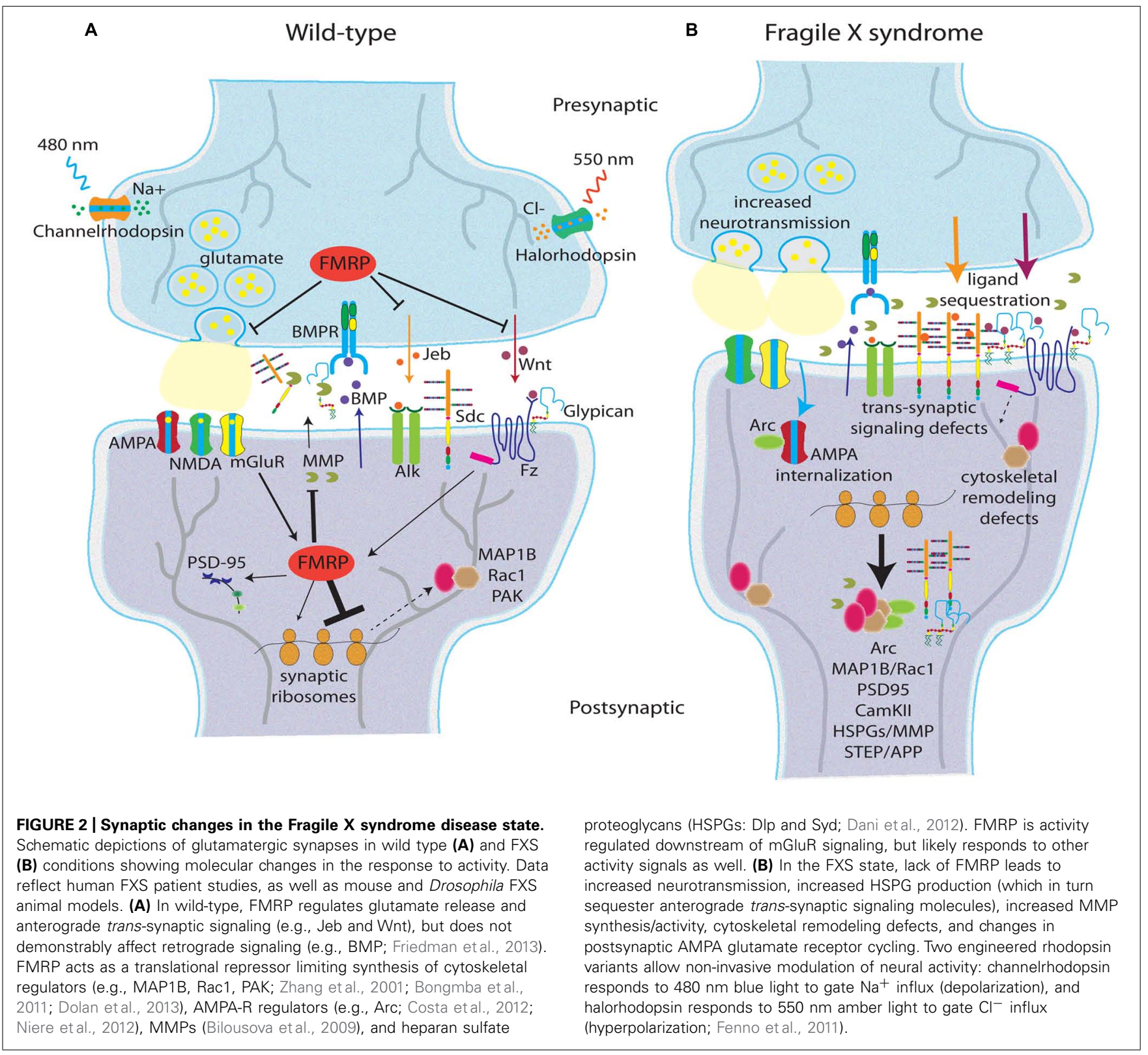

neuronal activity and regulates A-D processes including synapse elimination (Figure 2; Antar et al., 2004; Gabel et al., 2004; Tessier and Broadie, 2008; Wang et al., 2008a; Pfeiffer et al., 2010). FXS may be characterized by a failure to remove immature synaptic connections and properly balance E/I synapse ratio during critical period development (Comery et al., 1997; Irwin et al., 2000, 2001; Galvez et al., 2005; McKinney et al., 2005). For example, Fmr1 KO mice display brain-region specific increases and decreases in GAD expression (D'Hulst et al., 2006; Adusei et al., 2010); increased in cortex, brainstem, and diencephalon (El Idrissi et al., 2005), and decreased in amygdala (Olmos-Serrano et al., 2010). FMRP also regulates GABA-A receptor expression (Liu et al., 2013), as Fmr1 KOs show reduced GABA-R subunit mRNA (D'Hulst et al., 2006; Gantois et al., 2006) and protein (El Idrissi et al., 2005; Curia et al., 2009; Adusei et al., 2010). Recent work suggests that the timing rather than the absolute expression levels of $\mathrm{GABA}_{\mathrm{A}} \mathrm{Rs} \alpha 1, \alpha 2$, and gephyrin are altered in Fmr1 KO mice (Kratovac and Corbin, 2013), once again supporting the theory of critical period dysfunction. It is now clear that GABAergic changes are regionally specific, as Fmr1 KO mice display reduced inhibitory synapses within the basolateral amygdala (Olmos-Serrano et al., 2010), yet increased inhibitory synapses are noted in CA1 region of hippocampus (Dahlhaus and El-Husseini, 2010), providing direct evidence of E/I imbalance. Fmr1-deficient mice exhibit defects in GABAergic neocortical circuits (Selby et al., 2007), with differences in the neocortical E/I balance (Gibson et al., 2008). There is some conflicting data from functional GABAergic studies, with decreased tonic inhibition in recordings from subicular neurons (Curia et al., 2009), decreased tonic and phasic inhibition in the amygdala (Olmos-Serrano et al., 2010), and increased inhibitory 
transmission in striatal spiny neurons (Centonze et al., 2008) all reported in the mouse FXS model. A recent study reports a cell-specific presynaptic role for FMRP in excitatory neurotransmission onto inhibitory interneurons in layer 4 of mouse cortex (Patel et al., 2013), with mice mosaic for Fmrl displaying decreased glutamate release probability. This defect was not observed in neurotransmission between excitatory neurons, showing a cellspecific role for FMRP and a potential mechanistic basis for E/I imbalance in the FXS disease state.

The opposing side of the E/I ratio - excitatory signaling - is even better explored in ASD models, especially in the FXS disease state (Rubenstein and Merzenich, 2003). Excitatory neurons are intrinsically more excitable in Fmr1 KO mice (Gibson et al., 2008), with elevated $\mathrm{Ca}^{2+}$ signaling (Goncalves et al., 2013) and excitatory networks that are structurally hyperconnected (although individual excitatory connections are slower; Testa-Silva et al., 2012). Excessive mGluR signaling, as a reporter of glutamatergic synapse activity state, is widely reported (Bear et al., 2004; Bear, 2005). The mGluR theory of FXS suggests that disease symptoms are due to exaggerated downstream consequences of aberrant mGluR1/5 signaling. Crucially, FMRP is locally synthesized in response to mGluR activation (Weiler et al., 1997), and mGluR-mediated hippocampal LTD is exaggerated in Fmrl $\mathrm{KO}$ mice (Huber et al., 2002; Nosyreva and Huber, 2006). FMRP is dephosphorylated (by PP2A) upon stimulation of group I mGluRs, which leads to a rapid increase in translation (Narayanan et al., 2007). In line with these studies, mGluR5 heterozygosity rescues many of Fmr1 KO mice phenotypes (Dolen et al., 2007). Also, group 1 mGluR antagonists [e.g., MPEP (2-methyl-6-(phenylethynyl)-pyridine)] ameliorate several behavioral phenotypes in Fmrl KO mice (Yan et al., 2005; Choi et al., 2010b). Recent mechanistic studies show that mGluRA activation starts a cascade of events leading to FMRP phosphorylation and subsequent synthesis of Arc, and ultimately mGluRassociated LTD (Niere et al., 2012). In addition, activation of serotonin 7 receptors (5-HT7) can reverse mGluR-induced AMPA internalization in FXS model mice, effectively correcting mGluRLTD (Costa et al., 2012). Although initial formation of auditory cortex is normal in Fmrl KO mice, mutants fail to undergo experience-dependent reorganization, suggesting an altered auditory critical period that is mGluR-dependent, as MPEP suppressed the sound-induced reorganization phenotype (Kim et al., 2013a). Sensory-dependent reorganization of auditory cortex has been explored at length, with A-D changes in hippocampus including neurogenesis, learning and memory, and neural connectivity (Chaudhury et al., 2013).

There are some caveats with the mouse FXS model. One issue is the timing of the FMRP loss, as in mouse models the Fmr1 gene is deleted and therefore not expressed (Mientjes et al., 2006), whereas the human gene is silenced via methylation during embryonic development, but is expressed at early stages (Willemsen et al., 2002). Furthermore, human patients may display Fmr1 mosaicism across cell types, due to methylation specificity or variable presence of a premutation (Stoger et al., 2011). Finally, mouse Fmr1 phenotypic effects are often surprisingly mild, transient, and heavily dependent on genetic background (Spencer et al., 2011). Although the Drosophila FXS model does not address the first two issues, $d f m r 1$ null phenotypes are generally both more robust and more penetrant (Tessier and Broadie, 2012). Excitatory synaptic signaling (glutamatergic and cholinergic) pathways have both been extensively studied in the Drosophila FXS model (Figure 2). Electrophysiological studies indicate increased excitability, A-D synaptic vesicle cycling and neurotransmission in dfmr1 null glutamatergic synapses (Zhang etal., 2001; Gatto and Broadie, 2008). Drosophila FMRP and sole mGluR (DmGluRA) display mutual feedback regulation, as FMRP expression increases with the loss of $d m G l u R A$, and DmGluRA expression increases with loss of $d$ fmrl (Pan et al., 2008). Crucially, many FXS phenotypes are ameliorated by feeding of mGluR antagonists (e.g., MPEP; McBride et al., 2005; Choi et al., 2011), and MPEP phenocopies the genetic loss of $d m G l u R A$ (Pan and Broadie, 2007; Pan et al., 2008). Importantly, $d f m r 1$; $d m G l u R A$ double null mutants partially rescue excitatory defects witnessed under high frequency stimulation paradigms (Repicky and Broadie, 2009), providing a partial genetic basis for a hyperexcitable state in FXS. In the absence of FMRP, increased mGluR function leads to decreased cyclic AMP, which is further correlated with deficits in olfactory learning and memory (Kanellopoulos et al., 2012). Intriguingly, cAMP positively regulates transcription of $d f m r 1$, via PKA and CREB (Kanellopoulos et al., 2012), thereby linking glutamatergic signaling and FMRP at the nucleus. In addition, recent work in our laboratory has identified alterations in the inhibitory circuitry of $d f m r 1$ null flies. $d f m r l$ mutants are characterized by reduced GAD expression in the adult brain, developmental stage-specific dysmorphia in GABAergic axons innervating the $\mathrm{MB}$ calyx, and altered GABAergic $\mathrm{Ca}^{2+}$ dynamics (Gatto et al., 2014). This data importantly implicates altered inhibitory neurotransmission in the Drosophila model of FXS, and further validates the conservation of FMRP function in the fruit fly brain.

\section{DYSMORPHIC SYNAPSES IN ASD DISEASE STATES}

Most ASD human studies on synaptic dysmorphia focus on the dendritic domain. For example, ASD patients display increased dendritic spine densities on cortical projection neurons (Hutsler and Zhang, 2010). FXS patients also display elevated spine density, with processes displaying elongated, "tortuous" structures (Irwin etal., 2001), perhaps suggestive of defects in synapse elimination. Similar dendritic dysmorphia are common in many other neurological disease states (Marin-Padilla, 1972; Purpura, 1974; Kaufmann and Moser, 2000), which may reflect developmental arrest or an attempted compensation for the lack of functionally mature spines (Fiala et al., 1998). In particular, it should be noted that these dendritic phenotypes are not restricted to the autism spectrum (sociolinguist deficits), as individuals with schizophrenia (perception deficits) and Alzheimer's disease (memory dysfunction) also display abnormal dendritic spine architectures (Penzes et al., 2011). These three forms of neurological dysfunction are distinct in symptomology, yet this specificity may be rooted in the timing and onset of synaptic dysfunction (Figure 1B).

Protrusion dynamics are just as important for synaptogenesis in genetic model systems (Ziv and Smith, 1996; Luikart et al., 2008). In the mouse FXS model, for example, there is delayed functional spine formation in the hippocampus (Braun and Segal, 2000), and 
ultimately fewer spines with mature, bulbous morphology (Irwin et al., 2000). SD leads to changes in spine protrusion dynamics in neonatal mice (Lendvai et al., 2000), demonstrating A-D regulation. Specifically, Fmr1 KO mice deficits may result from deficits in experience-dependent plasticity during critical periods of synaptic refinement (Dolen et al., 2007; Bureau et al., 2008). During in vivo time lapse imaging through cranial windows in neonatal mice, layer $2 / 3$ neurons show a dramatic decrease in dendritic spine dynamics during the first 2 weeks as mushroom-shaped spines replace filopodia and protospines, whereas Fmr1 KO mice show developmental delays in the downregulation of spine turnover and the transition to mature spines (Cruz-Martin et al., 2010). Importantly, mGluR blockage accentuated these phenotypes in Fmr1 KO mice (Cruz-Martin et al., 2010), providing a different link to A-D synaptic remodeling in the FXS disease state.

The dynamic nature of dendrites enhances their ability to sample the extracellular space for suitable presynaptic terminals (Ziv and Smith, 1996; Bonhoeffer and Yuste, 2002). Immature synapses from as adhesions between dendritic filopodia and axons (Fiala et al., 1998). Perturbations in these dynamics lead to altered synaptogenesis, for example, as demonstrated in Ephrin B-deficient (Kayser et al., 2008) and neurotrophin-deficient (Luikart et al., 2008) conditions. Following initial contact, spine dynamics are necessary for A-D remodeling (Lendvai et al., 2000; Yuste and Bonhoeffer, 2001, Yuste and Bonhoeffer, 2004; Holtmaat et al., 2006), and then strongly downregulated at the end of the critical period of synapse selection (Ziv and Smith, 1996). In FXS animal models, the failure to stabilize dendritic spines in developmental critical periods suggests Fmrl null protrusions have problems maintaining proper balance between stability and dynamism (Antar et al., 2006; Pfeiffer and Huber, 2007), resulting in fewer mature synaptic connections (Cruz-Martin et al., 2010). FMRP presumably modulates synaptic stability through regulation of mRNAs coding for dendritic spine regulators (Bagni and Greenough, 2005; Bassell and Warren, 2008), such as the key postsynaptic scaffold PSD-95 (postsynaptic density protein 95) as one example (Figure 2; Zalfa et al., 2007). Recent reviews outline the spine dysmorphia in the mouse FXS model in more detail (He and Portera-Cailliau, 2013).

Differences in axonal development in the mouse FXS model have not been as extensively studied. However, FMRP is localized at axon growth cones, which are far less dynamic in Fmr1 KO mice (Antar etal., 2006). More thorough studies in the Drosophila FXS model demonstrate progressive differences in axonal projection and synaptic process pruning in the central brain MB of dfmrl null mutants (Tessier and Broadie, 2012). The Drosophila model demonstrates defects in the development of neuronal architecture (Zhang et al., 2001) and inappropriate A-D pruning (Tessier and Broadie, 2009) throughout the brain. For example, the synapses of small ventrolateral neurons (sLNvS) in the circadian regulation circuitry are overelaborated in $\mathrm{dfmr} 1$ nulls (Dockendorff et al., 2002; Gatto and Broadie, 2009), a developmental phenotype that can be rescued only during the late pupal/early adult critical period, but not in early pupal stages or in mature adult stages (Gatto and Broadie, 2009), demonstrating a transient critical period requirement for FMRP. In the MB circuit, FMRP is required to limit outgrowth during an early phase and to subsequently prune synaptic branches in a later phase, and both phases are dependent on activity input (Tessier and Broadie, 2008). Furthermore, MB neurons in $d f m r 1$ nulls demonstrate age-dependent increases in calcium signaling dynamics, as well as deficient expression of several calcium-binding proteins (Tessier and Broadie, 2011), suggesting activity is driving a calcium signaling cascade coupling structural and functional developmental changes in the FXS disease state. Collectively, these defects all map to the early-use, A-D critical period of synaptic remodeling.

\section{A-D TRANSLATION MISREGULATION IN THE ASD FRAGILE X SYNDROME}

Autism spectrum disorders have been linked to hundreds of genes (Abrahams and Geschwind, 2008; Toro et al., 2010; Devlin and Scherer, 2012), and the number keeps jumping higher, with candidates in pathways affecting many distinct neuronal functions (Delorme et al., 2013). Importantly, however, many of these genes are modulated by neural activity, either directly or indirectly (Morrow et al., 2008; Chahrour et al., 2012; Ebert and Greenberg, 2013), and a number are known to be involved in A-D neural circuit modification (Toro et al., 2010). Rare de novo mutations have implicated a large network of genes directly involved in synaptogenesis and synaptic function (Gilman et al., 2011). Nevertheless, ASD modeling is made difficult by the underlying genetic diversity, and this difficulty is compounded by the array of symptoms described in human conditions and debates about appropriate genetic models (Crawley, 2007). The genetic bases of autism can be divided into a number of molecular groups: (1) chromatin remodeling, (2) cytoskeletal dynamics, (3) synaptic scaffolds, (4) neurotransmitter receptors and transporters, (5) second messengers, (6) cell adhesion molecules, and (7) secreted proteins (Persico and Bourgeron, 2006). Clearly the genetic basis of ASDs is massive area, and we focus here only on the FXS disease state, which may be an A-D translation control point for a number of these protein classes.

The monogenic FXS disease state (Verkerk et al., 1991) is typically caused by an unstable $5^{\prime}$ trinucleotide expansion in the promoter region of the Fmrl gene leading to hypermethylation and transcriptional silencing (Leehey et al., 2008). FXS patients exhibit delayed developmental trajectories, working memory deficits, circadian defects, hypersensitivity to sensory input, seizures, increased anxiety and hyperactivity (Harris et al., 2008), and a 30\% comorbidity with autism (Zingerevich et al., 2009). Furthermore, FMRP may be associated with other neurological disease states, as schizophrenic patients have reduced FMRP in the periphery (Kovacs et al., 2013) and cerebellum (Fatemi et al., 2010), correlating with poor performance on perceptual integration tasks (Kelemen et al., 2013). The expanding web of FMRP associations (Bourgeois et al., 2009; Hagerman et al., 2010; Fatemi and Folsom, 2011) underlines the importance of this mRNA-binding translational regulator, with hundreds of candidate mRNA targets (Miyashiro et al., 2003; Darnell et al., 2011; Bagni et al., 2012). FMRP forms large cytosolic ribonuclear particles (RNPs), which are associated with mRNA transport, stability, and translation control (Bagni et al., 2012). RNP transport dynamics are altered in Fmr1 KO mice, with reduced kinesin-associated 
mRNAs (Dictenberg etal., 2008). However, FMRP does not appear to be necessary for steady-state maintenance or constitutive localization of the majority of its target mRNAs (Steward et al., 1998; Dictenberg et al., 2008), although direct measurement of protein synthesis in hippocampal slices (Dolen et al., 2007), hippocampal culture (Osterweil et al., 2010), and synaptosomes (Muddashetty et al., 2007) shows global elevations in the Fmr1 KO mouse.

Fragile X mental retardation protein is such an important focus because it is poised to directly and quickly respond to activity changes at the synapse. FMRP transports mRNA within the neuron and specifically at synapses in an A-D manner via association with microtubule-associated motor proteins (Kanai et al., 2004; Antar et al., 2005; Ferrari et al., 2007; Dictenberg et al., 2008; Charalambous et al., 2013). Targets of FMRP (Billuart and Chelly, 2003) include the small GTPase Rac1 and its effector p-21 activated kinase $(P A K)$, functioning as actin regulators (Bokoch, 2003). $\mathrm{Racl}$ is necessary for dendritic spine development, loss of FMRP leads to over-activation of Rac1 (Figure 2B), and Rac1 pharmacological inhibition leads to suppression of LTD in Fmr1 KO mice (Bongmba et al., 2011). In addition, A-D stimulation of hippocampal synapses leads to increased phosphorylated PAK in wild-type, but not Fmr1 KO mice, and mutants were unable to maintain actin cytoskeletal A-D changes (Chen et al., 2010). Moreover, small molecule inhibition of PAK suppresses Fmr1 null phenotypes including dendritic spine morphology, seizures, hyperactivity, and repetitive movements (Dolan et al., 2013). Another target, PSD95 is an adaptor protein associated with glutamatergic receptors (Sheng and Kim, 2002); mice deficient in PSD-95 show dendritic spine dysmorphia in striatum and hippocampus (Vickers et al., 2006). FMRP may regulate PSD-95 partially through stabilization of PSD-95 mRNA, a process that is enhanced with mGluR activation (Figure 2A; Zalfa et al., 2007). FMRP also associates with futsch/MAP1B mRNA, a microtubule regulator of synaptic growth (Roos et al., 2000), that can be localized at the growth cone of developing axons (Antar et al., 2006), and is localized within FMRP-RNP granules in cultured hippocampal neurons (Antar etal., 2005). FMRP and futsch associate in co-immunoprecipitation assays, and its expression is inversely correlated with FMRP expression (Zhang et al., 2001). Importantly, futsch loss of function corrects the synaptic overgrowth phenotype in $d f m r 1$ nulls (Figure 2B; Zhang et al., 2001). Application of the axon guidance molecule Semaphorin-3A (Sema3A) to hippocampal culture leads to MAP1B protein synthesis, but this response is attenuated in Fmr1 null neurons (Li et al., 2009), thereby linking the activity of an axon guidance molecule with local FMRP-dependent translation. More recent work has shown that FMRP regulation of futsch is downstream of BMP and Spartin signaling (Nahm et al., 2013), thereby linking a key trans-synaptic signaling pathway with cytoskeletal changes in presynaptic neurons.

Several recent studies have provided new mechanistic insights about FMRP function at the synapse. Two recently identified FMRP targets are striatal-enriched protein tyrosine phosphatase (STEP) and amyloid precursor protein (APP), which appear to underlie at least a portion of mouse Fmrl phenotypes, as genetic reduction of either can suppress audiogenic seizure, anxiety, and social deficits in the disease model condition (Westmark et al., 2011; Goebel-Goody et al., 2012; Figure 2). Another target of FMRP is Arc mRNA (Zalfa etal., 2003), an A-D immediate early gene (Link et al., 1995) strongly linked to synaptic function (Park et al., 2008). Importantly, Arc protein functions to stimulate endocytosis of AMPA glutamate receptors (Chowdhury et al., 2006), an action correlated with the A-D induction of LTD (Park etal., 2008). FMRP plays an important modulatory role in this A-D process, acting as a translational repressor of Arc synthesis during mGluR-LTD (Niere et al., 2012). FMRP also regulates several potassium ion channels. For example, FMRP interacts with Kv3.1b mRNA in brainstem synaptosomes, and the A-D increase in Kv3.1b channel expression in wild type mice is abolished in Fmr1 null mice (Strumbos et al., 2010). Moreover, FMRP can directly interact with potassium channel proteins to regulate channel kinetics, including Slack channels (Brown et al., 2010) and the $\beta 4$ subunit of BK channels (Deng et al., 2013). Therefore, FMRP can no longer be described as solely a translational regulator, with protein-protein interactions regulating excitability demonstrating an additional vital role for FMRP function.

The final area of focus for FMRP regulation lies in the extracellular space. Both mouse and Drosophila FXS models have recently been documented to show large increase in the levels of synaptic matrix metalloproteases (MMPs), a family of extracellular proteases involved in synaptic development, function, and plasticity (Figures 2A,B; Rivera et al., 2010). MMPs cleave secreted as well as membrane-anchored proteins during synaptogenesis and A-D synaptic remodeling (Ethell and Ethell, 2007). Specifically, MMP-9 expression and activity are increased in Fmrl KO mice (Bilousova et al., 2009), with MMP-9 locally translated at synaptodendritic domains in an A-D manner (Dziembowska et al., 2012). MMP-9 mRNA is transported and regulated by FMRP, and increased MMP-9 expression is found in Fmr1 null synaptosomes from mouse hippocampus (Janusz et al., 2013). Crucially, a drug inhibitor of MMPs, minocycline, effectively restores synaptic architecture and behavioral defects in the mouse FXS model (Figure 2; Bilousova et al., 2009). The mechanistic link between MMPs and ASDs may lie with MMP substrates, especially the HSPGs, which are well-established proteolytic targets of MMPs (Choi et al., 2012). HSPGs bind a variety of molecules, including growth factors, morphogens, and cell surface receptors, effectively modulating a hosts of biological functions (Bishop et al., 2007). In BTBR autism mouse models (Scattoni et al., 2011), hippocampal sclerosis (HS) immunoreactivity is reduced (Meyza et al., 2012). Conditional inactivation (neuronal specific) of Ext1, an essential enzyme for HS synthesis, leads to defective glutamatergic neurotransmission and behavioral abnormalities similar to autistic phenotypes (Irie et al., 2012). Disruption of HSPGs in Drosophila leads to trans-synaptic signaling defects at the NMJ (Dani et al., 2012), causing impairments of synaptic structural and functional development. Moreover, in the Drosophila FXS model, both MMP mutation and the minocycline MMP inhibitor (MMPIs) treatment effectively suppresses synaptic architecture defects in motor neurons, clock neurons, and neurons of the central brain MB learning/memory center (Siller and Broadie, 2011). Perhaps linking these two mechanisms, the Drosophila FXS model displays 
dramatic upregulation of synaptic HSPGs (Figure 2), including a GPI-anchored Glypican and transmembrane Syndecan (Sdc; Friedman et al., 2013). These elevated co-receptors in turn inappropriately sequester Jelly Belly (Jeb) and Wnt Wg trans-synaptic signaling ligands to alter intercellular communication between pre- and postsynaptic cells during synaptogenesis (Figures 2A,B). Genetic correction of the synaptic HSPG upregulation in $d f m r 1$ null mutants corrects both structural overelaboration and elevated neurotransmission (Friedman et al., 2013), demonstrating this signaling mechanism to be causative to A-D synaptogenic defects in this FXS disease state model. Based on these extensive studies in mice and flies, MMPIs are currently in development for FXS therapeutics as discussed below.

\section{ASD THERAPEUTIC AVENUES}

The A-D model of ASDs, especially as it applies to the regulation of critical period development of appropriate E/I synaptic ratios, suggests a number of therapeutic strategies. For example, the overabundant mGluR signaling theory underlying FXS dysfunction is supported by numerous mGluR mutant studies in mouse and Drosophila animal models (Bear et al., 2004, 2008; Bear, 2005; McBride et al., 2005; Dolen et al., 2007, 2010; Pan and Broadie, 2007; Dolen and Bear, 2008; Pan et al., 2008; Repicky and Broadie, 2009). Importantly, mGluR antagonists (such as MPEP) effectively rescue many of the mouse and Drosophila FXS model cellular and behavioral defects associated with FXS (McBride et al., 2005; Pan and Broadie, 2007; Bolduc et al., 2008; Dolen and Bear, 2008; Choi et al., 2010a; Dolen etal., 2010). MPEP is not available for human use due to toxicity, but new generation mGluR antagonists are in development (Levenga et al., 2010; Wang et al., 2010b; Pop et al., 2013). For example, chronic application of the mGluR antagonist CTEP suppresses learning and memory deficits and leads to regional improvements in brain function in Fmrl KO mice, as determined by perfusion imaging as an indirect measure of neural activity (Michalon et al., 2014), although it is important to note that CTEP also affected wild-type learning and memory. This first use of functional imaging in a mouse ASD model is an important step forward. Current FXS patient clinical trials include other mGluR antagonists (e.g., mavoglurant; Gantois et al., 2013) as well as GABA-B receptor agonists (e.g., arbaclofen; Henderson et al., 2012). Fenobam, a selective mGluR antagonist, improved prepulse inhibition in 6 of 12 FXS patients (Berry-Kravis et al., 2009). mGluR reverse agonists in phase II and III clinical trials were recently extended to younger children (Levenga et al., 2010), recognizing the early developmental focus likely necessary for effective intervention. For illustration, the rescue of spine morphology in cultured neurons from Fmr1 KO mice by mGluR blockage is effective in young neurons but less so in older neurons ( $\mathrm{Su}$ et al., 2011). Thus, it is important for interventions to target A-D critical periods.

On this opposing side of the E/I balance lies the therapeutic potential to increase GABA levels or potentiate GABA receptors, with the goal to alleviating FXS symptoms of hypoinhibition (Paluszkiewicz et al., 2011; Coghlan et al., 2012). Altered GABAergic inhibition is a common thread in many neurodevelopmental disorders and represent an important focus for therapeutics. Pharmacological approaches to GABAergic modulation address several components of inhibitory neurotransmission, including the GABA reuptake blockers Riluzole (Mantz et al., 1994; Jahn et al., 2008; Erickson et al., 2011b) and Tiagabine (Nielsen et al., 1991), GABA $\mathrm{R}$ activators Ganaxolone (Biagini et al., 2010; Reddy and Rogawski, 2010) and Gaboxadol (Deacon et al., 2007; Lundahl etal., 2007; Olmos-Serrano etal., 2010), GABAB R activator Arbaclofen (Pacey et al., 2009), and Vigabatrin, an inhibitor of GABA catabolism (French et al., 1996; Coppola et al., 1997). Acamprosate is also interesting, as a drug that both antagonizes mGluR5 (Blednov and Harris, 2008) and agonizes $\mathrm{GABA}_{\mathrm{A}}$ Rs (Mann et al., 2008). A small uncontrolled trial with three adult FXS patients showed improvement in social behavior and communication after 16-28 weeks on acamprosate (Erickson etal., 2010), and similar gains in social communication were found in a small uncontrolled sample of autistic children (Erickson et al., 2011a).

Alternative pharmaceutical approaches to FXS focus on MMP and perhaps HSPG function in the synaptomatrix (Siller and Broadie, 2011; Dani and Broadie, 2012; Dani et al., 2012; Friedman et al., 2013). One obvious approach is the use of MMPIs, of which a large collection has been developed for human clinical trials on inflammatory and vascular diseases (Hu et al., 2007). For example, the tetracycline-derivative minocycline acting as an MMPI spurs maturation of hippocampal dendritic spines and represses anxiety and memory defects in the FXS mouse model (Bilousova et al., 2009), and similarly suppresses synaptic architecture defects in motor neurons, clock neurons, and MB learning/memory center neurons in the Drosophila FXS model (Siller and Broadie, 2011). The drug therefore offers a directed approach toward deficits in A-D mechanisms at the synapse as it aims to correct overactive MMP in the absence of FMRP. Minocycline has previously been successful in treating a variety of neurological disorders, including multiple sclerosis, Huntington's disease, Parkinson's disease, and Alzheimer's disease (Wang et al., 2003; Choi et al., 2007; Kim and Suh, 2009). Minocycline treatments led to a longterm reduction in hyperactivity and audiogenic seizures in young, but not old mice (Dansie et al., 2013). In human trials, minocycline led to improved language, behavior, and attention in FXS patients in an uncontrolled study (Utari et al., 2010), and a recent 3-month double-blind, placebo-controlled trial with young FXS patients showed improvements in anxiety, mood, and clinical global impression (CGI) of FXS individuals given minocycline (Leigh etal., 2013). The mechanistic link between minocycline and MMPs in human patients has also been explored, as reduced MMP-9 activity correlates with CGI improvements in FXS patients (Dziembowska et al., 2013). Finally, the PAK-associated cytoskeletal changes in FXS models have been pharmaceutically targeted, with significant suppression of FXS phenotypes in the Fmr1 null mouse (Dolan et al., 2013). There may be a clinical path forward targeting PAK and/or downstream cytoskeletal perturbations.

A quite different avenue for ASD treatment targets A-D critical period development via environmental enrichment and training intervention following early diagnosis (Dawson et al., 2010; Woo and Leon, 2013). To illustrate the impact of environmental input on cognitive development, Romanian orphans who received limited sensory stimulation can have profound social and 
cognitive defects, and many develop post-institutional autistic syndrome (Hoksbergen et al., 2005), suggesting that an ASD-like state can be achieved through purely environmental impoverishment. Thankfully many of these children make significant cognitive and social gains upon adoption and placement into enriched environments (Nelson et al., 2007). Importantly, enriched environments increase sensory input activity and have profound effects on A-D synaptic dynamics (Greenough et al., 1985; Beaulieu and Colonnier, 1987; Moser etal., 1995). In animal models, FXS mutant mice display a host of striking improvements when reared in enriched environments, including greater spine hippocampal spine density (Lauterborn etal., 2013) and improved spike timing long-term potentiation (LTP; Meredith et al., 2007). As a group of syndromes with strong links to A-D synaptic developmental defects, enrichment approaches are popular in ASD treatments (Reichow and Volkmar, 2010; Warren et al., 2011). For example, a peer-mediated theater-based intervention strategy for ASD children showed significant gains in core social deficits (Corbett et al., 2013). Similarly, a recent 6-month controlled trial showed significant gains in autistic children who underwent sensorimotor enrichment through olfactory and tactile stimulation and exercises for other cross-sensory stimulation (Woo and Leon, 2013). These behavioral intervention strategies are, crucially, focusing on multisensory domains and may enable great improvements in both social and cognitive abilities of ASD children.

\section{PART 3: IN VIVO MANIPULATION/READOUT OF ACTIVITY-DEPENDENT CHANGES}

The recent emergence of tools to non-invasively drive and monitor neural activity represents a pioneering step forward for A-D neurodevelopmental studies. Compared to the relatively narrow and invasive strategies of traditional electrophysiology (Biran et al., 2005; Bjornsson et al., 2006), new optogenetic techniques provide simultaneous access to groups of neurons, which can be selectively targeted with a range of transgenic drivers (Kim and Jun, 2013). On the one hand, new optogenetic techniques using engineered rhodopsin variants have enormously advanced our ability to control activity with pulsed application of specific wavelengths of light in defined populations of neurons (Fenno et al., 2011). On the other hand, optical recording techniques, such as calcium sensors and voltage-sensitive fluorescent reporters, provide individual and massed readouts of neural activity throughout the imaged circuitry, albeit at a cost in sensitivity and temporal resolution compared to electrophysiological recordings (Grienberger and Konnerth, 2012; Mutoh et al., 2012). Thus, these new transgenic techniques provide unprecedented abilities to both drive and record in vivo neural activity, and therefore show great promise for the systematic dissection of A-D critical period mechanisms at the heart of ASD disease states.

Techniques for detecting neural calcium flux have been progressing for decades (Shimomura et al., 1962; Tsien et al., 1985), taking advantage of $\mathrm{Ca}^{2+}$ dynamics as a readout of neural activity (Berridge et al., 2003). Resting $\mathrm{Ca}^{2+}$ concentrations in neurons are typically $<100 \mathrm{nM}$ and rise 10 - to 100 -fold following a single action potential (Berridge et al., 2000), providing the ability to monitor spike number, timing, frequency, and levels of synaptic input (Yasuda et al., 2004). Genetically encoded calcium indicators (GECIs), such as the frGECIs and GCamps (Kotlikoff, 2007), have revolutionized in vivo $\mathrm{Ca}^{2+}$ imaging. The latest generations of GCamp sensors are especially exciting, as they display ultrasensitive kinetics and stably provide readout of neural activity over extensive periods of time (Akerboom et al., 2012; Chen et al., 2013). For instance, GCamp6 effectively records neural activity from large groups of neurons to small synaptic compartments, in animals ranging from Drosophila to mice (Chen et al., 2013). The recent development of red-shifted GECIs reduces tissue scattering, phototoxicity, and background fluorescence, and allows the simultaneous use of other tools, such as ChR2, which is activated with $480 \mathrm{~nm}$ light and would therefore overlap and interfere with traditional green fluorescent protein (GFP)-based calcium sensors (Akerboom et al., 2013). The tandem development of multiphoton imaging and GECIs now provide exquisite access for activity monitoring.

Although $\mathrm{Ca}^{2+}$ imaging serves as readout for diverse forms of A-D changes (e.g., depolarization, influx, store release, second messenger cascades), the direct detection of changes in membrane voltage would represent a more specific, direct readout of electrical activity. Small fluorescent hydrophobic dyes have long been able to detect changes in membrane potential, and can also be used to characterize propagation of electrical signals through a given circuit (Salzberg et al., 1973). However, these dyes have low penetrance to deep areas of the brain, and are not genetically targetable. Early generations of genetically encoded voltage indicator proteins (GEVIs) overcame some of these limitations (Siegel and Isacoff, 1997; Barnett et al., 2012), but failed to reliably demonstrate robust signals in intact animals. In contrast, the recently developed ArcLight system is a voltage sensor probes (VSP)-based fluorescent voltage sensor with greatly increased signal-to-noise ratio (Jin et al., 2012). In intact Drosophila brains, the ArcLight system effectively reports both action potentials and subthreshold events, demonstrating beautiful sensitivity (Cao et al., 2013). The in vivo applications for this new tool are exciting. For example, ArcLight has provided the ability to record rhythmic activity in Drosophila clock neurons, which have so far been inaccessible to electrophysiology approaches (Cao et al., 2013). Thus, GEVIs and GECIs are exciting new tools that grant non-invasive and increasingly penetrant representations of in vivo neural activity.

\section{OPTOGENETIC CONTROL OF NEURONAL ACTIVITY}

Optogenetic techniques have revolutionized the ability to direct and dissect A-D processes during critical period development (Williams and Deisseroth, 2013). Delivery of engineered rhodopsin variants into targeted neurons provides a non-invasive means to control neuronal firing rates via pulses of specific wavelengths of light. ChR2 facilitate depolarization of the membrane by gating influx of $\mathrm{Na}^{+}$ions when illuminated by blue light (see Figure 2A; Fenno et al., 2011). Conversely, halorhodopsins (eNpHR) respond to amber light by mediating $\mathrm{Cl}^{-}$ion influx, thereby hyperpolarizing the membrane and inhibiting firing (Figure 2A; Zhang et al., 2007; Gradinaru et al., 2008). To date, most optogenetic studies have been either electrophysiological or behavioral work in mature animals including, for example, an 
alternative to deep brain stimulation in Parkinson's disease model mice (Gradinaru et al., 2009), reduction of anxiety (Tye et al., 2011), serotonergic modulation of behavior (Warden et al., 2012), dopaminergic depression alleviation (Tye et al., 2013), and memory extinction (Van den Oever et al., 2013). However, developmental applications of optogenetic A-D modulation are beginning to appear. For example, ChR2-expressing Drosophila MB neurons respond to short blue light illumination $(6 \mathrm{~h})$ during critical period development with significant decreases in synaptic process branching, but this A-D synaptic pruning is completely abolished in FXS model animals (Tessier and Broadie, 2008, 2012). In mouse, ChR2 optogenetic stimulation causes a lasting increase in postsynaptic spine density and increased concentration of CaMKII, when paired with glutamate uncaging (Zhang et al., 2008). Furthermore, optogenetics is now capable of producing cortical maps, and can be coupled with $\mathrm{Ca}^{2+}$ imaging for readouts of activity alterations (Patterson et al., 2013). In addition, the coupling of optogenetic stimulation and immediate early active gene NPAS4 mRNA facilitates identification of transfected neurons in mice (Bepari et al., 2012). The capacity to manipulate A-D neuronal structure and function in vivo in a developmental context is simply remarkable, and recent studies highlight the promise of these rapidly evolving techniques.

In the past year, optogenetics techniques have particularly begun to blossom. For example, delivery of ChR2 to thalamic neurons was recently shown to effectively silence cortical seizures in mice (Paz et al., 2013). Conversely, expression of eNpHR in hippocampal neurons also provided protection against seizures (Sukhotinsky et al., 2013). Halorhodopsin channels can also provide in vivo inhibition of motor activity (Liske et al., 2013). The emergence of red-shifted GECIs and optogenetic channels now facilitates dual transgenic manipulation and functional readout in the same animal (Akerboom et al., 2013). Combinatorial dye labeling can also facilitate the simultaneous detection of structural and functional changes without the use of genetics (Siegel and Lohmann, 2013). The development of optochemical G proteincoupled receptors (GPCRs), including light-agonized mGluRs, have been shown to be fast, bistable means to effectively suppress excitability and inhibit neurotransmitter release both in brain slices and in vivo (Levitz et al., 2013). The InSynC (inhibition of synapses with chromophore-assisted light inactivation) technique has been developed to directly inhibit neurotransmitter release, via a genetically encoded singlet oxygen generator (miniSOG) fused to two synaptic proteins, vesicle-associated membrane protein 2 (VAMP2) and synaptophysin (Lin etal., 2013b). Multiphoton uncaging of glutamate and GABA analogs has been demonstrated on individual dendritic spines in hippocampal slices (Hayama etal., 2013). Red-shifted excitatory optogenes (ReaChR) have improved membrane trafficking, higher photocurrents and faster kinetics, scatter less in passing through the tissue, and have been capable of driving action potentials in awake mice with illumination through the intact skull (Lin et al., 2013a).

Despite the justifiable excitement, it is important to note also important caveats to optogenetic applications, particularly for the use in A-D developmental studies. First, it was recently reported that long-term expression of ChR2 can alter axonal morphology in mice (Miyashita et al., 2013). In addition, high-level, long-term expression of fluorescent probes can lead to structural artifacts and phototoxicity (Packer et al., 2013). Second, optogenetics are generally delivered through viral means in mammalian models, and it has recently been reported that adeno-associated viruses (AAVs) can form tissue deposits after injection, which can lead to continued infection over time and alterations in the expression of the optogene (Packer et al., 2013). This problem may be avoided with single cell electroporation (Judkewitz et al., 2009), but this limits the applications. Third, extreme stimulation can lead to an exhaustion of synaptic transmission (Kittelmann et al., 2013). Therefore, it is important to modulate the expression and long-term, high frequency use of optogenes, and to use appropriate controls to detect any artifacts. Alternative approaches to optogenetics include the use of genetically targeted TrpA1 channels, which are a class of temperature-gated excitatory cation channels for depolarizing neurons (Viswanath et al., 2003; Dhaka etal., 2006; Hamada et al., 2008). Work in Drosophila illustrates the power of $\operatorname{TrpA} 1$ manipulations, specifically in comparison to ChR2 optogenetics, as neurons expressing TrpA1 can show stronger and longer lasting electrophysiological effects (Pulver et al., 2009).

\section{Drosophila METHODS FOR STUDYING A-D DEVELOPMENTAL MECHANISMS}

The "relative" simplicity of the Drosophila brain (hundreds of thousands of neurons) provides a high level of understanding about clonal lineages and connectivity among small, defined populations of neurons, even down to the individually identified single neuron level (Chou et al., 2010; Chiang et al., 2011; Lovick et al., 2013; Takemura et al., 2013; Wong et al., 2013). Importantly, Drosophila genetics allows precise delivery of transgenic tools to these targeted neuronal populations using the GAL4/UAS bipartite system (Jones, 2009), and with the MARCM technique for clonal analysis down to the individually identified single neuron level (Lee and Luo, 2001; Ostrovsky et al., 2013). Our lab has utilized these techniques particularly to analyze individually identified neurons in the FXS disease model (Pan and Broadie, 2007; Tessier and Broadie, 2008; Gatto and Broadie, 2009; Siller and Broadie, 2011), as our best-defined Drosophila ASD model. More recently, Drosophila has gained an expansive catalog of highly selective neuronal GAL4 drivers, which utilize limited regulatory sequences for exquisitely limited expression (Jenett et al., 2012; Manning et al., 2012). These new tools are providing the capacity to target defined neuronal circuits within the Drosophila brain at a never-before achieved level of resolution. The use of selective drivers for high-resolution morphological readouts of individual neurons, in combination with non-invasive methods of activity modulation, will greatly enhance our understanding of A-D mechanisms of synapse remodeling. We predict that the utilization of these new classes of neural drivers (in $\mathrm{MB}$, projection neuron, fan body, ellipsoid body, retina, etc.), in combination with both optogenetic and alternative activity modulation techniques, will provide much better dissection of neuron class-specific A-D developmental mechanisms within the next few years. These studies will lead to a deeper understanding of ASD model disease states within precise maps of brain circuits, such as the MB (Parnas et al., 2013; 
Perisse et al., 2013) and antennal lobes (Tanaka et al., 2012), which will provide a foundation for deciphering the molecular genetic bases of these disease states and engineering effecting treatment strategies.

What are the current limitations on this use of the Drosophila system? For optogenetics, Drosophila requires an essential cofactor, all-trans retinal (ATR), for ChR2 activation (Schroll et al., 2006; Ataman et al., 2008), although this feature does provide a useful control. Moreover, fluorescent tags on optogenetic channels label targeted neurons to grant cell-autonomous morphological readouts of A-D modifications, but fail to illuminate their synaptic partners, although clever mapping techniques are being developed [e.g., Genetic Reconstitution Across Synaptic Partners (GRASP); Feinberg et al., 2008]. For example, the GRASP technique was recently used to synaptically link MB Kenyon cells with modulatory aminergic neurons (Pech et al., 2013). In a similar fashion, the CaLexA (calcium-dependent nuclear import of Lexa) neural tracing method may be useful for mapping synaptic partners (Masuyama etal., 2012). Alternatively, synaptic mapping studies may be more suited for larger subsets of neurons (broader GAL4 drivers), which are coupled to known targets and could then be assayed through standard immunohistochemistry. Further downstream, the use of immediate early neural genes, may help illuminate downstream effects of activity modulation (e.g., Dhr38; Fujita et al., 2013). Importantly, use of the multiple methods now available for A-D manipulations during neurodevelopmental studies (e.g., ChR2, eNpHR, TrpA1, NaChBac) in the Drosophila FXS model can be used to directly test whether targeted brain circuitry is capable of responding appropriately to activity during defined developmental critical periods. Moreover, the capacity to genetically target subsets of neurons may allow suppression of downstream ASD-related phenotypes. For example, in the Drosophila FXS model, hypoinhibition (e.g., reduced GABAergic input) might be suppressed by increased depolarization of inhibitory interneurons using a GAD:Gal4 driver crossed to ChR2, and hyperexcitation (e.g., elevated mGluR activity) could similarly be suppressed by selectively hyperpolarizing specific groups of glutamatergic neurons with halorhodopsin. Such studies in the particularly well-characterized Drosophila FXS model could ultimately lead to new intervention strategies in FXS patients and, by extension, the treatment of other patient groups suffering ASDs.

\section{ACKNOWLEDGMENTS}

We thank Dr. Cheryl Gatto for critical input on this manuscript. This work is supported by NIH grant R01 MH096832 to Kendal Broadie.

\section{REFERENCES}

Abrahams, B. S., and Geschwind, D. H. (2008). Advances in autism genetics: on the threshold of a new neurobiology. Nat. Rev. Genet. 9, 341-355. doi: $10.1038 /$ nrg2346

Adusei, D. C., Pacey, L. K., Chen, D., and Hampson, D. R. (2010). Early developmental alterations in GABAergic protein expression in fragile $\mathrm{X}$ knockout mice. Neuropharmacology 59, 167-171. doi: 10.1016/j.neuropharm.2010.05.002

Akerboom, J., Carreras Calderon, N., Tian, L., Wabnig, S., Prigge, M., Tolo, J., et al. (2013). Genetically encoded calcium indicators for multi-color neural activity imaging and combination with optogenetics. Front. Mol. Neurosci. 6:2. doi: 10.3389/fnmol.2013.00002
Akerboom, J., Chen, T. W., Wardill, T. J., Tian, L., Marvin, J. S., Mutlu, S., et al. (2012). Optimization of a GCaMP calcium indicator for neural activity imaging. J. Neurosci. 32, 13819-13840. doi: 10.1523/JNEUROSCI.2601-12.2012

Alvarez, V. A., and Sabatini, B. L. (2007). Anatomical and physiological plasticity of dendritic spines. Annu. Rev. Neurosci. 30, 79-97. doi: 10.1146/annurev.neuro.30.051606.094222

Amir, R. E., Van Den Veyver, I. B., Wan, M., Tran, C. Q., Francke, U., and Zoghbi, H. Y. (1999). Rett syndrome is caused by mutations in X-linked MECP2, encoding methyl-CpG-binding protein 2. Nat. Genet. 23, 185-188. doi: 10.1038/13810

Antar, L. N., Afroz, R., Dictenberg, J. B., Carroll, R. C., and Bassell, G. J. (2004). Metabotropic glutamate receptor activation regulates fragile $\mathrm{X}$ mental retardation protein and FMR1 mRNA localization differentially in dendrites and at synapses. J. Neurosci. 24, 2648-2655. doi: 10.1523/JNEUROSCI.0099-04.2004

Antar, L. N., Dictenberg, J. B., Plociniak, M., Afroz, R., and Bassell, G. J. (2005). Localization of FMRP-associated mRNA granules and requirement of microtubules for activity-dependent trafficking in hippocampal neurons. Genes Brain Behav. 4, 350-359. doi: 10.1111/j.1601-183X.2005.00128.x

Antar, L. N., Li, C., Zhang, H., Carroll, R. C., and Bassell, G. J. (2006). Local functions for FMRP in axon growth cone motility and activity-dependent regulation of filopodia and spine synapses. Mol. Cell. Neurosci. 32, 37-48. doi: 10.1016/j.mcn.2006.02.001

Ataman, B., Ashley, J., Gorczyca, D., Gorczyca, M., Mathew, D., Wichmann, C., et al. (2006). Nuclear trafficking of Drosophila Frizzled-2 during synapse development requires the PDZ protein dGRIP. Proc. Natl. Acad. Sci. U.S.A. 103, 7841-7846. doi: 10.1073/pnas.0600387103

Ataman, B., Ashley, J., Gorczyca, M., Ramachandran, P., Fouquet, W., Sigrist, S. J., et al. (2008). Rapid activity-dependent modifications in synaptic structure and function require bidirectional Wnt signaling. Neuron 57, 705-718. doi: 10.1016/j.neuron.2008.01.026

Bacci, A., Huguenard, J. R., and Prince, D. A. (2005). Modulation of neocortical interneurons: extrinsic influences and exercises in self-control. Trends Neurosci. 28, 602-610. doi: 10.1016/j.tins.2005.08.007

Bagni, C., and Greenough, W. T. (2005). From mRNP trafficking to spine dysmorphogenesis: the roots of fragile X syndrome. Nat. Rev. Neurosci. 6, 376-387. doi: $10.1038 /$ nrn 1667

Bagni, C., Tassone, F., Neri, G., and Hagerman, R. (2012). Fragile X syndrome: causes, diagnosis, mechanisms, and therapeutics. J. Clin. Invest. 122, 4314-4322. doi: 10.1172/JCI63141

Baines, R. A., Uhler, J. P., Thompson, A., Sweeney, S. T., and Bate, M. (2001). Altered electrical properties in Drosophila neurons developing without synaptic transmission. J. Neurosci. 21, 1523-1531

Baker, K. B., Wray, S. P., Ritter, R., Mason, S., Lanthorn, T. H., and Savelieva, K. V. (2010). Male and female Fmr1 knockout mice on C57 albino background exhibit spatial learning and memory impairments. Genes Brain Behav. 9, 562-574. doi: 10.1111/j.1601-183X.2010.00585.x

Barbosa, A. C., Kim, M. S., Ertunc, M., Adachi, M., Nelson, E. D., Mcanally, J., et al. (2008). MEF2C, a transcription factor that facilitates learning and memory by negative regulation of synapse numbers and function. Proc. Natl. Acad. Sci. U.S.A. 105, 9391-9396. doi: 10.1073/pnas.0802679105

Barlow, H. B. (1953a). Action potentials from the frog's retina. J. Physiol. 119, 58-68. Barlow, H. B. (1953b). Summation and inhibition in the frog's retina. J. Physiol. 119, 69-88.

Barnett, L., Platisa, J., Popovic, M., Pieribone, V. A., and Hughes, T. (2012). A fluorescent, genetically-encoded voltage probe capable of resolving action potentials. PLoS ONE 7:e43454. doi: 10.1371/journal.pone.0043454

Bassell, G. J., and Warren, S. T. (2008). Fragile X syndrome: loss of local mRNA regulation alters synaptic development and function. Neuron 60, 201-214. doi: 10.1016/j.neuron.2008.10.004

Batish, M., Van Den Bogaard, P., Kramer, F. R., and Tyagi, S. (2012). Neuronal mRNAs travel singly into dendrites. Proc. Natl. Acad. Sci. U.S.A. 109, 4645-4650. doi: 10.1073/pnas.1111226109

Bear, M. F. (2005). Therapeutic implications of the mGluR theory of fragile X mental retardation. Genes Brain Behav. 4, 393-398. doi: 10.1111/j.1601183X.2005.00135.x

Bear, M. F., Dolen, G., Osterweil, E., and Nagarajan, N. (2008). Fragile X: translation in action. Neuropsychopharmacology 33, 84-87. doi: 10.1038/sj.npp.1301610

Bear, M. F., Huber, K. M., and Warren, S. T. (2004). The mGluR theory of fragile X mental retardation. Trends Neurosci. 27, 370-377. doi: 10.1016/j.tins.2004.04.009 
Beaulieu, C., and Colonnier, M. (1987). Effect of the richness of the environment on the cat visual cortex. J. Comp. Neurol. 266, 478-494. doi: 10.1002/cne.9026 60404

Belmonte, M. K., Cook, E. H. Jr., Anderson, G. M., Rubenstein, J. L., Greenough, W. T., Beckel-Mitchener, A., et al. (2004). Autism as a disorder of neural information processing: directions for research and targets for therapy. Mol. Psychiatry 9, 646-663. doi: 10.1038/sj.mp.4001499

Ben-Sasson, A., Hen, L., Fluss, R., Cermak, S. A., Engel-Yeger, B., and Gal, E. (2009). A meta-analysis of sensory modulation symptoms in individuals with autism spectrum disorders. J. Autism Dev. Disord. 39, 1-11. doi: 10.1007/s10803-0080593-3

Bepari, A. K., Sano, H., Tamamaki, N., Nambu, A., Tanaka, K. F., and Takebayashi, H. (2012). Identification of optogenetically activated striatal medium spiny neurons by Npas4 expression. PLoS ONE 7:e52783. doi: 10.1371/journal.pone.00 52783

Berke, B., Wittnam, J., Mcneill, E., Van Vactor, D. L., and Keshishian, H. (2013). Retrograde BMP signaling at the synapse: a permissive signal for synapse maturation and activity-dependent plasticity. J. Neurosci. 33, 17937-17950. doi 10.1523/JNEUROSCI.6075-11.2013

Berridge, M. J., Bootman, M. D., and Roderick, H. L. (2003). Calcium signalling: dynamics, homeostasis and remodelling. Nat. Rev. Mol. Cell Biol. 4, 517-529. doi: 10.1038/nrm1155

Berridge, M. J., Lipp, P., and Bootman, M. D. (2000). Signal transduction. The calcium entry pas de deux. Science 287, 1604-1605. doi: 10.1126/science.287.5458.1604

Berry-Kravis, E. (2002). Epilepsy in fragile X syndrome. Dev. Med. Child Neurol. 44, 724-728. doi: 10.1111/j.1469-8749.2002.tb00277.x

Berry-Kravis, E., Hessl, D., Coffey, S., Hervey, C., Schneider, A., Yuhas, J., et al (2009). A pilot open label, single dose trial of fenobam in adults with fragile $\mathrm{X}$ syndrome. J. Med. Genet. 46, 266-271. doi: 10.1136/jmg.2008.063701

Biagini, G., Panuccio, G., and Avoli, M. (2010). Neurosteroids and epilepsy. Curr. Opin. Neurol. 23, 170-176. doi: 10.1097/WCO.0b013e32833735cf

Billuart, P., and Chelly, J. (2003). From fragile X mental retardation protein to Rac1 GTPase: new insights from Fly CYFIP. Neuron 38, 843-845. doi: 10.1016/S08966273(03)00362-3

Bilousova, T. V., Dansie, L., Ngo, M., Aye, J., Charles, J. R., Ethell, D. W., et al. (2009) Minocycline promotes dendritic spine maturation and improves behavioural performance in the fragile X mouse model. J. Med. Genet. 46, 94-102. doi: 10.1136/jmg.2008.061796

Biran, R., Martin, D. C., and Tresco, P. A. (2005). Neuronal cell loss accompanies the brain tissue response to chronically implanted silicon microelectrode arrays. Exp. Neurol. 195, 115-126. doi: 10.1016/j.expneurol.2005.04.020

Bishop, G. H., and Clare, M. (1951). Radiation path from geniculate to optic cortex in cat. J. Neurophysiol. 14, 496-505.

Bishop, G. H., and Clare, M. H. (1952). Sites of origin of electric potentials in striate cortex. J. Neurophysiol. 15, 201-220.

Bishop, G. H., and Clare, M. H. (1955). Organization and distribution of fibers in the optic tract of the cat. J. Comp. Neurol. 103, 269-304. doi: 10.1002/cne.901030204

Bishop, J. R., Schuksz, M., and Esko, J. D. (2007). Heparan sulphate proteoglycans fine-tune mammalian physiology. Nature 446, 1030-1037. doi: 10.1038/nature05817

Bjornsson, C. S., Oh, S. J., Al-Kofahi, Y. A., Lim, Y. J., Smith, K. L., Turner, J. N., et al. (2006). Effects of insertion conditions on tissue strain and vascular damage during neuroprosthetic device insertion. J. Neural Eng. 3, 196-207. doi: 10.1088/1741-2560/3/3/002

Blednov, Y. A., and Harris, R. A. (2008). Metabotropic glutamate receptor 5 (mGluR5) regulation of ethanol sedation, dependence and consumption: relationship to acamprosate actions. Int. J. Neuropsychopharmacol. 11, 775-793. doi: $10.1017 /$ S1461145708008584

Bogdanik, L., Mohrmann, R., Ramaekers, A., Bockaert, J., Grau, Y., Broadie, K., et al. (2004). The Drosophila metabotropic glutamate receptor DmGluRA regulates activity-dependent synaptic facilitation and fine synaptic morphology. J. Neurosci 24, 9105-9116. doi: 10.1523/JNEUROSCI.2724-04.2004

Bokoch, G. M. (2003). Biology of the p21-activated kinases. Annu. Rev. Biochem. 72, 743-781. doi: 10.1146/annurev.biochem.72.121801.161742

Bolduc, F. V., Bell, K., Cox, H., Broadie, K. S., and Tully, T. (2008). Excess protein synthesis in Drosophila fragile $\mathrm{X}$ mutants impairs long-term memory. Nat. Neurosci. 11, 1143-1145. doi: 10.1038/nn.2175
Bolduc, F. V., Bell, K., Rosenfelt, C., Cox, H., and Tully, T. (2010a). Fragile X mental retardation 1 and filamin a interact genetically in Drosophila long-term memory. Front. Neural Circuits 3:22. doi: 10.3389/neuro.04.022.2009

Bolduc, F. V., Valente, D., Nguyen, A. T., Mitra, P. P., and Tully, T. (2010b). An assay for social interaction in Drosophila fragile X mutants. Fly (Austin) 4, 216-225. doi: 10.4161/fly.4.3.12280

Bongmba, O. Y., Martinez, L. A., Elhardt, M. E., Butler, K., and Tejada-Simon, M. V. (2011). Modulation of dendritic spines and synaptic function by Racl: a possible link to fragile X syndrome pathology. Brain Res. 1399, 79-95. doi: 10.1016/j.brainres.2011.05.020

Bonhoeffer, T., and Yuste, R. (2002). Spine motility. Phenomenology, mechanisms, and function. Neuron 35, 1019-1027. doi: 10.1016/S0896-6273(02)00906-6

Bourgeois, J. A., Coffey, S. M., Rivera, S. M., Hessl, D., Gane, L. W., Tassone, F., et al. (2009). A review of fragile X premutation disorders: expanding the psychiatric perspective. J. Clin. Psychiatry 70, 852-862. doi: 10.4088/JCP.08m04476

Braun, K., and Segal, M. (2000). FMRP involvement in formation of synapses among cultured hippocampal neurons. Cereb. Cortex 10, 1045-1052. doi: $10.1093 /$ cercor/10.10.1045

Broser, P., Grinevich, V., Osten, P., Sakmann, B., and Wallace, D. J. (2008). Critical period plasticity of axonal arbors of layer $2 / 3$ pyramidal neurons in rat somatosensory cortex: layer-specific reduction of projections into deprived cortical columns. Cereb. Cortex 18, 1588-1603. doi: 10.1093/cercor/bhm189

Brown, M. R., Kronengold, J., Gazula, V. R., Chen, Y., Strumbos, J. G., Sigworth, F. J., et al. (2010). Fragile X mental retardation protein controls gating of the sodium-activated potassium channel Slack. Nat. Neurosci. 13, 819-821. doi: 10.1038/nn.2563

Bureau, I., Shepherd, G. M., and Svoboda, K. (2008). Circuit and plasticity defects in the developing somatosensory cortex of FMR1 knock-out mice. J. Neurosci. 28, 5178-5188. doi: 10.1523/JNEUROSCI.1076-08.2008

Cao, G., Platisa, J., Pieribone, V. A., Raccuglia, D., Kunst, M., and Nitabach, M. N. (2013). Genetically targeted optical electrophysiology in intact neural circuits. Cell 154, 904-913. doi: 10.1016/j.cell.2013.07.027

Casanova, M. F. (2006). Neuropathological and genetic findings in autism: the significance of a putative minicolumnopathy. Neuroscientist 12, 435-441. doi: 10.1177/1073858406290375

Castillo, P. E., Chiu, C. Q., and Carroll, R. C. (2011). Long-term plasticity at inhibitory synapses. Curr. Opin. Neurobiol. 21, 328-338. doi: 10.1016/j.conb.2011.01.006

Centonze, D., Rossi, S., Mercaldo, V., Napoli, I., Ciotti, M. T., De Chiara, V., et al. (2008). Abnormal striatal GABA transmission in the mouse model for the fragile X syndrome. Biol. Psychiatry 63, 963-973. doi: 10.1016/j.biopsych.2007. 09.008

Chahrour, M. H., Yu, T. W., Lim, E. T., Ataman, B., Coulter, M. E., Hill, R. S., et al. (2012). Whole-exome sequencing and homozygosity analysis implicate depolarization-regulated neuronal genes in autism. PLoS Genet. 8:e1002635. doi: 10.1371/journal.pgen.1002635

Chang, E. F., and Merzenich, M. M. (2003). Environmental noise retards auditory cortical development. Science 300, 498-502. doi: 10.1126/science.1082163

Charalambous, D. C., Pasciuto, E., Mercaldo, V., Pilo Boyl, P., Munck, S., Bagni, C., et al. (2013). KIF1Bbeta transports dendritically localized mRNPs in neurons and is recruited to synapses in an activity-dependent manner. Cell. Mol. Life Sci. 70, 335-356. doi: 10.1007/s00018-012-1108-0

Chaudhury, S., Nag, T. C., Jain, S., and Wadhwa, S. (2013). Role of sound stimulation in reprogramming brain connectivity. J. Biosci. 38, 605-614. doi: 10.1007/s12038013-9341-8

Chen, L. Y., Rex, C. S., Babayan, A. H., Kramar, E. A., Lynch, G., Gall, C. M., et al. (2010). Physiological activation of synaptic Rac > PAK (p-21 activated kinase) signaling is defective in a mouse model of fragile X syndrome. J. Neurosci. 30, 10977-10984. doi: 10.1523/JNEUROSCI.1077-10.2010

Chen, T. W., Wardill, T. J., Sun, Y., Pulver, S. R., Renninger, S. L., Baohan, A., et al. (2013). Ultrasensitive fluorescent proteins for imaging neuronal activity. Nature 499, 295-300. doi: 10.1038/nature12354

Chiang, A. S., Lin, C. Y., Chuang, C. C., Chang, H. M., Hsieh, C. H., Yeh, C. W., et al. (2011). Three-dimensional reconstruction of brain-wide wiring networks in Drosophila at single-cell resolution. Curr. Biol. 21, 1-11. doi: 10.1016/j.cub.2010.11.056

Choi, C. H., Mcbride, S. M., Schoenfeld, B. P., Liebelt, D. A., Ferreiro, D., Ferrick, N. J., et al. (2010a). Age-dependent cognitive impairment in a Drosophila 
fragile X model and its pharmacological rescue. Biogerontology 11,347-362. doi: 10.1007/s10522-009-9259-6

Choi, H. C., Kim, Y. I., Song, H. K., Kim, J. E., Kim, D. S., and Kang, T. C. (2010b). Effects of selective serotonin reuptake inhibitors on GABAergic inhibition in the hippocampus of normal and pilocarpine induced epileptic rats. Brain Res. 1357, 131-141. doi: 10.1016/j.brainres.2010.08.010

Choi, C. H., Schoenfeld, B. P., Bell, A. J., Hinchey, P., Kollaros, M., Gertner, M. J. et al. (2011). Pharmacological reversal of synaptic plasticity deficits in the mouse model of fragile X syndrome by group II mGluR antagonist or lithium treatment. Brain Res. 1380, 106-119. doi: 10.1016/j.brainres.2010.11.032

Choi, S., Kim, J. Y., Park, J. H., Lee, S. T., Han, I. O., and Oh, E. S. (2012). The matrix metalloproteinase-7 regulates the extracellular shedding of syndecan-2 from colon cancer cells. Biochem. Biophys. Res. Commun. 417, 1260-1264. doi: 10.1016/j.bbrc.2011.12.120

Choi, Y., Kim, H. S., Shin, K. Y., Kim, E. M., Kim, M., Kim, H. S., et al. (2007). Minocycline attenuates neuronal cell death and improves cognitive impairment in Alzheimer's disease models. Neuropsychopharmacology 32, 2393-2404. doi 10.1038/sj.npp.1301377

Chou, Y. H., Spletter, M. L., Yaksi, E., Leong, J. C., Wilson, R. I., and Luo, L. (2010). Diversity and wiring variability of olfactory local interneurons in the Drosophila antennal lobe. Nat. Neurosci. 13, 439-449. doi: 10.1038/nn.2489

Chowdhury, S., Shepherd, J. D., Okuno, H., Lyford, G., Petralia, R. S., Plath N., et al. (2006). Arc/Arg3.1 interacts with the endocytic machinery to regulate AMPA receptor trafficking. Neuron 52, 445-459. doi: 10.1016/j.neuron.2006. 08.033

Clare, M. H., and Bishop, G. H. (1954). Responses from an association area secondarily activated from optic cortex. J. Neurophysiol. 17, 271-277.

Coffee, R. L. Jr., Tessier, C. R., Woodruff, E. A. III, and Broadie, K. (2010). Fragile $\mathrm{X}$ mental retardation protein has a unique, evolutionarily conserved neuronal function not shared with FXR1P or FXR2P. Dis. Model. Mech. 3, 471-485. doi: 10.1242/dmm.004598

Coffee, R. L. Jr., Williamson, A. J., Adkins, C. M., Gray, M. C., Page, T. L., and Broadie, K. (2012). In vivo neuronal function of the fragile $\mathrm{X}$ mental retardation protein is regulated by phosphorylation. Hum. Mol. Genet. 21, 900-915. doi: 10.1093/hmg/ddr527

Coghlan, S., Horder, J., Inkster, B., Mendez, M. A., Murphy, D. G., and Nutt, D. J. (2012). GABA system dysfunction in autism and related disorders: from synapse to symptoms. Neurosci. Biobehav. Rev. 36, 2044-2055. doi: 10.1016/j.neubiorev.2012.07.005

Cohen, S., and Greenberg, M. E. (2008). Communication between the synapse and the nucleus in neuronal development, plasticity, and disease. Annu. Rev. Cell Dev. Biol. 24, 183-209. doi: 10.1146/annurev.cellbio.24.110707.175235

Comery, T. A., Harris, J. B., Willems, P. J., Oostra, B. A., Irwin, S. A., Weiler, I. J., et al. (1997). Abnormal dendritic spines in fragile X knockout mice: maturation and pruning deficits. Proc. Natl. Acad. Sci. U.S.A. 94, 5401-5404. doi: 10.1073/pnas.94.10.5401

Cook, D., Sanchez-Carbente Mdel, R., Lachance, C., Radzioch, D., Tremblay, S., Khandjian, E. W., et al. (2011). Fragile X related protein 1 clusters with ribosomes and messenger RNAs at a subset of dendritic spines in the mouse hippocampus. PLoS ONE 6:e26120. doi: 10.1371/journal.pone.0026120

Coppola, G., Terraciano, A. M., and Pascotto, A. (1997). Vigabatrin as add-on therapy in children and adolescents with refractory epilepsy: an open trial. Brain Dev. 19, 459-463. doi: 10.1016/S0387-7604(97)00063-6

Corbett, B. A., Swain, D. M., Coke, C., Simon, D., Newsom, C., Houchins-Juarez, N., et al. (2013). Improvement in social deficits in autism spectrum disorders using a theatre-based, peer-mediated intervention. Autism Res. doi: 10.1002/aur.1341 [Epub ahead of print].

Costa, L., Spatuzza, M., D’Antoni, S., Bonaccorso, C. M., Trovato, C., Musumeci, S. A., et al. (2012). Activation of 5-HT7 serotonin receptors reverses metabotropic glutamate receptor-mediated synaptic plasticity in wild-type and Fmrl knockout mice, a model of fragile X syndrome. Biol. Psychiatry 72, 924-933. doi: 10.1016/j.biopsych.2012.06.008

Costa-Mattioli, M., Sossin, W. S., Klann, E., and Sonenberg, N. (2009). Translational control of long-lasting synaptic plasticity and memory. Neuron 61, 10-26. doi: 10.1016/j.neuron.2008.10.055

Courchesne, E., and Pierce, K. (2005). Why the frontal cortex in autism might be talking only to itself: local over-connectivity but long-distance disconnection. Curr. Opin. Neurobiol. 15, 225-230. doi: 10.1016/j.conb.2005.03.001
Crawley, J. N. (2007). Mouse behavioral assays relevant to the symptoms of autism. Brain Pathol. 17, 448-459. doi: 10.1111/j.1750-3639.2007.00096.x

Cruz-Martin, A., Crespo, M., and Portera-Cailliau, C. (2010). Delayed stabilization of dendritic spines in fragile X mice. J. Neurosci. 30, 7793-7803. doi: 10.1523/JNEUROSCI.0577-10.2010

Curia, G., Papouin, T., Seguela, P., and Avoli, M. (2009). Downregulation of tonic GABAergic inhibition in a mouse model of fragile X syndrome. Cereb. Cortex 19, 1515-1520. doi: 10.1093/cercor/bhn159

Dahlhaus, R., and El-Husseini, A. (2010). Altered neuroligin expression is involved in social deficits in a mouse model of the fragile $\mathrm{X}$ syndrome. Behav. Brain Res. 208, 96-105. doi: 10.1016/j.bbr.2009.11.019

Dani, N., and Broadie, K. (2012). Glycosylated synaptomatrix regulation of transsynaptic signaling. Dev. Neurobiol. 72, 2-21. doi: 10.1002/dneu.20891

Dani, N., Nahm, M., Lee, S., and Broadie, K. (2012). A targeted glycan-related gene screen reveals heparan sulfate proteoglycan sulfation regulates WNT and BMP trans-synaptic signaling. PLoS Genet. 8:e1003031. doi: 10.1371/journal.pgen.1003031

Dansie, L. E., Phommahaxay, K., Okusanya, A. G., Uwadia, J., Huang, M., Rotschafer, S. E., et al. (2013). Long-lasting effects of minocycline on behavior in young but not adult fragile X mice. Neuroscience 246, 186-198. doi: 10.1016/j.neuroscience.2013.04.058

Darnell, J. C., Van Driesche, S. J., Zhang, C., Hung, K. Y., Mele, A., Fraser, C. E., et al. (2011). FMRP stalls ribosomal translocation on mRNAs linked to synaptic function and autism. Cell 146, 247-261. doi: 10.1016/j.cell.2011.06.013

David, A., Dolan, B. P., Hickman, H. D., Knowlton, J. J., Clavarino, G., Pierre, P., et al. (2012). Nuclear translation visualized by ribosome-bound nascent chain puromycylation. J. Cell Biol. 197, 45-57. doi: 10.1083/jcb.201112145

Dawson, G., Rogers, S., Munson, J., Smith, M., Winter, J., Greenson, J., et al. (2010). Randomized, controlled trial of an intervention for toddlers with autism: the Early Start Denver Model. Pediatrics 125, e17-e23. doi: 10.1542/peds. 2009-0958

Deacon, S., Staner, L., Staner, C., Legters, A., Loft, H., and Lundahl, J. (2007). Effect of short-term treatment with gaboxadol on sleep maintenance and initiation in patients with primary insomnia. Sleep 30, 281-287.

Delorme, R., Ey, E., Toro, R., Leboyer, M., Gillberg, C., and Bourgeron, T. (2013). Progress toward treatments for synaptic defects in autism. Nat. Med. 19, 685-694. doi: $10.1038 / \mathrm{nm} .3193$

Deng, P. Y., Rotman, Z., Blundon, J. A., Cho, Y., Cui, J., Cavalli, V., et al. (2013). FMRP regulates neurotransmitter release and synaptic information transmission by modulating action potential duration via BK channels. Neuron 77, 696-711. doi: 10.1016/j.neuron.2012.12.018

Devlin, B., and Scherer, S. W. (2012). Genetic architecture in autism spectrum disorder. Curr. Opin. Genet. Dev. 22, 229-237. doi: 10.1016/j.gde.2012.03.002

Dhaka, A., Viswanath, V., and Patapoutian, A. (2006). Trp ion channels and temperature sensation. Annu. Rev. Neurosci. 29, 135-161. doi: 10.1146/annurev.neuro.29.051605.112958

D’Hulst, C., De Geest, N., Reeve, S. P., Van Dam, D., De Deyn, P. P., Hassan, B. A., et al. (2006). Decreased expression of the GABAA receptor in fragile X syndrome. Brain Res. 1121, 238-245. doi: 10.1016/j.brainres.2006.08.115

Dickson, P. E., Corkill, B., Mckimm, E., Miller, M. M., Calton, M. A., Goldowitz, D., et al. (2013). Effects of stimulus salience on touchscreen serial reversal learning in a mouse model of fragile X syndrome. Behav. Brain Res. 252, 126-135. doi: 10.1016/j.bbr.2013.05.060

Dictenberg, J. B., Swanger, S. A., Antar, L. N., Singer, R. H., and Bassell, G. J. (2008). A direct role for FMRP in activity-dependent dendritic mRNA transport links filopodial-spine morphogenesis to fragile X syndrome. Dev. Cell 14, 926-939. doi: 10.1016/j.devcel.2008.04.003

Dockendorff, T. C., Su, H. S., Mcbride, S. M., Yang, Z., Choi, C. H., Siwicki, K. K., et al. (2002). Drosophila lacking dfmrl activity show defects in circadian output and fail to maintain courtship interest. Neuron 34, 973-984. doi: 10.1016/S08966273(02)00724-9

Dolan, B. M., Duron, S. G., Campbell, D. A., Vollrath, B., Shankaranarayana Rao, B. S., Ko, H. Y., et al. (2013). Rescue of fragile X syndrome phenotypes in Fmrl KO mice by the small-molecule PAK inhibitor FRAX486. Proc. Natl. Acad. Sci. U.S.A. 110, 5671-5676. doi: 10.1073/pnas.1219383110

Dolen, G., and Bear, M. F. (2008). Role for metabotropic glutamate receptor 5 (mGluR5) in the pathogenesis of fragile X syndrome. J. Physiol. 586, 1503-1508. doi: 10.1113/jphysiol.2008.150722 
Dolen, G., Carpenter, R. L., Ocain, T. D., and Bear, M. F. (2010). Mechanismbased approaches to treating fragile X. Pharmacol. Ther. 127, 78-93. doi: 10.1016/j.pharmthera.2010.02.008

Dolen, G., Osterweil, E., Rao, B. S., Smith, G. B., Auerbach, B. D., Chattarji, S., et al. (2007). Correction of fragile X syndrome in mice. Neuron 56, 955-962. doi: 10.1016/j.neuron.2007.12.001

Duch, C., Vonhoff, F., and Ryglewski, S. (2008). Dendrite elongation and dendritic branching are affected separately by different forms of intrinsic motoneuron excitability. J. Neurophysiol. 100, 2525-2536. doi: 10.1152/jn.90758.2008

Dziembowska, M., Milek, J., Janusz, A., Rejmak, E., Romanowska, E., Gorkiewicz, T., et al. (2012). Activity-dependent local translation of matrix metalloproteinase-9. J. Neurosci. 32, 14538-14547. doi: 10.1523/JNEUROSCI.6028-11.2012

Dziembowska, M., Pretto, D. I., Janusz, A., Kaczmarek, L., Leigh, M. J., Gabriel, N., et al. (2013). High MMP-9 activity levels in fragile X syndrome are lowered by minocycline. Am. J. Med. Genet. A 161A, 1897-1903. doi: 10.1002/ajmg.a.36023

Eaton, B. A., and Davis, G. W. (2005). LIM kinasel controls synaptic stability downstream of the type II BMP receptor. Neuron 47, 695-708. doi: 10.1016/j.neuron.2005.08.010

Ebert, D. H., and Greenberg, M. E. (2013). Activity-dependent neuronal signalling and autism spectrum disorder. Nature 493, 327-337. doi: 10.1038/nature 11860

Elbert, T., Pantev, C., Wienbruch, C., Rockstroh, B., and Taub, E. (1995). Increased cortical representation of the fingers of the left hand in string players. Science 270, 305-307. doi: 10.1126/science.270.5234.305

El Idrissi, A., Ding, X. H., Scalia, J., Trenkner, E., Brown, W. T., and Dobkin, C. (2005). Decreased GABA(A) receptor expression in the seizure-prone fragile X mouse. Neurosci. Lett. 377, 141-146. doi: 10.1016/j.neulet.2004.11.087

Elvira, G., Wasiak, S., Blandford, V., Tong, X. K., Serrano, A., Fan, X., et al. (2006). Characterization of an RNA granule from developing brain. Mol. Cell. Proteomics 5, 635-651. doi: 10.1074/mcp.M500255-MCP200

Erickson, C. A., Early, M., Stigler, K. A., Wink, L. K., Mullett, J. E., and Mcdougle, C. J. (2011a). An open-label naturalistic pilot study of acamprosate in youth with autistic disorder. J. Child Adolesc. Psychopharmacol. 21, 565-569. doi: 10.1089/cap.2011.0034

Erickson, C. A., Weng, N., Weiler, I. J., Greenough, W. T., Stigler, K. A., Wink, L. K., et al. (2011b). Open-label riluzole in fragile X syndrome. Brain Res. 1380, 264-270. doi: 10.1016/j.brainres.2010.10.108

Erickson, C. A., Mullett, J. E., and Mcdougle, C. J. (2010). Brief report: acamprosate in fragile X syndrome. J. Autism Dev. Disord. 40, 1412-1416. doi: 10.1007/s10803010-0988-9

Ethell, I. M., and Ethell, D. W. (2007). Matrix metalloproteinases in brain development and remodeling: synaptic functions and targets. J. Neurosci. Res. 85 2813-2823. doi: 10.1002/jnr.21273

Fatemi, S. H., and Folsom, T. D. (2011). The role of fragile X mental retardation protein in major mental disorders. Neuropharmacology 60, 1221-1226. doi: 10.1016/j.neuropharm.2010.11.011

Fatemi, S. H., Folsom, T. D., Reutiman, T. J., and Thuras, P. D. (2009a). Expression of $\mathrm{GABA}(\mathrm{B})$ receptors is altered in brains of subjects with autism. Cerebellum 8 , 64-69. doi: 10.1007/s12311-008-0075-3

Fatemi, S. H., Reutiman, T. J., Folsom, T. D., and Thuras, P. D. (2009b). GABA(A) receptor downregulation in brains of subjects with autism. J. Autism Dev. Disord. 39, 223-230. doi: 10.1007/s10803-008-0646-7.

Fatemi, S. H., Halt, A. R., Stary, J. M., Kanodia, R., Schulz, S. C., and Realmuto G. R. (2002). Glutamic acid decarboxylase 65 and $67 \mathrm{kDa}$ proteins are reduced in autistic parietal and cerebellar cortices. Biol. Psychiatry 52, 805-810. doi: 10.1016/S0006-3223(02)01430-0

Fatemi, S. H., Kneeland, R. E., Liesch, S. B., and Folsom, T. D. (2010). Fragile X mental retardation protein levels are decreased in major psychiatric disorders. Schizophr. Res. 124, 246-247. doi: 10.1016/j.schres.2010.07.017

Featherstone, D. E., and Broadie, K. (2000). Surprises from Drosophila: genetic mechanisms of synaptic development and plasticity. Brain Res. Bull. 53, 501-511. doi: 10.1016/S0361-9230(00)00383-X

Feinberg, E. H., Vanhoven, M. K., Bendesky, A., Wang, G., Fetter, R. D., Shen, K., et al. (2008). GFP Reconstitution Across Synaptic Partners (GRASP) defines cell contacts and synapses in living nervous systems. Neuron 57, 353-363. doi: 10.1016/j.neuron.2007.11.030

Feldmeyer, D., Brecht, M., Helmchen, F., Petersen, C. C., Poulet, J. F., Staiger J. F., et al. (2013). Barrel cortex function. Prog. Neurobiol. 103, 3-27. doi: 10.1016/j.pneurobio.2012.11.002
Fenno, L., Yizhar, O., and Deisseroth, K. (2011). The development and application of optogenetics. Annu. Rev. Neurosci. 34, 389-412. doi: 10.1146/annurev-neuro061010-113817

Ferrari, F., Mercaldo, V., Piccoli, G., Sala, C., Cannata, S., Achsel, T., et al. (2007). The fragile X mental retardation protein-RNP granules show an mGluR-dependent localization in the post-synaptic spines. Mol. Cell. Neurosci. 34, 343-354. doi: 10.1016/j.mcn.2006.11.015

Fiala, J. C., Feinberg, M., Popov, V., and Harris, K. M. (1998). Synaptogenesis via dendritic filopodia in developing hippocampal area CA1. J. Neurosci. 18, 8900-8911.

Flavell, S. W., Cowan, C. W., Kim, T. K., Greer, P. L., Lin, Y., Paradis, S., et al. (2006). Activity-dependent regulation of MEF2 transcription factors suppresses excitatory synapse number. Science 311, 1008-1012. doi: 10.1126/science.11 22511

Flavell, S. W., and Greenberg, M. E. (2008). Signaling mechanisms linking neuronal activity to gene expression and plasticity of the nervous system. Annu. Rev. Neurosci. 31, 563-590. doi: 10.1146/annurev.neuro.31.060407. 125631

French, J. A., Mosier, M., Walker, S., Sommerville, K., and Sussman, N. (1996). A double-blind, placebo-controlled study of vigabatrin three g/day in patients with uncontrolled complex partial seizures. Vigabatrin Protocol 024 Investigative Cohort. Neurology 46, 54-61. doi: 10.1212/WNL.46.1.54

Friedman, S. H., Dani, N., Rushton, E., and Broadie, K. (2013). Fragile X mental retardation protein regulates trans-synaptic signaling in Drosophila. Dis. Model. Mech. 6, 1400-1413. doi: 10.1242/dmm.012229

Frith, C. (2004). Is autism a disconnection disorder? Lancet Neurol. 3, 577. doi: 10.1016/S1474-4422(04)00875-0

Fujita, N., Nagata, Y., Nishiuchi, T., Sato, M., Iwami, M., and Kiya, T. (2013). Visualization of neural activity in insect brains using a conserved immediate early gene, Hr38. Curr. Biol. 23, 2063-2070. doi: 10.1016/j.cub.2013.08.051

Fukuda, T., Itoh, M., Ichikawa, T., Washiyama, K., and Goto, Y. (2005). Delayed maturation of neuronal architecture and synaptogenesis in cerebral cortex of Mecp2-deficient mice. J. Neuropathol. Exp. Neurol. 64, 537-544.

Gabel, L. A., Won, S., Kawai, H., Mckinney, M., Tartakoff, A. M., and Fallon, J. R. (2004). Visual experience regulates transient expression and dendritic localization of fragile X mental retardation protein. J. Neurosci. 24, 10579-10583. doi: 10.1523/JNEUROSCI.2185-04.2004

Galvez, R., Smith, R. L., and Greenough, W. T. (2005). Olfactory bulb mitral cell dendritic pruning abnormalities in a mouse model of the Fragile$\mathrm{X}$ mental retardation syndrome: further support for FMRP's involvement in dendritic development. Brain Res. Dev. Brain Res. 157, 214-216. doi: 10.1016/j.devbrainres.2005.03.010

Gant, J. C., Thibault, O., Blalock, E. M., Yang, J., Bachstetter, A., Kotick, J., et al. (2009). Decreased number of interneurons and increased seizures in neuropilin 2 deficient mice: implications for autism and epilepsy. Epilepsia 50, 629-645. doi: 10.1111/j.1528-1167.2008.01725.x

Gantois, I., Pop, A. S., De Esch, C. E., Buijsen, R. A., Pooters, T., GomezMancilla, B., et al. (2013). Chronic administration of AFQ056/Mavoglurant restores social behaviour in Fmrl knockout mice. Behav. Brain Res. 239, 72-79. doi: 10.1016/j.bbr.2012.10.059

Gantois, I., Vandesompele, J., Speleman, F., Reyniers, E., D’Hooge, R., Severijnen, L. A., et al. (2006). Expression profiling suggests underexpression of the GABA(A) receptor subunit delta in the fragile X knockout mouse model. Neurobiol. Dis. 21, 346-357. doi: 10.1016/j.nbd.2005.07.017

Gao, W. J., Wormington, A. B., Newman, D. E., and Pallas, S. L. (2000) Development of inhibitory circuitry in visual and auditory cortex of postnatal ferrets: immunocytochemical localization of calbindin- and parvalbumincontaining neurons. J. Comp. Neurol. 422, 140-157. doi: 10.1002/(SICI)10969861(20000619)422:1<140::AID-CNE9>3.0.CO;2-0

Gatto, C. L., and Broadie, K. (2008). Temporal requirements of the fragile X mental retardation protein in the regulation of synaptic structure. Development 135, 2637-2648. doi: 10.1242/dev.022244

Gatto, C. L., and Broadie, K. (2009). Temporal requirements of the fragile X mental retardation protein in modulating circadian clock circuit synaptic architecture. Front. Neural Circuits 3:8. doi: 10.3389/neuro.04.008.2009

Gatto, C. L., and Broadie, K. (2010). Genetic controls balancing excitatory and inhibitory synaptogenesis in neurodevelopmental disorder models. Front. Synaptic Neurosci. 2:4. doi: 10.3389/fnsyn.2010.00004 
Gatto, C. L., Pereira, D., and Broadie, K. (2014). GABAergic circuit dysfunction in the Drosophila Fragile X syndrome model. Neurobiol. Dis. doi: 10.1016/j.nbd.2014.01.008 [Epub ahead of print].

Geschwind, D. H., and Levitt, P. (2007). Autism spectrum disorders: developmental disconnection syndromes. Curr. Opin. Neurobiol. 17, 103-111. doi 10.1016/j.conb.2007.01.009

Geschwind, N. (1965a). Disconnexion syndromes in animals and man. I. Brain 88, 237-294. doi: 10.1093/brain/88.2.237

Geschwind, N. (1965b). Disconnexion syndromes in animals and man. II. Brain 88, 585-644. doi: 10.1093/brain/88.3.585

Gibson, J. R., Bartley, A. F., Hays, S. A., and Huber, K. M. (2008). Imbalance of neocortical excitation and inhibition and altered UP states reflect network hyperexcitability in the mouse model of fragile X syndrome. J. Neurophysiol. 100, 2615-2626. doi: 10.1152/jn.90752.2008

Gilman, S. R., Iossifov, I., Levy, D., Ronemus, M., Wigler, M., and Vitkup, D. (2011) Rare de novo variants associated with autism implicate a large functional network of genes involved in formation and function of synapses. Neuron 70, 898-907. doi: 10.1016/j.neuron.2011.05.021

Goebel-Goody, S. M., Wilson-Wallis, E. D., Royston, S., Tagliatela, S. M., Naegele, J. R., and Lombroso, P. J. (2012). Genetic manipulation of STEP reverses behavioral abnormalities in a fragile X syndrome mouse model. Genes Brain Behav. 11, 586-600. doi: 10.1111/j.1601-183X.2012.00781.x

Golshani, P., Goncalves, J. T., Khoshkhoo, S., Mostany, R., Smirnakis, S., and Portera-Cailliau, C. (2009). Internally mediated developmental desynchronization of neocortical network activity. J. Neurosci. 29, 10890-10899. doi: 10.1523/JNEUROSCI.2012-09.2009

Goncalves, J. T., Anstey, J. E., Golshani, P., and Portera-Cailliau, C. (2013). Circuit level defects in the developing neocortex of fragile X mice. Nat. Neurosci. 16 903-909. doi: 10.1038/nn.3415

Graber, T. E., Hebert-Seropian, S., Khoutorsky, A., David, A., Yewdell, J. W., Lacaille, J. C., et al. (2013). Reactivation of stalled polyribosomes in synaptic plasticity. Proc. Natl. Acad. Sci. U.S.A. 110, 16205-16210. doi: 10.1073/pnas.1307747110

Gradinaru, V., Mogri, M., Thompson, K. R., Henderson, J. M., and Deisseroth, K. (2009). Optical deconstruction of parkinsonian neural circuitry. Science 324, 354-359. doi: 10.1126/science. 1167093

Gradinaru, V., Thompson, K. R., and Deisseroth, K. (2008). eNpHR: a natronomonas halorhodopsin enhanced for optogenetic applications. Brain Cell Biol. 36, 129-139. doi: 10.1007/s11068-008-9027-6

Greenberg, M. E., Ziff, E. B., and Greene, L. A. (1986). Stimulation of neuronal acetylcholine receptors induces rapid gene transcription. Science $234,80-83$. doi: 10.1126/science.3749894

Greenough, W. T., Hwang, H. M., and Gorman, C. (1985). Evidence for active synapse formation or altered postsynaptic metabolism in visual cortex of rats reared in complex environments. Proc. Natl. Acad. Sci. U.S.A. 82, 4549-4552. doi: 10.1073/pnas.82.13.4549

Greer, P. L., and Greenberg, M. E. (2008). From synapse to nucleus: calciumdependent gene transcription in the control of synapse development and function. Neuron 59, 846-860. doi: 10.1016/j.neuron.2008.09.002

Grienberger, C., and Konnerth, A. (2012). Imaging calcium in neurons. Neuron 73, 862-885. doi: 10.1016/j.neuron.2012.02.011

Grillo, F. W., Song, S., Teles-Grilo Ruivo, L. M., Huang, L., Gao, G., Knott, G. W., et al. (2013). Increased axonal bouton dynamics in the aging mouse cortex. Proc. Natl. Acad. Sci. U.S.A. 110, E1514-E1523. doi: 10.1073/pnas.12187 31110

Grutzendler, J., Kasthuri, N., and Gan, W. B. (2002). Long-term dendritic spine stability in the adult cortex. Nature 420,812-816. doi: 10.1038/nature01276

Hagerman, R., Hoem, G., and Hagerman, P. (2010). Fragile X and autism: intertwined at the molecular level leading to targeted treatments. Mol. Autism 1, 12. doi: 10.1186/2040-2392-1-12

Hagerman, R. J., Berry-Kravis, E., Kaufmann, W. E., Ono, M. Y., Tartaglia, N., Lachiewicz, A., et al. (2009). Advances in the treatment of fragile X syndrome. Pediatrics 123, 378-390. doi: 10.1542/peds.2008-0317

Hagerman, R. J., and Hagerman, P. J. (2002). The fragile X premutation: into the phenotypic fold. Curr. Opin. Genet. Dev. 12, 278-283. doi: 10.1016/S0959437X(02)00299-X

Hamada, F. N., Rosenzweig, M., Kang, K., Pulver, S. R., Ghezzi, A., Jegla, T. J., et al. (2008). An internal thermal sensor controlling temperature preference in Drosophila. Nature 454, 217-220. doi: 10.1038/nature07001
Harris, S. W., Hessl, D., Goodlin-Jones, B., Ferranti, J., Bacalman, S., Barbato, I., et al. (2008). Autism profiles of males with fragile X syndrome. Am. J. Ment. Retard. 113, 427-438. doi: 10.1352/2008.113:427-438.

Hartwig, C. L., Worrell, J., Levine, R. B., Ramaswami, M., and Sanyal, S. (2008). Normal dendrite growth in Drosophila motor neurons requires the AP-1 transcription factor. Dev. Neurobiol. 68, 1225-1242. doi: 10.1002/dneu. 20655

Hayama, T., Noguchi, J., Watanabe, S., Takahashi, N., Hayashi-Takagi, A., EllisDavies, G. C., et al. (2013). GABA promotes the competitive selection of dendritic spines by controlling local $\mathrm{Ca}^{2+}$ signaling. Nat. Neurosci. 16, 1409-1416. doi: 10.1038/nn.3496

He, C. X., and Portera-Cailliau, C. (2013). The trouble with spines in fragile X syndrome: density, maturity and plasticity. Neuroscience 251, 120-128. doi: 10.1016/j.neuroscience.2012.03.049

Hebb, D. O. (1949). The Organization of Behavior: A Neuropsychological Theory. New York: Wiley.

Henderson, C., Wijetunge, L., Kinoshita, M. N., Shumway, M., Hammond, R. S., Postma, F. R., et al. (2012). Reversal of disease-related pathologies in the fragile X mouse model by selective activation of GABAB receptors with arbaclofen. Sci. Transl. Med. 4, 152ra128. doi: 10.1126/scitranslmed.3004218.

Hensch, T. K. (2003). Controlling the critical period. Neurosci. Res. 47, 17-22. doi: 10.1016/S0168-0102(03)00164-0

Hensch, T. K. (2004). Critical period regulation. Annu. Rev. Neurosci. 27, 549-579. doi: 10.1146/annurev.neuro.27.070203.144327

Hensch, T. K. (2005). Critical period plasticity in local cortical circuits. Nat. Rev. Neurosci. 6, 877-888. doi: 10.1038/nrn1787

Hessl, D., Berry-Kravis, E., Cordeiro, L., Yuhas, J., Ornitz, E. M., Campbell, A., et al. (2009). Prepulse inhibition in fragile X syndrome: feasibility, reliability, and implications for treatment. Am. J. Med. Genet. B Neuropsychiatr. Genet. 150B, 545-553. doi: 10.1002/ajmg.b.30858

Hoksbergen, R., Ter Laak, J., Rijk, K., Van Dijkum, C., and Stoutjesdijk, F. (2005). Post-institutional autistic syndrome in Romanian adoptees. J. Autism Dev. Disord. 35, 615-623. doi: 10.1007/s10803-005-0005-x

Holtmaat, A., and Svoboda, K. (2009). Experience-dependent structural synaptic plasticity in the mammalian brain. Nat. Rev. Neurosci. 10, 647-658. doi: $10.1038 / \mathrm{nrn} 2699$

Holtmaat, A., Wilbrecht, L., Knott, G. W., Welker, E., and Svoboda, K. (2006). Experience-dependent and cell-type-specific spine growth in the neocortex. Nature 441, 979-983. doi: 10.1038/nature04783

Holtmaat, A. J., Trachtenberg, J. T., Wilbrecht, L., Shepherd, G. M., Zhang, X., Knott, G. W., et al. (2005). Transient and persistent dendritic spines in the neocortex in vivo. Neuron 45, 279-291. doi: 10.1016/j.neuron.2005.01.003

Hong, E. J., Mccord, A. E., and Greenberg, M. E. (2008). A biological function for the neuronal activity-dependent component of Bdnf transcription in the development of cortical inhibition. Neuron 60, 610-624. doi: 10.1016/j.neuron.2008.09.024

Honig, L. S., Herrmann, K., and Shatz, C. J. (1996). Developmental changes revealed by immunohistochemical markers in human cerebral cortex. Cereb. Cortex 6 , 794-806. doi: 10.1093/cercor/6.6.794

Hornberg, H., and Holt, C. (2013). RNA-binding proteins and translational regulation in axons and growth cones. Front. Neurosci. 7:81. doi: 10.3389/fnins.2013.00081

Hu, J., Van Den Steen, P. E., Sang, Q. X., and Opdenakker, G. (2007). Matrix metalloproteinase inhibitors as therapy for inflammatory and vascular diseases. Nat. Rev. Drug Discov. 6, 480-498. doi: 10.1038/nrd2308

Hubel, D. H., and Wiesel, T. N. (1959). Receptive fields of single neurones in the cat's striate cortex. J. Physiol. 148, 574-591.

Hubel, D. H., and Wiesel, T. N. (1962). Receptive fields, binocular interaction and functional architecture in the cat's visual cortex. J. Physiol. 160, 106-154.

Hubel, D. H., and Wiesel, T. N. (1970). The period of susceptibility to the physiological effects of unilateral eye closure in kittens. J. Physiol. 206, 419-436.

Huber, K. M., Gallagher, S. M., Warren, S. T., and Bear, M. F. (2002). Altered synaptic plasticity in a mouse model of fragile X mental retardation. Proc. Natl. Acad. Sci. U.S.A. 99, 7746-7750. doi: 10.1073/pnas.122205699

Huntley, G. W. (1997). Differential effects of abnormal tactile experience on shaping representation patterns in developing and adult motor cortex. J. Neurosci. 17, 9220-9232. 
Hutsler, J. J., and Zhang, H. (2010). Increased dendritic spine densities on cortical projection neurons in autism spectrum disorders. Brain Res. 1309, 83-94. doi: 10.1016/j.brainres.2009.09.120

Inada, K., Kohsaka, H., Takasu, E., Matsunaga, T., and Nose, A. (2011). Optical dissection of neural circuits responsible for Drosophila larval locomotion with halorhodopsin. PLoS ONE 6:e29019. doi: 10.1371/journal.pone.0029019

Irie, F., Badie-Mahdavi, H., and Yamaguchi, Y. (2012). Autism-like sociocommunicative deficits and stereotypies in mice lacking heparan sulfate. Proc Natl. Acad. Sci. U.S.A. 109, 5052-5056. doi: 10.1073/pnas.1117881109

Irwin, S. A., Galvez, R., and Greenough, W. T. (2000). Dendritic spine structural anomalies in fragile-X mental retardation syndrome. Cereb. Cortex 10, 10381044. doi: 10.1093/cercor/10.10.1038

Irwin, S. A., Patel, B., Idupulapati, M., Harris, J. B., Crisostomo, R. A., Larsen, B. P., et al. (2001). Abnormal dendritic spine characteristics in the temporal and visual cortices of patients with fragile-X syndrome: a quantitative examination. Am. J. Med. Genet. 98, 161-167. doi: 10.1002/1096-8628(20010115)98:2<161::AIDAJMG1025>3.0.CO;2-B

Jahn, K., Schlesinger, F., Jin, L. J., Dengler, R., Bufler, J., and Krampfl, K. (2008). Molecular mechanisms of interaction between the neuroprotective substance riluzole and GABA(A)-receptors. Naunyn Schmiedebergs Arch. Pharmacol. 378, 53-63. doi: 10.1007/s00210-008-0290-y

Janusz, A., Milek, J., Perycz, M., Pacini, L., Bagni, C., Kaczmarek, L., et al. (2013). The fragile X mental retardation protein regulates matrix metalloproteinase $9 \mathrm{mRNA}$ at synapses. J. Neurosci. 33, 18234-18241. doi: 10.1523/JNEUROSCI.220713.2013

Jarecki, J., and Keshishian, H. (1995). Role of neural activity during synaptogenesis in Drosophila. J. Neurosci. 15, 8177-8190.

Jenett, A., Rubin, G. M., Ngo, T. T., Shepherd, D., Murphy, C., Dionne, H., et al. (2012). A GAL4-driver line resource for Drosophila neurobiology. Cell Rep. 2, 991-1001. doi: 10.1016/j.celrep.2012.09.011

Jin, L., Han, Z., Platisa, J., Wooltorton, J. R., Cohen, L. B., and Pieribone, V. A. (2012). Single action potentials and subthreshold electrical events imaged in neurons with a fluorescent protein voltage probe. Neuron 75, 779-785. doi: 10.1016/j.neuron.2012.06.040

Johnson, K. G., Tenney, A. P., Ghose, A., Duckworth, A. M., Higashi, M. E., Parfitt, K., et al. (2006). The HSPGs Syndecan and Dallylike bind the receptor phosphatase LAR and exert distinct effects on synaptic development. Neuron 49, 517-531. doi: 10.1016/j.neuron.2006.01.026

Jones, W. D. (2009). The expanding reach of the GAL4/UAS system into the behavioral neurobiology of Drosophila. BMB Rep. 42, 705-712. doi: 10.5483/BMBRep.2009.42.11.705

Jontes, J. D., and Smith, S. J. (2000). Filopodia, spines, and the generation of synaptic diversity. Neuron 27, 11-14. doi: 10.1016/S0896-6273(00)00003-9

Judkewitz, B., Rizzi, M., Kitamura, K., and Hausser, M. (2009). Targeted single-cell electroporation of mammalian neurons in vivo. Nat. Protoc. 4, 862-869. doi: 10.1038/nprot.2009.56

Jung, R. (1958). Excitation, inhibition and coordination of cortical neurones. Exp. Cell Res. 14, 262-271.

Kanai, Y., Dohmae, N., and Hirokawa, N. (2004). Kinesin transports RNA: isolation and characterization of an RNA-transporting granule. Neuron 43, 513-525. doi: 10.1016/j.neuron.2004.07.022

Kanellopoulos, A. K., Semelidou, O., Kotini, A. G., Anezaki, M., and Skoulakis, E. M. (2012). Learning and memory deficits consequent to reduction of the fragile X mental retardation protein result from metabotropic glutamate receptormediated inhibition of cAMP signaling in Drosophila. J. Neurosci. 32, 1311113124. doi: 10.1523/JNEUROSCI.1347-12.2012

Katz, L. C., and Shatz, C. J. (1996). Synaptic activity and the construction of cortical circuits. Science 274, 1133-1138. doi: 10.1126/science.274.5290.1133

Kaufmann, W. E., and Moser, H. W. (2000). Dendritic anomalies in disorders associated with mental retardation. Cereb. Cortex 10, 981-991. doi: 10.1093/cercor/10.10.981

Kayser, M. S., Nolt, M. J., and Dalva, M. B. (2008). EphB receptors couple dendritic filopodia motility to synapse formation. Neuron 59, 56-69. doi: 10.1016/j.neuron.2008.05.007

Kelemen, O., Kovacs, T., and Keri, S. (2013). Contrast, motion, perceptual integration, and neurocognition in schizophrenia: the role of fragile-X related mechanisms. Prog. Neuropsychopharmacol. Biol. Psychiatry 46, 92-97. doi: 10.1016/j.pnpbp.2013.06.017.
Keshishian, H., and Kim, Y. S. (2004). Orchestrating development and function: retrograde BMP signaling in the Drosophila nervous system. Trends Neurosci. 27, 143-147. doi: 10.1016/j.tins.2004.01.004

Kilgard, M. P., and Merzenich, M. M. (1998). Cortical map reorganization enabled by nucleus basalis activity. Science 279, 1714-1718. doi: 10.1126/science.279.5357.1714

Kim, H., Gibboni, R., Kirkhart, C., and Bao, S. (2013a). Impaired critical period plasticity in primary auditory cortex of fragile X model mice. J. Neurosci. 33, 15686-15692. doi: 10.1523/JNEUROSCI.3246-12.2013

Kim, S. H., Thurm, A., Shumway, S., and Lord, C. (2013b). Multisite study of new autism diagnostic interview-revised (ADI-R) algorithms for toddlers and young preschoolers. J. Autism Dev. Disord. 43, 1527-1538. doi: 10.1007/s10803-0121696-4

Kim, H. S., and Suh, Y. H. (2009). Minocycline and neurodegenerative diseases. Behav. Brain Res. 196, 168-179. doi: 10.1016/j.bbr.2008.09.040

Kim, S. A., and Jun, S. B. (2013). Optical measurement of neural activity in the brain. Exp. Neurobiol. 22, 158-166. doi: 10.5607/en.2013.22.3.158

Kim, S. H., and Lord, C. (2012). Combining information from multiple sources for the diagnosis of autism spectrum disorders for toddlers and young preschoolers from 12 to 47 months of age. J. Child Psychol. Psychiatry 53, 143-151. doi: 10.1111/j.1469-7610.2011.02458.x

Kittelmann, M., Liewald, J. F., Hegermann, J., Schultheis, C., Brauner, M., Steuer Costa, W., etal. (2013). In vivo synaptic recovery following optogenetic hyperstimulation. Proc. Natl. Acad. Sci. U.S.A. 110, E3007-E3016. doi: 10.1073/pnas.1305679110

Koles, K., and Budnik, V. (2012). Wnt signaling in neuromuscular junction development. Cold Spring Harb. Perspect. Biol. 4. doi: 10.1101/cshperspect.a008045

Koleske, A. J. (2013). Molecular mechanisms of dendrite stability. Nat. Rev. Neurosci. 14, 536-550. doi: 10.1038/nrn3486

Kooy, R. F. (2003). Of mice and the fragile X syndrome. Trends Genet. 19, 148-154. doi: 10.1016/S0168-9525(03)00017-9

Korkut, C., Ataman, B., Ramachandran, P., Ashley, J., Barria, R., Gherbesi, N., et al. (2009). Trans-synaptic transmission of vesicular Wnt signals through Evi/Wntless. Cell 139, 393-404. doi: 10.1016/j.cell.2009.07.051

Korkut, C., and Budnik, V. (2009). WNTs tune up the neuromuscular junction. Nat. Rev. Neurosci. 10, 627-634. doi: 10.1038/nrn2681

Koshino, H., Carpenter, P. A., Minshew, N. J., Cherkassky, V. L., Keller, T. A., and Just, M. A. (2005). Functional connectivity in an fMRI working memory task in high-functioning autism. Neuroimage 24, 810-821. doi: 10.1016/j.neuroimage.2004.09.028

Kotlikoff, M. I. (2007). Genetically encoded $\mathrm{Ca}^{2+}$ indicators: using genetics and molecular design to understand complex physiology. J. Physiol. 578, 55-67. doi: 10.1113/jphysiol.2006.120212

Kovacs, T., Kelemen, O., and Keri, S. (2013). Decreased fragile X mental retardation protein (FMRP) is associated with lower IQ and earlier illness onset in patients with schizophrenia. Psychiatry Res. 210, 690-693. doi: 10.1016/j.psychres.2012.12.022

Kratovac, S., and Corbin, J. G. (2013). Developmental changes in expression of inhibitory neuronal proteins in the fragile $\mathrm{X}$ Syndrome mouse basolateral amygdala. Brain Res. 1537, 69-78. doi: 10.1016/j.brainres.2013.08.052

Kremer, M. C., Christiansen, F., Leiss, F., Paehler, M., Knapek, S., Andlauer, T. F., et al. (2010). Structural long-term changes at mushroom body input synapses. Curr. Biol. 20, 1938-1944. doi: 10.1016/j.cub.2010.09.060

Kreutz, M. R., and Sala, C. (2012). Synaptic Plasticity: Dynamics, Development and Disease. New York: Springer. doi: 10.1007/978-3-7091-0932-8

Krichevsky, A. M., and Kosik, K. S. (2001). Neuronal RNA granules: a link between RNA localization and stimulation-dependent translation. Neuron 32, 683-696. doi: 10.1016/S0896-6273(01)00508-6

Kroon, T., Sierksma, M. C., and Meredith, R. M. (2013). Investigating mechanisms underlying neurodevelopmental phenotypes of autistic and intellectual disability disorders: a perspective. Front. Syst. Neurosci. 7:75. doi: 10.3389/fnsys.2013. 00075

Kuffler, S. W. (1953). Discharge patterns and functional organization of mammalian retina. J. Neurophysiol. 16, 37-68.

Lauterborn, J. C., Jafari, M., Babayan, A. H., and Gall, C. M. (2013). Environmental enrichment reveals effects of genotype on hippocampal spine morphologies in the mouse model of fragile X syndrome. Cereb. Cortex doi: 10.1093/cercor/bht249 [Epub ahead of print]. 
Lebeau, G., Miller, L. C., Tartas, M., Mcadam, R., Laplante, I., Badeaux, F., et al. (2011). Staufen 2 regulates mGluR long-term depression and Maplb mRNA distribution in hippocampal neurons. Learn. Mem. 18, 314-326. doi: 10.1101/lm.2100611

LeBlanc, J. J., and Fagiolini, M. (2011). Autism: a "critical period" disorder? Neural Plast. 2011, 921680. doi: 10.1155/2011/921680

Lee, T., and Luo, L. (2001). Mosaic analysis with a repressible cell marker (MARCM) for Drosophila neural development. Trends Neurosci. 24, 251-254. doi: 10.1016/S0166-2236(00)01791-4

Leehey, M. A., Berry-Kravis, E., Goetz, C. G., Zhang, L., Hall, D. A., Li, L., et al (2008). FMR1 CGG repeat length predicts motor dysfunction in premutation carriers. Neurology 70, 1397-1402. doi: 10.1212/01.wnl.0000281692.98200.f5

Leigh, M. J., Nguyen, D. V., Mu, Y., Winarni, T. I., Schneider, A., Chechi, T., et al. (2013). A randomized double-blind, placebo-controlled trial of minocycline in children and adolescents with fragile X syndrome. J. Dev. Behav. Pediatr. 34 147-155. doi: 10.1097/DBP.0b013e318287cd17

Lendvai, B., Stern, E. A., Chen, B., and Svoboda, K. (2000). Experience-dependent plasticity of dendritic spines in the developing rat barrel cortex in vivo. Nature 404, 876-881. doi: 10.1038/35009107

Levenga, J., De Vrij, F. M., Oostra, B.A., and Willemsen, R. (2010). Potential therapeutic interventions for fragile X syndrome. Trends Mol. Med. 16, 516-527. doi: 10.1016/j.molmed.2010.08.005

Levitz, J., Pantoja, C., Gaub, B., Janovjak, H., Reiner, A., Hoagland, A., et al. (2013). Optical control of metabotropic glutamate receptors. Nat. Neurosci. 16, 507-516. doi: 10.1038/nn.3346

Li, C., Bassell, G. J., and Sasaki, Y. (2009). Fragile X mental retardation protein is involved in protein synthesis-dependent collapse of growth cones induced by semaphorin-3A. Front. Neural Circuits 3:11. doi: 10.3389/neuro.04.011.2009

Li, H., Zhong, X., Chau, K. F., Williams, E. C., and Chang, Q. (2011). Loss of activity-induced phosphorylation of MeCP2 enhances synaptogenesis, LTP and spatial memory. Nat. Neurosci. 14, 1001-1008. doi: 10.1038/nn.2866

Lichtman, J. W., and Colman, H. (2000). Synapse elimination and indelible memory. Neuron 25, 269-278. doi: 10.1016/S0896-6273(00)80893-4

Lin, J. Y., Knutsen, P. M., Muller, A., Kleinfeld, D., and Tsien, R. Y. (2013a). ReaChR a red-shifted variant of channelrhodopsin enables deep transcranial optogenetic excitation. Nat. Neurosci. 16, 1499-1508. doi: 10.1038/nn.3502

Lin, J. Y., Sann, S. B., Zhou, K., Nabavi, S., Proulx, C. D., Malinow, R., et al (2013b). Optogenetic inhibition of synaptic release with chromophore-assisted light inactivation (CALI). Neuron 79, 241-253. doi: 10.1016/j.neuron.2013. 05.022

Lin, Y., Bloodgood, B. L., Hauser, J. L., Lapan, A. D., Koon, A. C., Kim, T. K., et al. (2008). Activity-dependent regulation of inhibitory synapse development by Npas4. Nature 455, 1198-1204. doi: 10.1038/nature07319

Link, W., Konietzko, U., Kauselmann, G., Krug, M., Schwanke, B., Frey, U., et al. (1995). Somatodendritic expression of an immediate early gene is regulated by synaptic activity. Proc. Natl. Acad. Sci. U.S.A. 92, 5734-5738 doi 10.1073/pnas.92.12.5734

Liske, H., Towne, C., Anikeeva, P., Zhao, S., Feng, G., Deisseroth, K., et al. (2013). Optical inhibition of motor nerve and muscle activity in vivo. Muscle Nerve 47, 916-921. doi: 10.1002/mus.23696

Liu, B., Li, L., Chen, J., Wang, Z., Li, Z., and Wan, Q. (2013). Regulation of GABAA receptors by fragile X mental retardation protein. Int. J. Physiol. Pathophysiol. Pharmacol. 5, 169-176.

Lnenicka, G. A., Spencer, G. M., and Keshishian, H. (2003). Effect of reduced impulse activity on the development of identified motor terminals in Drosophila larvae. J. Neurobiol. 54, 337-345. doi: 10.1002/neu.10133

Lovick, J. K., Ngo, K. T., Omoto, J. J., Wong, D. C., Nguyen, J. D., and Hartenstein, V. (2013). Postembryonic lineages of the Drosophila brain: I. Development of the lineage-associated fiber tracts. Dev. Biol. 384, 228-257. doi: 10.1016/j.ydbio.2013.07.008

Luikart, B. W., Zhang, W., Wayman, G. A., Kwon, C. H., Westbrook, G. L., and Parada, L. F. (2008). Neurotrophin-dependent dendritic filopodial motility: a convergence on PI3K signaling. J. Neurosci. 28, 7006-7012. doi: 10.1523/JNEUROSCI.019508.2008

Lundahl, J., Staner, L., Staner, C., Loft, H., and Deacon, S. (2007). Short-term treatment with gaboxadol improves sleep maintenance and enhances slow wave sleep in adult patients with primary insomnia. Psychopharmacology (Berl.) 195, 139-146. doi: 10.1007/s00213-007-0866-0
Maffei, A., and Fontanini, A. (2009). Network homeostasis: a matter of coordination. Curr. Opin. Neurobiol. 19, 168-173. doi: 10.1016/j.conb.2009.05.012

Makinodan, M., Rosen, K. M., Ito, S., and Corfas, G. (2012). A critical period for social experience-dependent oligodendrocyte maturation and myelination. Science 337, 1357-1360. doi: 10.1126/science.1220845

Malenka, R. C., and Bear, M. F. (2004). LTP and LTD: an embarrassment of riches. Neuron 44, 5-21. doi: 10.1016/j.neuron.2004.09.012

Mann, K., Kiefer, F., Spanagel, R., and Littleton, J. (2008). Acamprosate: recent findings and future research directions. Alcohol. Clin. Exp. Res. 32, 1105-1110. doi: 10.1111/j.1530-0277.2008.00690.x

Manning, L., Heckscher, E. S., Purice, M. D., Roberts, J., Bennett, A. L., Kroll, J. R., et al. (2012). A resource for manipulating gene expression and analyzing cis-regulatory modules in the Drosophila CNS. Cell Rep. 2, 1002-1013. doi: 10.1016/j.celrep.2012.09.009

Mantz, J., Laudenbach, V., Lecharny, J. B., Henzel, D., and Desmonts, J. M. (1994). Riluzole, a novel antiglutamate, blocks GABA uptake by striatal synaptosomes. Eur. J. Pharmacol. 257, R7-R8. doi: 10.1016/0014-2999(94) 90716-1

Marco, E. J., Hinkley, L. B., Hill, S. S., and Nagarajan, S. S. (2011). Sensory processing in autism: a review of neurophysiologic findings. Pediatr. Res. 69, 48R-54R. doi: 10.1203/PDR.0b013e3182130c54

Margulies, C., Tully, T., and Dubnau, J. (2005). Deconstructing memory in Drosophila. Curr. Biol. 15, R700-R713. doi: 10.1016/j.cub.2005.08.024

Marin-Padilla, M. (1972). Structural abnormalities of the cerebral cortex in human chromosomal aberrations: a Golgi study. Brain Res. 44, 625-629. doi: 10.1016/0006-8993(72)90324-1

Marrus, S. B., Portman, S. L., Allen, M. J., Moffat, K. G., and Diantonio, A. (2004). Differential localization of glutamate receptor subunits at the Drosophila neuromuscular junction. J. Neurosci. 24, 1406-1415. doi: 10.1523/JNEUROSCI.1575-03.2004

Masuyama, K., Zhang, Y., Rao, Y., and Wang, J. W. (2012). Mapping neural circuits with activity-dependent nuclear import of a transcription factor. J. Neurogenet. 26, 89-102. doi: 10.3109/01677063.2011.642910

McBride, S. M., Bell, A. J., and Jongens, T. A. (2012). Behavior in a Drosophila model of fragile X. Results Probl. Cell Differ. 54, 83-117. doi: 10.1007/978-3-642-2164976

McBride, S. M., Choi, C. H., Wang, Y., Liebelt, D., Braunstein, E., Ferreiro, D., et al. (2005). Pharmacological rescue of synaptic plasticity, courtship behavior, and mushroom body defects in a Drosophila model of fragile X syndrome. Neuron 45 , 753-764. doi: 10.1016/j.neuron.2005.01.038

McCabe, B. D., Marques, G., Haghighi, A. P., Fetter, R. D., Crotty, M. L., Haerry, T. E., et al. (2003). The BMP homolog Gbb provides a retrograde signal that regulates synaptic growth at the Drosophila neuromuscular junction. Neuron 39, 241-254. doi: 10.1016/S0896-6273(03)00426-4

McKinney, B. C., Grossman, A. W., Elisseou, N. M., and Greenough, W. T. (2005). Dendritic spine abnormalities in the occipital cortex of C57BL/6 Fmr1 knockout mice. Am. J. Med. Genet. B Neuropsychiatr. Genet. 136B, 98-102. doi: 10.1002/ajmg.b.30183

Meredith, R. M., Holmgren, C. D., Weidum, M., Burnashev, N., and Mansvelder, H. D. (2007). Increased threshold for spike-timing-dependent plasticity is caused by unreliable calcium signaling in mice lacking fragile X gene FMR1. Neuron 54, 627-638. doi: 10.1016/j.neuron.2007.04.028

Meyza, K. Z., Blanchard, D. C., Pearson, B. L., Pobbe, R. L., and Blanchard, R. J. (2012). Fractone-associated N-sulfated heparan sulfate shows reduced quantity in BTBR T+tf/J mice: a strong model of autism. Behav. Brain Res. 228, 247-253. doi: 10.1016/j.bbr.2011.11.004

Michalon, A., Bruns, A., Risterucci, C., Honer, M., Ballard, T. M., Ozmen, L., et al. (2014). Chronic metabotropic glutamate receptor 5 inhibition corrects local alterations of brain activity and improves cognitive performance in fragile $\mathrm{X}$ mice. Biol. Psychiatry 75, 189-197. doi: 10.1016/j.biopsych.2013.05.038

Mientjes, E. J., Nieuwenhuizen, I., Kirkpatrick, L., Zu, T., Hoogeveen-Westerveld, M., Severijnen, L., et al. (2006). The generation of a conditional Fmr1 knock out mouse model to study Fmrp function in vivo. Neurobiol. Dis. 21, 549-555. doi: 10.1016/j.nbd.2005.08.019

Mikuni, T., Uesaka, N., Okuno, H., Hirai, H., Deisseroth, K., Bito, H., et al. (2013). Arc/Arg3.1 is a postsynaptic mediator of activity-dependent synapse elimination in the developing cerebellum. Neuron 78, 1024-1035. doi: 10.1016/j.neuron.2013.04.036 
Miller, L. J., Mcintosh, D. N., Mcgrath, J., Shyu, V., Lampe, M., Taylor, A. K., et al. (1999). Electrodermal responses to sensory stimuli in individuals with fragile X syndrome: a preliminary report. Am. J. Med. Genet. 83, 268-279. doi: 10.1002/(SICI) 1096-8628(19990402)83:4<268::AID-AJMG7>3.0.CO;2-K

Mines, M. A., Yuskaitis, C. J., King, M. K., Beurel, E., and Jope, R. S. (2010). GSK3 influences social preference and anxiety-related behaviors during social interaction in a mouse model of fragile $\mathrm{X}$ syndrome and autism. PLoS ONE 5:e9706. doi: 10.1371/journal.pone.0009706

Miyashiro, K. Y., Beckel-Mitchener, A., Purk, T. P., Becker, K. G., Barret, T., Liu, L., et al. (2003). RNA cargoes associating with FMRP reveal deficits in cellular functioning in Fmrl null mice. Neuron 37, 417-431. doi: 10.1016/S08966273(03)00034-5

Miyashita, T., Shao, Y. R., Chung, J., Pourzia, O., and Feldman, D. E. (2013). Long-term channelrhodopsin-2 (ChR2) expression can induce abnormal axonal morphology and targeting in cerebral cortex. Front. Neural Circuits 7:8. doi: 10.3389/fncir.2013.00008

Morrow, E. M., Yoo, S. Y., Flavell, S. W., Kim, T. K., Lin, Y., Hill, R. S., et al. (2008). Identifying autism loci and genes by tracing recent shared ancestry. Science 321, 218-223. doi: 10.1126/science.1157657

Moser, M. B., Moser, E. I., Forrest, E., Andersen, P., and Morris, R. G. (1995). Spatial learning with a minislab in the dorsal hippocampus. Proc. Natl. Acad. Sci. U.S.A. 92, 9697-9701. doi: 10.1073/pnas.92.21.9697

Muddashetty, R. S., Kelic, S., Gross, C., Xu, M., and Bassell, G. J. (2007). Dysregulated metabotropic glutamate receptor-dependent translation of AMPA receptor and postsynaptic density-95 mRNAs at synapses in a mouse model of fragile X syndrome. J. Neurosci. 27, 5338-5348. doi: 10.1523/JNEUROSCI.0937-07.2007

Mundy, P. (2003). Annotation: the neural basis of social impairments in autism: the role of the dorsal medial-frontal cortex and anterior cingulate system. J. Child Psychol. Psychiatry 44, 793-809. doi: 10.1111/1469-7610.00165

Murdoch, J. D., and State, M. W. (2013). Recent developments in the genetics of autism spectrum disorders. Curr. Opin. Genet. Dev. 23, 310-315. doi: 10.1016/j.gde.2013.02.003

Murray, M. J. (2010). Attention-deficit/hyperactivity disorder in the context of autism spectrum disorders. Curr. Psychiatry Rep. 12, 382-388. doi 10.1007/s11920-010-0145-3

Musumeci, S. A., Hagerman, R. J., Ferri, R., Bosco, P., Dalla Bernardina, B., Tassinari, C. A., et al. (1999). Epilepsy and EEG findings in males with fragile X syndrome. Epilepsia 40, 1092-1099. doi: 10.1111/j.1528-1157.1999.tb00824.x

Mutoh, H., Akemann, W., and Knopfel, T. (2012). Genetically engineered fluorescent voltage reporters. ACS Chem. Neurosci. 3, 585-592. doi: 10.1021/cn300041b

Nahm, M., Lee, M. J., Parkinson, W., Lee, M., Kim, H., Kim, Y. J., etal. (2013). Spartin regulates synaptic growth and neuronal survival by inhibiting BMP-mediated microtubule stabilization. Neuron 77, 680-695. doi 10.1016/j.neuron.2012.12.015

Napoli, I., Mercaldo, V., Boyl, P. P., Eleuteri, B., Zalfa, F., De Rubeis, S., et al. (2008). The fragile X syndrome protein represses activity-dependent translation through CYFIP1, a new 4E-BP. Cell 134, 1042-1054. doi: 10.1016/j.cell.2008. 07.031

Narayanan, U., Nalavadi, V., Nakamoto, M., Pallas, D. C., Ceman, S., Bassell, G. J., et al. (2007). FMRP phosphorylation reveals an immediate-early signaling pathway triggered by group I mGluR and mediated by PP2A. J. Neurosci. 27, 14349-14357. doi: 10.1523/JNEUROSCI.2969-07.2007

Nataraj, K., and Turrigiano, G. (2011). Regional and temporal specificity of intrinsic plasticity mechanisms in rodent primary visual cortex. J. Neurosci. 31, 1793217940. doi: 10.1523/JNEUROSCI.4455-11.2011

Nelson, C. A. III, Zeanah, C. H., Fox, N. A., Marshall, P. J., Smyke, A. T., and Guthrie, D. (2007). Cognitive recovery in socially deprived young children: the Bucharest Early Intervention Project. Science 318, 1937-1940. doi: 10.1126/science.1143921

Nelson, S. B., and Turrigiano, G. G. (2008). Strength through diversity. Neuron 60 , 477-482. doi: 10.1016/j.neuron.2008.10.020

Nielsen, E. B., Suzdak, P. D., Andersen, K. E., Knutsen, L. J., Sonnewald, U., and Braestrup, C. (1991). Characterization of tiagabine (NO-328), a new potent and selective GABA uptake inhibitor. Eur. J. Pharmacol. 196, 257-266. doi: 10.1016/0014-2999(91)90438-V

Niere, F., Wilkerson, J. R., and Huber, K. M. (2012). Evidence for a fragile X mental retardation protein-mediated translational switch in metabotropic glutamate receptor-triggered Arc translation and long-term depression. J. Neurosci. 32, 5924-5936. doi: 10.1523/JNEUROSCI.4650-11.2012
Nitabach, M. N., Wu, Y., Sheeba, V., Lemon, W. C., Strumbos, J., Zelensky, P. K., et al. (2006). Electrical hyperexcitation of lateral ventral pacemaker neurons desynchronizes downstream circadian oscillators in the fly circadian circuit and induces multiple behavioral periods. J. Neurosci. 26, 479-489. doi: 10.1523/JNEUROSCI.3915-05.2006

Nosyreva, E. D., and Huber, K. M. (2006). Metabotropic receptor-dependent longterm depression persists in the absence of protein synthesis in the mouse model of fragile X syndrome. J. Neurophysiol. 95, 3291-3295. doi: 10.1152/jn.01316.2005

Olmos-Serrano, J. L., Paluszkiewicz, S. M., Martin, B. S., Kaufmann, W. E., Corbin, J. G., and Huntsman, M. M. (2010). Defective GABAergic neurotransmission and pharmacological rescue of neuronal hyperexcitability in the amygdala in a mouse model of fragile X syndrome. J. Neurosci. 30, 9929-9938. doi: 10.1523/JNEUROSCI.1714-10.2010

Osterweil, E. K., Krueger, D. D., Reinhold, K., and Bear, M. F. (2010). Hypersensitivity to mGluR5 and ERK1/2 leads to excessive protein synthesis in the hippocampus of a mouse model of fragile X syndrome. J. Neurosci. 30, 15616-15627. doi: 10.1523/JNEUROSCI.3888-10.2010

Ostrovsky, A., Cachero, S., and Jefferis, G. (2013). Clonal analysis of olfaction in Drosophila: generation of flies with mosaic labeling. Cold Spring Harb. Protoc. 2013, 335-341. doi: 10.1101/pdb.prot071712

Pacey, L. K., Heximer, S. P., and Hampson, D. R. (2009). Increased GABA(B) receptor-mediated signaling reduces the susceptibility of fragile $\mathrm{X}$ knockout mice to audiogenic seizures. Mol. Pharmacol. 76, 18-24. doi: 10.1124/mol.109.056127

Pacey, L. K., Xuan, I. C., Guan, S., Sussman, D., Henkelman, R. M., Chen, Y., et al. (2013). Delayed myelination in a mouse model of fragile X syndrome. Hum. Mol. Genet. 22, 3920-3930. doi: 10.1093/hmg/ddt246

Packard, M., Koo, E. S., Gorczyca, M., Sharpe, J., Cumberledge, S., and Budnik, V. (2002). The Drosophila Wnt, wingless, provides an essential signal for pre- and postsynaptic differentiation. Cell 111, 319-330. doi: 10.1016/S00928674(02)01047-4

Packer, A. M., Roska, B., and Hausser, M. (2013). Targeting neurons and photons for optogenetics. Nat. Neurosci. 16, 805-815. doi: 10.1038/nn.3427

Paluszkiewicz, S. M., Martin, B. S., and Huntsman, M. M. (2011). Fragile X syndrome: the GABAergic system and circuit dysfunction. Dev. Neurosci. 33, 349-364. doi: 10.1159/000329420

Pan, F., and Gan, W. B. (2008). Two-photon imaging of dendritic spine development in the mouse cortex. Dev. Neurobiol. 68, 771-778. doi: 10.1002/dneu.20630

Pan, L., and Broadie, K. S. (2007). Drosophila fragile X mental retardation protein and metabotropic glutamate receptor A convergently regulate the synaptic ratio of ionotropic glutamate receptor subclasses. J. Neurosci. 27, 12378-12389. doi: 10.1523/JNEUROSCI.2970-07.2007

Pan, L., Woodruff, E. III, Liang, P., and Broadie, K. (2008). Mechanistic relationships between Drosophila fragile X mental retardation protein and metabotropic glutamate receptor A signaling. Mol. Cell. Neurosci. 37, 747-760. doi: 10.1016/j.mcn.2008.01.003

Paradis, S., Sweeney, S. T., and Davis, G. W. (2001). Homeostatic control of presynaptic release is triggered by postsynaptic membrane depolarization. Neuron 30, 737-749. doi: 10.1016/S0896-6273(01)00326-9

Park, S., Park, J. M., Kim, S., Kim, J. A., Shepherd, J. D., Smith-Hicks, C. L., et al. (2008). Elongation factor 2 and fragile X mental retardation protein control the dynamic translation of Arc/Arg3.1 essential for mGluR-LTD. Neuron 59, 70-83. doi: 10.1016/j.neuron.2008.05.023

Parnas, M., Lin, A. C., Huetteroth, W., and Miesenbock, G. (2013). Odor discrimination in Drosophila: from neural population codes to behavior. Neuron 79, 932-944. doi: 10.1016/j.neuron.2013.08.006

Patel, A. B., Hays, S. A., Bureau, I., Huber, K. M., and Gibson, J. R. (2013). A target cell-specific role for presynaptic Fmrl in regulating glutamate release onto neocortical fast-spiking inhibitory neurons. J. Neurosci. 33, 2593-2604. doi: 10.1523/JNEUROSCI.2447-12.2013

Patterson, M. A., Lagier, S., and Carleton, A. (2013). Odor representations in the olfactory bulb evolve after the first breath and persist as an odor afterimage. Proc. Natl. Acad. Sci. U.S.A. 110, E3340-E3349. doi: 10.1073/pnas.1303873110

Paz, J. T., Davidson, T. J., Frechette, E. S., Delord, B., Parada, I., Peng, K., et al. (2013). Closed-loop optogenetic control of thalamus as a tool for interrupting seizures after cortical injury. Nat. Neurosci. 16, 64-70. doi: 10.1038/ nn.3269

Peabody, N. C., Pohl, J. B., Diao, F., Vreede, A. P., Sandstrom, D. J., Wang, H., et al. (2009). Characterization of the decision network for wing expansion in 
Drosophila using targeted expression of the TRPM8 channel. J. Neurosci. 29, 3343-3353. doi: 10.1523/JNEUROSCI.4241-08.2009

Pech, U., Pooryasin, A., Birman, S., and Fiala, A. (2013). Localization of the contacts between Kenyon cells and aminergic neurons in the Drosophila melanogaster brain using SplitGFP reconstitution. J. Comp. Neurol. 521, 3992-4026. doi: $10.1002 / \mathrm{cne} .23388$

Penzes, P., Cahill, M. E., Jones, K. A., Vanleeuwen, J. E., and Woolfrey, K. M. (2011). Dendritic spine pathology in neuropsychiatric disorders. Nat. Neurosci. 14, 285-293. doi: 10.1038/nn.2741

Perisse, E., Yin, Y., Lin, A. C., Lin, S., Huetteroth, W., and Waddell, S. (2013). Different Kenyon cell populations drive learned approach and avoidance in Drosophila. Neuron 79, 945-956. doi: 10.1016/j.neuron.2013.07.045

Persico, A. M., and Bourgeron, T. (2006). Searching for ways out of the autism maze: genetic, epigenetic and environmental clues. Trends Neurosci. 29, 349-358. doi 10.1016/j.tins.2006.05.010

Pfeiffer, B. E., and Huber, K. M. (2007). Fragile X mental retardation protein induces synapse loss through acute postsynaptic translational regulation. J. Neurosci. 27 3120-3130. doi: 10.1523/JNEUROSCI.0054-07.2007

Pfeiffer, B. E., Zang, T., Wilkerson, J. R., Taniguchi, M., Maksimova, M. A., Smith L. N., et al. (2010). Fragile X mental retardation protein is required for synapse elimination by the activity-dependent transcription factor MEF2. Neuron 66, 191-197. doi: 10.1016/j.neuron.2010.03.017

Pop, A. S., Gomez-Mancilla, B., Neri, G., Willemsen, R., and Gasparini, F. (2013). Fragile $\mathrm{X}$ syndrome: a preclinical review on metabotropic glutamate receptor 5 (mGluR5) antagonists and drug development. Psychopharmacology (Berl.). doi: 10.1007/s00213-013-3330-3 [Epub ahead of print].

Popescu, M. V., and Polley, D. B. (2010). Monaural deprivation disrupts development of binaural selectivity in auditory midbrain and cortex. Neuron $65,718-731$ doi: 10.1016/j.neuron.2010.02.019

Powell, E. M., Campbell, D. B., Stanwood, G. D., Davis, C., Noebels, J. L., and Levitt, P. (2003). Genetic disruption of cortical interneuron development causes region- and GABA cell type-specific deficits, epilepsy, and behavioral dysfunction. J. Neurosci. 23, 622-631.

Powell, S. B., Sejnowski, T. J., and Behrens, M. M. (2012). Behavioral and neurochemical consequences of cortical oxidative stress on parvalbumin-interneuron maturation in rodent models of schizophrenia. Neuropharmacology 62, 13221331. doi: 10.1016/j.neuropharm.2011.01.049

Prieto-Godino, L. L., Diegelmann, S., and Bate, M. (2012). Embryonic origin of olfactory circuitry in Drosophila: contact and activity-mediated interactions pattern connectivity in the antennal lobe. PLoS Biol. 10:e1001400. doi: 10.1371/journal.pbio. 1001400

Pulipparacharuvil, S., Renthal, W., Hale, C. F., Taniguchi, M., Xiao, G., Kumar, A., et al. (2008). Cocaine regulates MEF2 to control synaptic and behavioral plasticity. Neuron 59, 621-633. doi: 10.1016/j.neuron.2008.06.020

Pulver, S. R., Pashkovski, S. L., Hornstein, N. J., Garrity, P. A., and Griffith, L. C. (2009). Temporal dynamics of neuronal activation by channelrhodopsin-2 and TRPA1 determine behavioral output in Drosophila larvae. J. Neurophysiol. 101, 3075-3088. doi: 10.1152/jn.00071.2009

Puram, S. V., and Bonni, A. (2013). Cell-intrinsic drivers of dendrite morphogenesis. Development 140, 4657-4671. doi: 10.1242/dev.087676

Purpura, D. P. (1974). Dendritic spine “dysgenesis" and mental retardation. Science 186, 1126-1128. doi: 10.1126/science.186.4169.1126

Ramiro-Cortes, Y., and Israely, I. (2013). Long lasting protein synthesis- and activitydependent spine shrinkage and elimination after synaptic depression. PLoS ONE 8:e71155. doi: 10.1371/journal.pone.0071155

Ramocki, M. B., and Zoghbi, H. Y. (2008). Failure of neuronal homeostasis results in common neuropsychiatric phenotypes. Nature 455, 912-918. doi: 10.1038 /nature 07457

Reddy, D. S., and Rogawski, M. A. (2010). Ganaxolone suppression of behavioral and electrographic seizures in the mouse amygdala kindling model. Epilepsy Res. 89, 254-260. doi: 10.1016/j.eplepsyres.2010.01.009

Reichow, B., and Volkmar, F. R. (2010). Social skills interventions for individuals with autism: evaluation for evidence-based practices within a best evidence synthesis framework. J. Autism Dev. Disord. 40, 149-166. doi: 10.1007/s10803-0090842-0

Ren, Y., Kirkpatrick, C. A., Rawson, J. M., Sun, M., and Selleck, S. B. (2009). Cell type-specific requirements for heparan sulfate biosynthesis at the Drosophila neuromuscular junction: effects on synapse function, membrane trafficking, and mitochondrial localization. J. Neurosci. 29, 8539-8550. doi: 10.1523/JNEUROSCI.5587-08.2009

Repicky, S., and Broadie, K. (2009). Metabotropic glutamate receptor-mediated usedependent down-regulation of synaptic excitability involves the fragile $\mathrm{X}$ mental retardation protein. J. Neurophysiol. 101, 672-687. doi: 10.1152/jn.90953.2008

Rice, D., and Barone, S. Jr. (2000). Critical periods of vulnerability for the developing nervous system: evidence from humans and animal models. Environ. Health Perspect. 108(Suppl. 3), 511-533.

Rippon, G., Brock, J., Brown, C., and Boucher, J. (2007). Disordered connectivity in the autistic brain: challenges for the "new psychophysiology". Int. J. Psychophysiol. 63, 164-172. doi: 10.1016/j.ijpsycho.2006.03.012

Rivera, S., Khrestchatisky, M., Kaczmarek, L., Rosenberg, G. A., and Jaworski, D. M. (2010). Metzincin proteases and their inhibitors: foes or friends in nervous system physiology? J. Neurosci. 30, 15337-15357. doi: 10.1523/JNEUROSCI.346710.2010

Rochefort, N. L., Garaschuk, O., Milos, R. I., Narushima, M., Marandi, N., Pichler, B. et al. (2009). Sparsification of neuronal activity in the visual cortex at eye-opening. Proc. Natl. Acad. Sci. U.S.A. 106, 15049-15054. doi: 10.1073/pnas.0907660106

Rohrbough, J., O’Dowd, D. K., Baines, R. A., and Broadie, K. (2003). Cellular bases of behavioral plasticity: establishing and modifying synaptic circuits in the Drosophila genetic system. J. Neurobiol. 54, 254-271. doi: 10.1002/neu.10171

Roos, J., Hummel, T., Ng, N., Klambt, C., and Davis, G. W. (2000). Drosophila Futsch regulates synaptic microtubule organization and is necessary for synaptic growth. Neuron 26, 371-382. doi: 10.1016/S0896-6273(00)81170-8

Rotschafer, S., and Razak, K. (2013). Altered auditory processing in a mouse model of fragile X syndrome. Brain Res. 1506, 12-24. doi: 10.1016/j.brainres.2013.02.038

Rubenstein, J. L., and Merzenich, M. M. (2003). Model of autism: increased ratio of excitation/inhibition in key neural systems. Genes Brain Behav. 2, 255-267. doi: 10.1034/j.1601-183X.2003.00037.x

Salzberg, B. M., Davila, H. V., and Cohen, L. B. (1973). Optical recording of impulses in individual neurones of an invertebrate central nervous system. Nature 246, 508-509. doi: 10.1038/246508a0

Sanders, S. J., Murtha, M. T., Gupta, A. R., Murdoch, J. D., Raubeson, M. J., Willsey, A. J., et al. (2012). De novo mutations revealed by whole-exome sequencing are strongly associated with autism. Nature 485, 237-241. doi: 10.1038/nature10945

Sanes, J. R., and Lichtman, J. W. (1999). Development of the vertebrate neuromuscular junction. Annu. Rev. Neurosci. 22, 389-442. doi: 10.1146/annurev.neuro.22.1.389

Santini, E., Huynh, T. N., Macaskill, A. F., Carter, A. G., Pierre, P., Ruggero, D., et al. (2013). Exaggerated translation causes synaptic and behavioural aberrations associated with autism. Nature 493, 411-415. doi: 10.1038/nature11782

Scattoni, M. L., Ricceri, L., and Crawley, J. N. (2011). Unusual repertoire of vocalizations in adult BTBR T+tf/J mice during three types of social encounters. Genes Brain Behav. 10, 44-56. doi: 10.1111/j.1601-183X.2010.00623.x

Schlaug, G., Jancke, L., Huang, Y., and Steinmetz, H. (1995). In vivo evidence of structural brain asymmetry in musicians. Science 267, 699-701. doi: $10.1126 /$ science 7839149

Schroll, C., Riemensperger, T., Bucher, D., Ehmer, J., Voller, T., Erbguth, K., et al. (2006). Light-induced activation of distinct modulatory neurons triggers appetitive or aversive learning in Drosophila larvae. Curr. Biol. 16, 1741-1747. doi: 10.1016/j.cub.2006.07.023

Schuster, C. M. (2006). Glutamatergic synapses of Drosophila neuromuscular junctions: a high-resolution model for the analysis of experiencedependent potentiation. Cell Tissue Res. 326, 287-299. doi: 10.1007/s00441-0060290-5

Selby, L., Zhang, C., and Sun, Q. Q. (2007). Major defects in neocortical GABAergic inhibitory circuits in mice lacking the fragile $\mathrm{X}$ mental retardation protein. Neurosci. Lett. 412, 227-232. doi: 10.1016/j.neulet.2006.11.062

Shakiryanova, D., Klose, M. K., Zhou, Y., Gu, T., Deitcher, D. L., Atwood, H. L., et al. (2007). Presynaptic ryanodine receptor-activated calmodulin kinase II increases vesicle mobility and potentiates neuropeptide release. J. Neurosci. 27, 7799-7806. doi: 10.1523/JNEUROSCI.1879-07.2007

Sheng, M., and Kim, M. J. (2002). Postsynaptic signaling and plasticity mechanisms. Science 298, 776-780. doi: 10.1126/science.1075333

Shimomura, O., Johnson, F. H., and Saiga, Y. (1962). Extraction, purification and properties of aequorin, a bioluminescent protein from the luminous hydromedusan, Aequorea. J. Cell. Comp. Physiol. 59, 223-239. doi: 10.1002/jcp.10305 90302 
Siegel, F., Heimel, J. A., Peters, J., and Lohmann, C. (2012). Peripheral and central inputs shape network dynamics in the developing visual cortex in vivo. Curr. Biol. 22, 253-258. doi: 10.1016/j.cub.2011.12.026

Siegel, F., and Lohmann, C. (2013). Simultaneous imaging of structural plasticity and calcium dynamics in developing dendrites and axons. Cold Spring Harb. Protoc. 2013. doi: 10.1101/pdb.prot078592

Siegel, M. S., and Isacoff, E. Y. (1997). A genetically encoded optical probe of membrane voltage. Neuron 19, 735-741. doi: 10.1016/S0896-6273(00)80955-1

Sigrist, S. J., Reiff, D. F., Thiel, P. R., Steinert, J. R., and Schuster, C. M. (2003). Experience-dependent strengthening of Drosophila neuromuscular junctions. J. Neurosci. 23, 6546-6556.

Siller, S. S., and Broadie, K. (2011). Neural circuit architecture defects in a Drosophila model of fragile $\mathrm{X}$ syndrome are alleviated by minocycline treatment and genetic removal of matrix metalloproteinase. Dis. Model. Mech. 4, 673-685. doi: $10.1242 / \mathrm{dmm} .008045$

Simmons, D. R., Robertson, A. E., Mckay, L. S., Toal, E., Mcaleer, P., and Pollick, F. E. (2009). Vision in autism spectrum disorders. Vis. Res. 49, 2705-2739. doi: 10.1016/j.visres.2009.08.005

Singh, A. P., Vijayraghavan, K., and Rodrigues, V. (2010). Dendritic refinement of an identified neuron in the Drosophila CNS is regulated by neuronal activity and Wnt signaling. Development 137, 1351-1360. doi: 10.1242/dev.044131

Spencer, C. M., Alekseyenko, O., Hamilton, S. M., Thomas, A. M., Serysheva, E., Yuva-Paylor, L. A., et al. (2011). Modifying behavioral phenotypes in Fmr1KO mice: genetic background differences reveal autistic-like responses. Autism Res. 4, 40-56. doi: 10.1002/aur.168

Spitzer, N. C. (2006). Electrical activity in early neuronal development. Nature 444 , 707-712. doi: 10.1038/nature 05300

State, M. W., and Sestan, N. (2012). Neuroscience. The emerging biology of autism spectrum disorders. Science 337, 1301-1303. doi: 10.1126/science.1224989

Steward, O., Bakker, C. E., Willems, P. J., and Oostra, B. A. (1998). No evidence for disruption of normal patterns of mRNA localization in dendrites or dendritic transport of recently synthesized mRNA in FMR1 knockout mice, a model for human fragile-X mental retardation syndrome. Neuroreport 9, 477-481. doi: 10.1097/00001756-199802160-00022

Stoger, R., Genereux, D. P., Hagerman, R. J., Hagerman, P. J., Tassone, F., and Laird, C. D. (2011). Testing the FMR1 promoter for mosaicism in DNA methylation among CpG sites, strands, and cells in FMR1-expressing males with fragile $\mathrm{X}$ syndrome. PLoS ONE 6:e23648. doi: 10.1371/journal.pone.0023648

Strumbos, J. G., Brown, M. R., Kronengold, J., Polley, D. B., and Kaczmarek, L. K. (2010). Fragile X mental retardation protein is required for rapid experiencedependent regulation of the potassium channel Kv3.1b. J. Neurosci. 30, 10263 10271. doi: 10.1523/JNEUROSCI.1125-10.2010

Su, T., Fan, H. X., Jiang, T., Sun, W. W., Den, W. Y., Gao, M. M., et al. (2011). Early continuous inhibition of group $1 \mathrm{mGlu}$ signaling partially rescues dendritic spine abnormalities in the Fmrl knockout mouse model for fragile $\mathrm{X}$ syndrome. Psychopharmacology (Berl.) 215, 291-300. doi: 10.1007/s00213-010$2130-2$

Sukhotinsky, I., Chan, A. M., Ahmed, O. J., Rao, V. R., Gradinaru, V., Ramakrishnan, C., et al. (2013). Optogenetic delay of status epilepticus onset in an in vivo rodent epilepsy model. PLOS ONE 8:e62013. doi: 10.1371/journal.pone. 0062013

Sweeney, S. T., Broadie, K., Keane, J., Niemann, H., and O'Kane, C. J. (1995). Targeted expression of tetanus toxin light chain in Drosophila specifically eliminates synaptic transmission and causes behavioral defects. Neuron 14, 341-351. doi: 10.1016/0896-6273(95)90290-2

Takemura, S. Y., Bharioke, A., Lu, Z., Nern, A., Vitaladevuni, S., Rivlin, P. K., et al. (2013). A visual motion detection circuit suggested by Drosophila connectomics. Nature 500, 175-181. doi: 10.1038/nature12450

Tanaka, N. K., Endo, K., and Ito, K. (2012). Organization of antennal lobe-associated neurons in adult Drosophila melanogaster brain. J. Comp. Neurol. 520, 4067-4130. doi: $10.1002 /$ cne. 23142

Tessier, C. R., and Broadie, K. (2008). Drosophila fragile X mental retardation protein developmentally regulates activity-dependent axon pruning. Development 135 , 1547-1557. doi: 10.1242/dev.015867

Tessier, C. R., and Broadie, K. (2009). Activity-dependent modulation of neural circuit synaptic connectivity. Front. Mol. Neurosci. 2:8. doi: $10.3389 /$ neuro.02.008.2009
Tessier, C. R., and Broadie, K. (2011). The fragile X mental retardation protein developmentally regulates the strength and fidelity of calcium signaling in Drosophila mushroom body neurons. Neurobiol. Dis. 41, 147-159. doi: 10.1016/j.nbd.2010.09.002

Tessier, C. R., and Broadie, K. (2012). Molecular and genetic analysis of the Drosophila model of fragile X syndrome. Results Probl. Cell Differ. 54, 119-156. doi: 10.1007/978-3-642-21649-7_7

Testa-Silva, G., Loebel, A., Giugliano, M., De Kock, C. P., Mansvelder, H. D., and Meredith, R. M. (2012). Hyperconnectivity and slow synapses during early development of medial prefrontal cortex in a mouse model for mental retardation and autism. Cereb. Cortex 22, 1333-1342. doi: 10.1093/cercor/bhr224

Thomas, U., and Sigrist, S. J. (2012). Glutamate receptors in synaptic assembly and plasticity: case studies on fly NMJs. Adv. Exp. Med. Biol. 970, 3-28. doi: 10.1007/978-3-7091-0932-8_1

Thompson, W. J. (1985). Activity and synapse elimination at the neuromuscular junction. Cell. Mol. Neurobiol. 5, 167-182. doi: 10.1007/BF00711091

Timmermans, W., Xiong, H., Hoogenraad, C. C., and Krugers, H. J. (2013). Stress and excitatory synapses: from health to disease. Neuroscience 248, 626-636. doi: 10.1016/j.neuroscience.2013.05.043

Toro, R., Konyukh, M., Delorme, R., Leblond, C., Chaste, P., Fauchereau, F., et al. (2010). Key role for gene dosage and synaptic homeostasis in autism spectrum disorders. Trends Genet. 26, 363-372. doi: 10.1016/j.tig.2010.05.007

Trachtenberg, J. T., Chen, B. E., Knott, G. W., Feng, G., Sanes, J. R., Welker, E., et al. (2002). Long-term in vivo imaging of experience-dependent synaptic plasticity in adult cortex. Nature 420, 788-794. doi: 10.1038/nature01273

Tripodi, M., Evers, J. F., Mauss, A., Bate, M., and Landgraf, M. (2008). Structural homeostasis: compensatory adjustments of dendritic arbor geometry in response to variations of synaptic input. PLoS Biol. 6:e260. doi: 10.1371/journal.pbio.0060260

Tsai, P. I., Wang, M., Kao, H. H., Cheng, Y. J., Lin, Y. J., Chen, R. H., et al. (2012). Activity-dependent retrograde laminin A signaling regulates synapse growth at Drosophila neuromuscular junctions. Proc. Natl. Acad. Sci. U.S.A. 109, 1769917704. doi: 10.1073/pnas. 1206416109

Tsien, R. Y., Rink, T. J., and Poenie, M. (1985). Measurement of cytosolic free $\mathrm{Ca}^{2+}$ in individual small cells using fluorescence microscopy with dual excitation wavelengths. Cell Calcium 6, 145-157. doi: 10.1016/0143-4160(85) 90041-7

Turrigiano, G. G., and Nelson, S. B. (2004). Homeostatic plasticity in the developing nervous system. Nat. Rev. Neurosci. 5, 97-107. doi: 10.1038/ nrn1327

Tye, K. M., Mirzabekov, J. J., Warden, M. R., Ferenczi, E. A., Tsai, H. C., Finkelstein, J., et al. (2013). Dopamine neurons modulate neural encoding and expression of depression-related behaviour. Nature 493, 537-541. doi: 10.1038/nature11740

Tye, K. M., Prakash, R., Kim, S. Y., Fenno, L. E., Grosenick, L., Zarabi, H., et al. (2011). Amygdala circuitry mediating reversible and bidirectional control of anxiety. Nature 471, 358-362. doi: 10.1038/nature09820

Utari, A., Chonchaiya, W., Rivera, S. M., Schneider, A., Hagerman, R. J., Faradz, S. M., et al. (2010). Side effects of minocycline treatment in patients with fragile $\mathrm{X}$ syndrome and exploration of outcome measures. Am. J. Intellect. Dev. Disabil. 115, 433-443. doi: 10.1352/1944-7558-115.5.433

van Alphen, B., Yap, M. H., Kirszenblat, L., Kottler, B., and Van Swinderen, B. (2013). A dynamic deep sleep stage in Drosophila. J. Neurosci. 33, 6917-6927. doi: 10.1523/JNEUROSCI.0061-13.2013

Van den Oever, M. C., Rotaru, D. C., Heinsbroek, J. A., Gouwenberg, Y., Deisseroth, K., Stuber, G. D., et al. (2013). Ventromedial prefrontal cortex pyramidal cells have a temporal dynamic role in recall and extinction of cocaine-associated memory. J. Neurosci. 33, 18225-18233. doi: 10.1523/JNEUROSCI.2412-13.2013

Verkerk, A. J., Pieretti, M., Sutcliffe, J. S., Fu, Y. H., Kuhl, D. P., Pizzuti, A., et al. (1991). Identification of a gene (FMR-1) containing a CGG repeat coincident with a breakpoint cluster region exhibiting length variation in fragile $\mathrm{X}$ syndrome. Cell 65, 905-914. doi: 10.1016/0092-8674(91)90397-H

Vickers, C. A., Stephens, B., Bowen, J., Arbuthnott, G. W., Grant, S. G., and Ingham, C. A. (2006). Neurone specific regulation of dendritic spines in vivo by post synaptic density 95 protein (PSD-95). Brain Res. 1090, 89-98. doi: 10.1016/j.brainres.2006.03.075

Viswanath, V., Story, G. M., Peier, A. M., Petrus, M. J., Lee, V. M., Hwang, S. W., et al. (2003). Opposite thermosensor in fruitfly and mouse. Nature 423, 822-823. doi: $10.1038 / 423822 \mathrm{a}$ 
Vonhoff, F., Kuehn, C., Blumenstock, S., Sanyal, S., and Duch, C. (2013). Temporal coherency between receptor expression, neural activity and AP-1-dependent transcription regulates Drosophila motoneuron dendrite development. Development 140, 606-616. doi: 10.1242/dev.089235

Walsh, M. K., and Lichtman, J. W. (2003). In vivo time-lapse imaging of synaptic takeover associated with naturally occurring synapse elimination. Neuron 37 67-73. doi: 10.1016/S0896-6273(02)01142-X

Wang, D. O., Martin, K. C., and Zukin, R. S. (2010a). Spatially restricting gene expression by local translation at synapses. Trends Neurosci. 33, 173-182. doi: 10.1016/j.tins.2010.01.005

Wang, L. W., Berry-Kravis, E., and Hagerman, R. J. (2010b). Fragile X: leading the way for targeted treatments in autism. Neurotherapeutics 7, 264-274. doi: 10.1016/j.nurt.2010.05.005

Wang, H., Dictenberg, J. B., Ku, L., Li, W., Bassell, G. J., and Feng, Y. (2008a). Dynamic association of the fragile $\mathrm{X}$ mental retardation protein as a messenger ribonucleoprotein between microtubules and polyribosomes. Mol. Biol. Cell 19, 105-114. doi: 10.1091/mbc.E07-06-0583

Wang, H., Wu, L. J., Zhang, F., and Zhuo, M. (2008b). Roles of calcium-stimulated adenylyl cyclase and calmodulin-dependent protein kinase IV in the regulation of FMRP by group I metabotropic glutamate receptors. J. Neurosci. 28, 4385-4397. doi: 10.1523/JNEUROSCI.0646-08.2008

Wang, X., Zhu, S., Drozda, M., Zhang, W., Stavrovskaya, I. G., Cattaneo, E., etal. (2003). Minocycline inhibits caspase-independent and dependent mitochondrial cell death pathways in models of Huntington's disease. Proc. Natl. Acad. Sci. U.S.A. 100, 10483-10487. doi: 10.1073/pnas.183 2501100

Warden, M. R., Selimbeyoglu, A., Mirzabekov, J. J., Lo, M., Thompson, K. R., Kim, S. Y., et al. (2012). A prefrontal cortex-brainstem neuronal projection that controls response to behavioural challenge. Nature 492, 428-432. doi: 10.1038 /nature11617

Warren, Z., Mcpheeters, M. L., Sathe, N., Foss-Feig, J. H., Glasser, A., and VeenstraVanderweele, J. (2011). A systematic review of early intensive intervention for autism spectrum disorders. Pediatrics 127, e1303-e1311. doi: 10.1542/peds.20112426

Wayman, G. A., Impey, S., Marks, D., Saneyoshi, T., Grant, W. F., Derkach, V., et al. (2006). Activity-dependent dendritic arborization mediated by CaM-kinase I activation and enhanced CREB-dependent transcription of Wnt-2. Neuron 50 897-909. doi: 10.1016/j.neuron.2006.05.008

Weiler, I. J., Irwin, S. A., Klintsova, A. Y., Spencer, C. M., Brazelton, A. D., Miyashiro, K., et al. (1997). Fragile X mental retardation protein is translated near synapses in response to neurotransmitter activation. Proc. Natl. Acad. Sci. U.S.A. 94, 53955400. doi: 10.1073/pnas.94.10.5395

West, A. E., and Greenberg, M. E. (2011). Neuronal activity-regulated gene transcription in synapse development and cognitive function. Cold Spring Harb. Perspect. Biol. 3. doi: 10.1101/cshperspect.a005744

Westmark, C. J., Westmark, P. R., O’Riordan, K. J., Ray, B. C., Hervey, C. M. Salamat, M. S., etal. (2011). Reversal of fragile X phenotypes by manipulation of AbetaPP/Abeta levels in Fmr1KO mice. PLoS ONE 6:e26549. doi: 10.1371/journal.pone.0026549

White, B. H., Osterwalder, T. P., Yoon, K. S., Joiner, W. J., Whim, M. D., Kaczmarek, L. K., et al. (2001). Targeted attenuation of electrical activity in Drosophila using a genetically modified $\mathrm{K}(+)$ channel. Neuron 31, 699-711. doi: 10.1016/S08966273(01)00415-9

Wiesel, T. N. (1982). Postnatal development of the visual cortex and the influence of environment. Nature 299, 583-591. doi: 10.1038/299583a0

Wiesel, T. N., and Hubel, D. H. (1963). Effects of visual deprivation on morphology and physiology of cells in the cats lateral geniculate body. J. Neurophysiol. 26, 978-993.

Wiesel, T. N., and Hubel, D. H. (1965a). Comparison of the effects of unilateral and bilateral eye closure on cortical unit responses in kittens. J. Neurophysiol. 28, 1029-1040.

Wiesel, T. N., and Hubel, D. H. (1965b). Extent of recovery from the effects of visual deprivation in kittens. J. Neurophysiol. 28, 1060-1072.

Willemsen, R., Bontekoe, C. J., Severijnen, L. A., and Oostra, B. A. (2002). Timing of the absence of FMR1 expression in full mutation chorionic villi. Hum. Genet. 110, 601-605. doi: 10.1007/s00439-002-0723-5

Williams, S. C., and Deisseroth, K. (2013). Optogenetics. Proc. Natl. Acad. Sci. U.S.A. 110, 16287. doi: $10.1073 /$ pnas. 1317033110
Wondolowski, J., and Dickman, D. (2013). Emerging links between homeostatic synaptic plasticity and neurological disease. Front. Cell. Neurosci. 7:223. doi: 10.3389/fncel.2013.00223

Wong, D. C., Lovick, J. K., Ngo, K. T., Borisuthirattana, W., Omoto, J. J., and Hartenstein, V. (2013). Postembryonic lineages of the Drosophila brain: II. Identification of lineage projection patterns based on MARCM clones. Dev. Biol. 384, 258-289. doi: 10.1016/j.ydbio.2013.07.009

Woo, C. C., and Leon, M. (2013). Environmental enrichment as an effective treatment for autism: a randomized controlled trial. Behav. Neurosci. 127, 487-497. doi: $10.1037 / \mathrm{a} 0033010$

Wu, G. Y., Deisseroth, K., and Tsien, R. W. (2001). Spaced stimuli stabilize MAPK pathway activation and its effects on dendritic morphology. Nat. Neurosci. 4, 151-158. doi: 10.1038/83976

Yan, Q. J., Rammal, M., Tranfaglia, M., and Bauchwitz, R. P. (2005). Suppression of two major Fragile $\mathrm{X}$ Syndrome mouse model phenotypes by the mGluR5 antagonist MPEP. Neuropharmacology 49, 1053-1066. doi: 10.1016/j.neuropharm.2005.06.004

Yasuda, R., Nimchinsky, E. A., Scheuss, V., Pologruto, T. A., Oertner, T. G., Sabatini, B. L., et al. (2004). Imaging calcium concentration dynamics in small neuronal compartments. Sci STKE 2004, pl5. doi: 10.1126/stke.2192004pl5

Ye, Q., and Miao, Q. L. (2013). Experience-dependent development of perineuronal nets and chondroitin sulfate proteoglycan receptors in mouse visual cortex. Matrix Biol. 32, 352-363. doi: 10.1016/j.matbio.2013.04.001

Yuste, R., and Bonhoeffer, T. (2001). Morphological changes in dendritic spines associated with long-term synaptic plasticity. Annu. Rev. Neurosci. 24, 1071-1089. doi: 10.1146/annurev.neuro.24.1.1071

Yuste, R., and Bonhoeffer, T. (2004). Genesis of dendritic spines: insights from ultrastructural and imaging studies. Nat. Rev. Neurosci. 5, 24-34. doi: $10.1038 / \mathrm{nrn} 1300$

Zalfa, F., Eleuteri, B., Dickson, K. S., Mercaldo, V., De Rubeis, S., Di Penta, A., et al. (2007). A new function for the fragile $\mathrm{X}$ mental retardation protein in regulation of PSD-95 mRNA stability. Nat. Neurosci. 10, 578-587. doi: 10.1038/nn1893

Zalfa, F., Giorgi, M., Primerano, B., Moro, A., Di Penta, A., Reis, S., et al. (2003). The fragile X syndrome protein FMRP associates with BC1 RNA and regulates the translation of specific mRNAs at synapses. Cell 112, 317-327. doi: 10.1016/S00928674(03)00079-5

Zang, T., Maksimova, M. A., Cowan, C. W., Bassel-Duby, R., Olson, E. N., and Huber, K. M. (2013). Postsynaptic FMRP bidirectionally regulates excitatory synapses as a function of developmental age and MEF2 activity. Mol. Cell. Neurosci. 56, 39-49. doi: 10.1016/j.mcn.2013.03.002

Zars, T., Fischer, M., Schulz, R., and Heisenberg, M. (2000). Localization of a short-term memory in Drosophila. Science 288, 672-675. doi: 10.1126/science.288.5466.672

Zhang, F., Wang, L. P., Brauner, M., Liewald, J. F., Kay, K., Watzke, N., et al. (2007). Multimodal fast optical interrogation of neural circuitry. Nature 446, 633-639. doi: $10.1038 /$ nature05744

Zhang, Y. P., Holbro, N., and Oertner, T. G. (2008). Optical induction of plasticity at single synapses reveals input-specific accumulation of alphaCaMKII. Proc. Natl. Acad. Sci. U.S.A. 105, 12039-12044. doi: 10.1073/pnas.0802940105

Zhang, Y. Q., Bailey, A. M., Matthies, H. J., Renden, R. B., Smith, M. A., Speese, S. D., etal. (2001). Drosophila fragile X-related gene regulates the MAP1B homolog Futsch to control synaptic structure and function. Cell 107, 591-603. doi: 10.1016/S0092-8674(01)00589-X

Zhong, Y., and Wu, C. F. (2004). Neuronal activity and adenylyl cyclase in environment-dependent plasticity of axonal outgrowth in Drosophila. J. Neurosci. 24, 1439-1445. doi: 10.1523/JNEUROSCI.0740-02.2004

Zhou, Z., Hong, E. J., Cohen, S., Zhao, W. N., Ho, H. Y., Schmidt, L., et al. (2006). Brain-specific phosphorylation of MeCP2 regulates activity-dependent Bdnf transcription, dendritic growth, and spine maturation. Neuron 52, 255-269. doi: 10.1016/j.neuron.2006.09.037

Zingerevich, C., Greiss-Hess, L., Lemons-Chitwood, K., Harris, S. W., Hessl, D. Cook, K., et al. (2009). Motor abilities of children diagnosed with fragile X syndrome with and without autism. J. Intellect. Disabil. Res. 53, 11-18. doi: 10.1111/j.1365-2788.2008.01107.x

Zito, K., Parnas, D., Fetter, R. D., Isacoff, E. Y., and Goodman, C. S. (1999). Watching a synapse grow: noninvasive confocal imaging of synaptic growth in Drosophila. Neuron 22, 719-729. doi: 10.1016/S0896-6273(00) 80731-X 
Ziv, N. E., and Smith, S. J. (1996). Evidence for a role of dendritic filopodia in synaptogenesis and spine formation. Neuron 17, 91-102. doi: 10.1016/S08966273(00)80283-4

Zoghbi, H. Y., and Bear, M. F. (2012). Synaptic dysfunction in neurodevelopmental disorders associated with autism and intellectual disabilities. Cold Spring Harb. Perspect. Biol. 4. doi: 10.1101/cshperspect.a009886

Zuo, Y., Yang, G., Kwon, E., and Gan, W. B. (2005). Long-term sensory deprivation prevents dendritic spine loss in primary somatosensory cortex. Nature 436, $261-$ 265. doi: 10.1038/nature03715

Zwaigenbaum, L., Bryson, S., and Garon, N. (2013). Early identification of autism spectrum disorders. Behav. Brain Res. 251, 133-146. doi: 10.1016/j.bbr.2013.04.004

Zwart, M. F., Randlett, O., Evers, J. F., and Landgraf, M. (2013). Dendritic growth gated by a steroid hormone receptor underlies increases in activity in the developing Drosophila locomotor system. Proc. Natl. Acad. Sci. U.S.A. 110, E3878-E3887. doi: $10.1073 /$ pnas. 1311711110
Conflict of Interest Statement: The authors declare that the research was conducted in the absence of any commercial or financial relationships that could be construed as a potential conflict of interest.

Received: 20 December 2013; accepted: 21 January 2014; published online: 07 February 2014.

Citation: Doll CA and Broadie K (2014) Impaired activity-dependent neural circuit assembly and refinement in autism spectrum disorder genetic models. Front. Cell. Neurosci. 8:30. doi: 10.3389/fncel.2014.00030

This article was submitted to the journal Frontiers in Cellular Neuroscience.

Copyright (C) 2014 Doll and Broadie. This is an open-access article distributed under the terms of the Creative Commons Attribution License (CC BY). The use, distribution or reproduction in other forums is permitted, provided the original author (s) or licensor are credited and that the original publication in this journal is cited, in accordance with accepted academic practice. No use, distribution or reproduction is permitted which does not comply with these terms. 